WSARCH: Uma arquitetura para a provisão de web services com qualidade de serviço

Júlio Cezar Estrella 

SERVIÇO DE PÓS-GRADUAÇÃO DO ICMC-USP

Data de Depósito: 05 de abril de 2010

Assinatura:

\section{WSARCH: Uma arquitetura para a provisão de web services com qualidade de serviço}

Júlio Cezar Estrella

Orientadora: Profa. Dra. Regina Helena Carlucci Santana

Tese apresentada ao Instituto de Ciências Matemáticas e de Computação - ICMC-USP, como parte dos requisitos para obtenção do título de Doutor em Ciências - Ciências de Computação e Matemática Computacional.

USP - São Carlos

Abril/2010 

Gradeço primeiramente ao senhor Deus Pai por eu existir. Ao senhor Osvaldo e à senhora Maria Odete, meus queridos pais que sempre me motivaram e incentivou a ser um homem crítico, lutador e a não desistir em hipótese alguma diante das dificuldades. Às minhas irmãs Ana e Heloisa, que também sempre me apoiaram e torceram por mim mesmo estando distantes. À minha namorada Fernanda (Fer) que me apoiou imensamente desde o início do doutorado. Não poderia deixar de destacar o quanto a presença da Fer foi importante durante os quatro anos de trabalho. À professora Regina, minha orientadora, por ter me orientado durante este período e pelas discussões que tivemos para melhorar o desenvolvimento do trabalho. Sua paciência e a capacidade de direcionamento do projeto em momentos oportunos foram de fundamental importância para que este trabalho chegasse a este estágio. Ao professor Marcos que me concedeu oportunidades de participar de outras atividades extracurriculares, as quais me proporcionaram diversos outros aprendizados. Também agradeço à professora Sarita que me ajudou na escrita e correções de artigos e também à professora Kalinka pelas sugestões para melhorar o trabalho. Não poderia deixar de mencionar o apoio do professor Mônaco, em que tivemos a oportunidade de desenvolver alguns trabalhos em conjunto. Agradeço também aos meus amigos e colegas de laboratório Jonathan, Thiago, Maycon, Pedro Nobile, Paulo Eustáquio, Bruno Guazzelli, Douglas pelo convívio do diaa-dia, pelo apoio moral e pela ajuda durante o período de desenvolvimento do doutorado. Em especial ao Bruno, Thiago e Kenji que não mediram esforços em me ajudar com a implementação do protótipo da arquitetura desde que esta foi concebida, permitindo que as inúmeras discussões técnicas e filosóficas enriquecessem a proposta deste trabalho. Devo mencionar a ajuda do Kenji em algumas fases da implementação e na melhoria do código da arquitetura, bem como sua participação no planejamento e execução dos experimentos de validação do protótipo da WSARCH. Também não poderia deixar de agradecer ao Luís Nakamura, Ricardo e ao Maycon pelas correções que fizeram no texto desta tese. Agradeço também à FAPESP (Fundação de Amparo à Pesquisa do Estado de São Paulo) pelo apoio financeiro concedido, o qual possibilitou minha dedicação integral a esse projeto com uma bolsa de estudo durante o período do doutorado, além de reserva técnica para a compra de recursos computacionais e o custeio para a participação 
em eventos nacionais e internacionais relacionados ao tema de pesquisa do doutorado. 
Sta tese tem como objetivo o projeto e implementação de uma arquitetura orientada a serviços, denominada WSARCH - Web Services Architecture, que possibilita acesso a Web Services com Qualidade de Serviço (QoS). Os atributos de QoS que devem ser considerados, visando à avaliação de desempenho de Web services e a obtenção de QoS em uma arquitetura orientada a serviços, são identificados e discutidos. Esses atributos de QoS são mapeados para os componentes participantes de uma arquitetura orientada a serviços que incorpora qualidade de serviço. A arquitetura proposta prevê a monitoração dos provedores de serviços e um módulo que utiliza os dados obtidos para a localização do serviço apropriado. Visando a validação da arquitetura proposta e dos atributos definidos desenvolveu-se um protótipo da WSARCH. O protótipo desenvolvido permite que estudos de avaliação de desempenho sejam realizados considerando os diferentes componentes da arquitetura, algoritmos, protocolos e padrões. A proposta da WSARCH se insere em um contexto em que é importante definir como deve ser projetada uma arquitetura SOA com foco em desempenho, uma vez que a correta caracterização do que avaliar, e como avaliar, se faz necessário. Nesta tese, a avaliação de desempenho está focada nas diferentes entidades que participam de uma arquitetura orientada a serviço: cliente, provedor e os demais participantes. 

7 His thesis aims at the design and implementation of a service-oriented architecture, named WSARCH - Web Services Architecture, which allows accessing Web Services with Quality of Service (QoS). The attributes of QoS that shall be considered, aiming at evaluating the performance of Web Services in order to achieve QoS in a service-oriented architecture are identified and discussed. These QoS attributes were mapped to the components participating in a service-oriented architecture that incorporates quality of service. The proposed architecture provides the monitoring of service providers and a module that uses the data to locate the appropriate service. Aiming at the validation of the proposed architecture and the set of attributes proposed, a prototype of WSARCH was developed. The prototype allows performance evaluation studies being conducted considering the different components of the architecture, algorithms, protocols and standards. The proposal of WSARCH is inserted in a context where is important to define how a SOA architecture focusing on performance shall be designed, since the correct characterization of what to evaluate, and how to evaluate is necessary. In this thesis, the evaluation of performance is focused on the different entities participating in a service-oriented architecture: client, provider and other participants. 



\section{Abstract}

Lista de Figuras

Lista de Tabelas

xiii

\section{Lista de Siglas}

XV

1 Introdução $\quad 1$

1.1 Considerações Iniciais $\ldots \ldots \ldots \ldots \ldots \ldots$

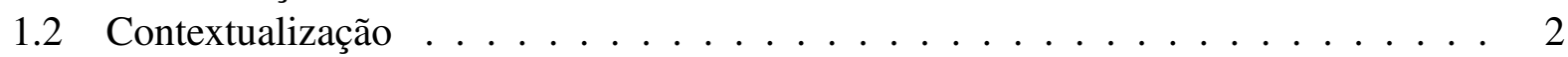

1.3 Motivação e Objetivos . . . . . . . . . . . . . . . . . . . . . . . . . . . . . . . .

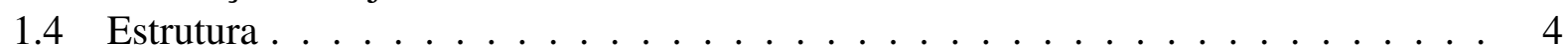

2 SOA e Qualidade de Serviços 5

2.1 Considerações Iniciais . . . . . . . . . . . . . . . . . . . . 5

2.2 Computação Distribuída . . . . . . . . . . . . . . . . . . . 6

2.3 SOA e Web Services . . . . . . . . . . . . . . . . . . . 7

2.3.1 Camada Física . . . . . . . . . . . . . . . . . . . . . 9

2.3.2 Camada de Descrição . . . . . . . . . . . . . . . . . . . . . . . . . . . . . 10

2.3.3 Camada de Descoberta . . . . . . . . . . . . . . . . . . 12

2.4 Qualidade de Serviço . . . . . . . . . . . . . . . . . . . . . . 13

2.4.1 Serviços Diferenciados em nível de aplicação . . . . . . . . . . . . . . . . 14

2.4.2 Service Level Agreements (SLA) . . . . . . . . . . . . . . . . . . 15

2.5 Considerações Finais . . . . . . . . . . . . . . . . . 17

3 Desempenho em SOA e QoS em Web Services 19

3.1 Considerações Iniciais . . . . . . . . . . . . . . . . . . . . . . 19

3.2 Trabalhos Relacionados . . . . . . . . . . . . . . . . . . . . . . . . . . . . .

3.2 .1 Composição de Web Services . . . . . . . . . . . . . . . . . . 20

3.2 .2 Qualidade de Serviço . . . . . . . . . . . . . . . . . 22

3.3 Limitações do Paradigma de Arquiteturas Orientadas a Serviço . . . . . . . . . . . 29 
3.3.1 Protocolos e Limitações de Hardware - Dispositivos Móveis . . . . . . . . 30

3.3.2 XML como Formato de Mensagem, XML Parser e Mensagens SOAP . . . 31

3.3 .3 Evolução de Web Services . . . . . . . . . . . . . . . . . . . . 34

3.3.4 Composição de Web Services . . . . . . . . . . . . . . . . . . . . . . . . . . . . 35

3.3.5 Segurança em Web Services . . . . . . . . . . . . . . . . 36

3.3 .6 Web Services Attachments . . . . . . . . . . . . . . . . . 38

3.3 .7 Registro UDDI . . . . . . . . . . . . . . . . . . 40

3.4 Índices de Carga e de Desempenho . . . . . . . . . . . . . . . . . . . . . . . . . . . . . . . . . . 43

3.4 .1 Índices de Carga . . . . . . . . . . . . . . . . . . . . . . . . . . . . . . . . . . . . 43

3.4 .2 Índices de Desempenho . . . . . . . . . . . . . . . . . . . . . . . . . . . . 44

3.5 Considerações Finais . . . . . . . . . . . . . . . . . . . . 46

4 A Arquitetura WSARCH 449

4.1 Considerações Iniciais . . . . . . . . . . . . . . . . . . . . . . . 49

4.2 A Arquitetura WSARCH . . . . . . . . . . . . . . . . . . . . . 49

4.3 Funcionamento e Sub-Módulos da WSARCH . . . . . . . . . . . . . . . . 51

4.4 Relação de Atributos de QoS com a WSARCH . . . . . . . . . . . . . . . . . . 56

4.4 QoS e Módulos da WSARCH . . . . . . . . . . . . . . 56

4.4.2 Fatores relacionados à interação entre os módulos da WSARCH . . . . . . 60

4.5 Implementação . . . . . . . . . . . . . . . . . . . . . . . 62

4.5.1 Monitoração dos Provedores de Serviços . . . . . . . . . . . . . . . . 63

4.5 .2 Comunicação . . . . . . . . . . . . . . . . . . . 65

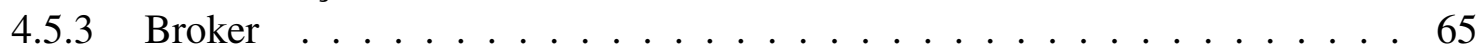

4.5 .4 Registro UDDI . . . . . . . . . . . . . . . . . . . 68

4.5.5 Implementação dos Provedores de Serviços . . . . . . . . . . . . . . . . . 69

4.5.6 Categorias das Aplicações . . . . . . . . . . . . . . . . . . 69

4.5 .7 LogServer . . . . . . . . . . . . . . . . . . . . . . . . . . . . . . . . . .

4.5 .8 Controle de Erros . . . . . . . . . . . . . . . . . . . 72

4.6 Composição de Serviços . . . . . . . . . . . . . . . . . . . . . 73

4.7 Considerações Finais . . . . . . . . . . . . . . . . . . 75

5 Validação da Arquitetura WSARCH $\quad 77$

5.1 Considerações Iniciais . . . . . . . . . . . . . . . . . . . . 77

5.2 Avaliação de Desempenho da WSARCH . . . . . . . . . . . . . . . . 78

5.2.1 Configuração do Ambiente . . . . . . . . . . . . . . . . . . 78

5.2.2 Planejamento dos Experimentos . . . . . . . . . . . . . . . . 79

5.3 Análise dos Resultados . . . . . . . . . . . . . . . . . . . . . 82

5.3.1 Análise Comportamental . . . . . . . . . . . . . . . . . . . . 82

5.3 .2 Sobrecarga no Broker . . . . . . . . . . . . . . . . 84

5.3 .3 Sobrecarga devido ao $\operatorname{LogServer} \ldots \ldots \ldots$. . . . . . . . . . 85

5.3.4 Influência da Carga de Trabalho . . . . . . . . . . . . . . . 87

5.3.5 Tempo de Processamento nos Provedores . . . . . . . . . . . . . . . . 89

5.3.6 Algoritmo de Escalonamento de Mensagens . . . . . . . . . . . . . . . . . 90

5.4 Considerações Finais . . . . . . . . . . . . . . . . . . . 100 
6 Conclusões $\quad 101$

6.1 Considerações iniciais . . . . . . . . . . . . . . . . . . . 101

6.2 Conclusões . . . . . . . . . . . . . . . . . . . . 102

6.3 Dificuldades relacionadas ao Projeto . . . . . . . . . . . . . . . . . 102

6.4 Contribuições . . . . . . . . . . . . . . . . . . . . 103

6.5 Produção Científica . . . . . . . . . . . . . . . . . . . 105

6.5.1 Relatórios Técnicos e Notas Didáticas . . . . . . . . . . . . . . . . 105

6.5 .2 Artigos . . . . . . . . . . . . . . . . . 105

6.5 .3 Livros e Capítulos . . . . . . . . . . . . . . . . . 106

6.5.4 Colaboração em projetos de pesquisa . . . . . . . . . . . . . . 106

6.5.5 Participação em projetos de pesquisa relacionados ao doutorado . . . . . . 107

6.6 Participação em Conferências . . . . . . . . . . . . . . . . . . . . . . 107

6.7 Trabalhos futuros . . . . . . . . . . . . . . . . . . . . 108 



\section{Lista de Figuras}

2.1 Arquitetura Orientada a Serviço . . . . . . . . . . . . . . . . . 7

2.2 Pilha conceitual dos Web Services (Brooks, 2002) . . . . . . . . . . . . . . 8

3.1 Lacuna existente na literatura quando levado em consideração os níveis arquiteturais e organizacionais $($ Branco, 2004) . . . . . . . . . . . . . . . . 45

3.2 Visão macroscópica do projeto de um índice de desempenho (Branco, 2004) . . . . 45

3.3 Estratégia para obtenção do índice de desempenho (Branco, 2004) . . . . . . . . . 46

3.4 Exemplo de utilização do índice de desempenho (Branco, 2004) . . . . . . . . . . 47

4.1 WSARCH - Modelo Abstrato . . . . . . . . . . . . . . . . . 51

4.2 WSARCH - Modelo Simplificado . . . . . . . . . . . . . . . . 52

4.3 WSARCH - Modelo Atual . . . . . . . . . . . . . . . . 53

4.4 Funcionamento do Ganglia na WSARCH . . . . . . . . . . . . . . . . . 64

4.5 Broker e Interfaces . . . . . . . . . . . . . . . . . . . . . 66

4.6 WSARCH - Informações de QoS . . . . . . . . . . . . . . . . . . . 67

4.7 Classificação das Aplicações $($ Branco, 2004) . . . . . . . . . . . . . . . . 70

4.8 Fluxo de composição de uma reserva de viagens . . . . . . . . . . . . . . . . 74

5.1 Distribuição das requisições - Cliente $($ Bronze $)$ X Provedor . . . . . . . . . . . . 83

5.2 Distribuição das requisições - Cliente (Gold) X Provedor . . . . . . . . . . . . . . 83

5.3 Comportamento típico do Broker da WSARCH . . . . . . . . . . . . . . . . . . 84

5.4 Arquitetura WSARCH com LogServer ativado/desativada . . . . . . . . . . . . . . 86

5.5 Comportamento da WSARCH quanto ao tempo de processamento nos provedores . 87

5.6 Sobrecarga da arquitetura mediante variação do tempo entre requisições . . . . . 87

5.7 Tempo médio de resposta para os experimentos Exp004 e Exp005 . . . . . . . . . 88

5.8 Sobrecarga da arquitetura com variação do tempo de processamento nos provedores de serviços . . . . . . . . . . . . . . . . . . . . . . 89

5.9 Tempo médio de resposta da arquitetura para diferentes clientes $\ldots \ldots$. . . . . . 90

5.10 Algoritmo de Classificação - 50\% Bronze . . . . . . . . . . . . . . . . . . 9 91

5.11 Algoritmo de Classificação - 50\% Gold . . . . . . . . . . . . . . . . . . . . . . . 92

5.12 Tempo médio de resposta para clientes Gold e Bronze . . . . . . . . . . . . . . . . 92

5.13 Clientes da classe Gold e Bronze x Tempo médio de SOA . . . . . . . . . . . . . 93

5.14 Sobrecarga da arquitetura para Clientes Gold e Bronze ． . . . . . . . . . . . . . . 93

5.15 Tempo de processamento médio: Clientes Gold x Clientes Bronze . . . . . . . . . 94

5.16 Algoritmo de Reserva de Recursos com 3 provedores para a classe Bronze . . . . . 95

5.17 Algoritmo de Reserva de Recursos com 4 provedores para a classe Gold . . . . . . 95 
5.18 Não ocorrência da diferenciação de serviços em relação ao tempo médio de resposta 96

5.19 Não ocorrência da diferenciação em relação ao elementos de SOA . . . . . . . . . 96

5.20 Diferenciação de serviços considerando a sobrecarga da WSARCH . . . . . . . . . 97

5.21 Não ocorrência da diferenciação de serviços para o tempo médio de processamento 97

5.22 Algoritmo de Reserva de Recursos com 2 provedores para a classe Bronze . . . . . 98

5.23 Algoritmo de Reserva de Recursos com 5 provedores para a classe Gold . . . . . . 98

5.24 Diferenciação de serviços para diferentes clientes . . . . . . . . . . . . . . . . . . 99

5.25 Diferenciação de serviços considerando os elementos de SOA . . . . . . . . . . . 99

5.26 Diferenciação de serviços considerando a sobrecarga da WSARCH . . . . . . . . . 99

5.27 Diferenciação de serviços para o tempo médio de processamento . . . . . . . . . . 100 


\section{Lista de Tabelas}

3.1 Ataques e impactos da segurança no desempenho de Web Services Adaptado de (Jensen et al., 2007) . . . . . . . . . . . . . . . . . . 37

4.1 Relação dos atributos de QoS com os módulos da WSARCH . . . . . . . . . . . 58

4.2 Informações de QoS armazenadas no registro UDDI . . . . . . . . . . . . . . . 68

5.1 Elementos de Hardware . . . . . . . . . . . . . . . . . . . . . . 78

5.2 Elementos de Software . . . . . . . . . . . . . . . . . . . . . 79

5.3 Fatores e níveis realativos aos experimentos . . . . . . . . . . 81

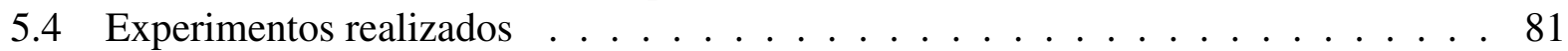

5.5 Média e Desvio Padrão do comportamento do Broker . . . . . . . . . . . . . . . . 85

5.6 Média e Desvio Padrão do comportamento da WSARCH em relação ao LogServer 86

5.7 Média e Desvio Padrão do comportamento da WSARCH para variação do tempo entre requisições . . . . . . . . . . . . . . . . . . . 88

5.8 Média e Desvio Padrão do comportamento da WSARCH para variação do tempo entre requisições . . . . . . . . . . . . . . . . . . 90 

ASCII - American Standard Code for Information Interchange

ATM - Asynchronous Transfer Mode

B2B - Business-to-Business

B2C - Business-to-Consumer

BPEL, BPEL4WS - Business Process Execution Language for Web Services

BPM - Business Process Management

CERN - Centro Europeu para Pesquisa Nuclear

CISC - Complex Instruction-Set Computer

CORBA - Common Objetct Request Broker Architecture

CPU - Central Processing Unit

DCOM - Distributed Component Object Model

DNS - Domain Name System

DOM - Document Object Model

DoS - Denial of Service

DTD - Data Type Definition

DIME - Direct Internet Message Encapsulation

EAI - Enterprise Application Integration

ESB - Enterprise Service Bus

FLOPS - Floating Point Operations per Second

FTP - File Transfer Protocol 


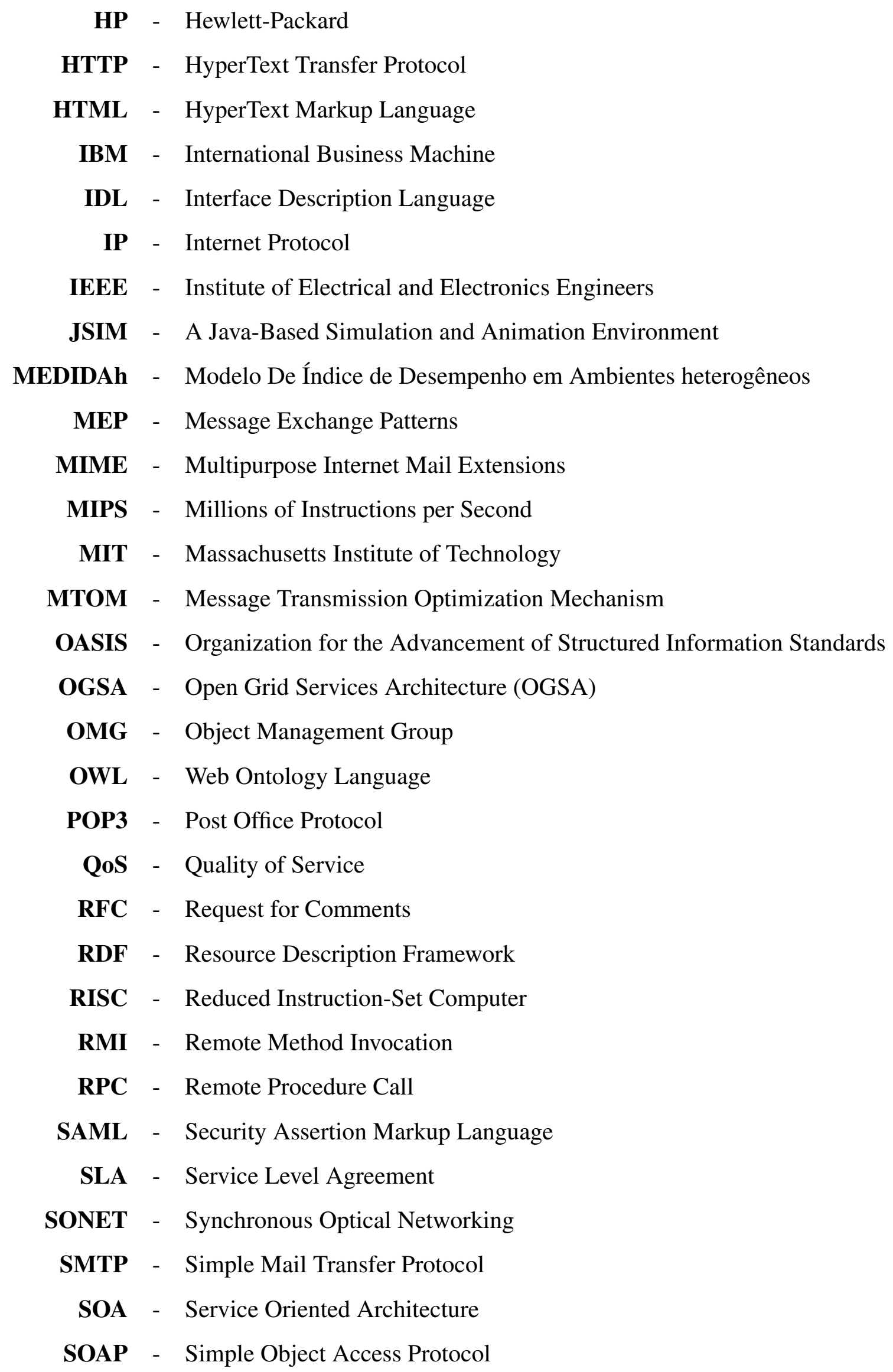




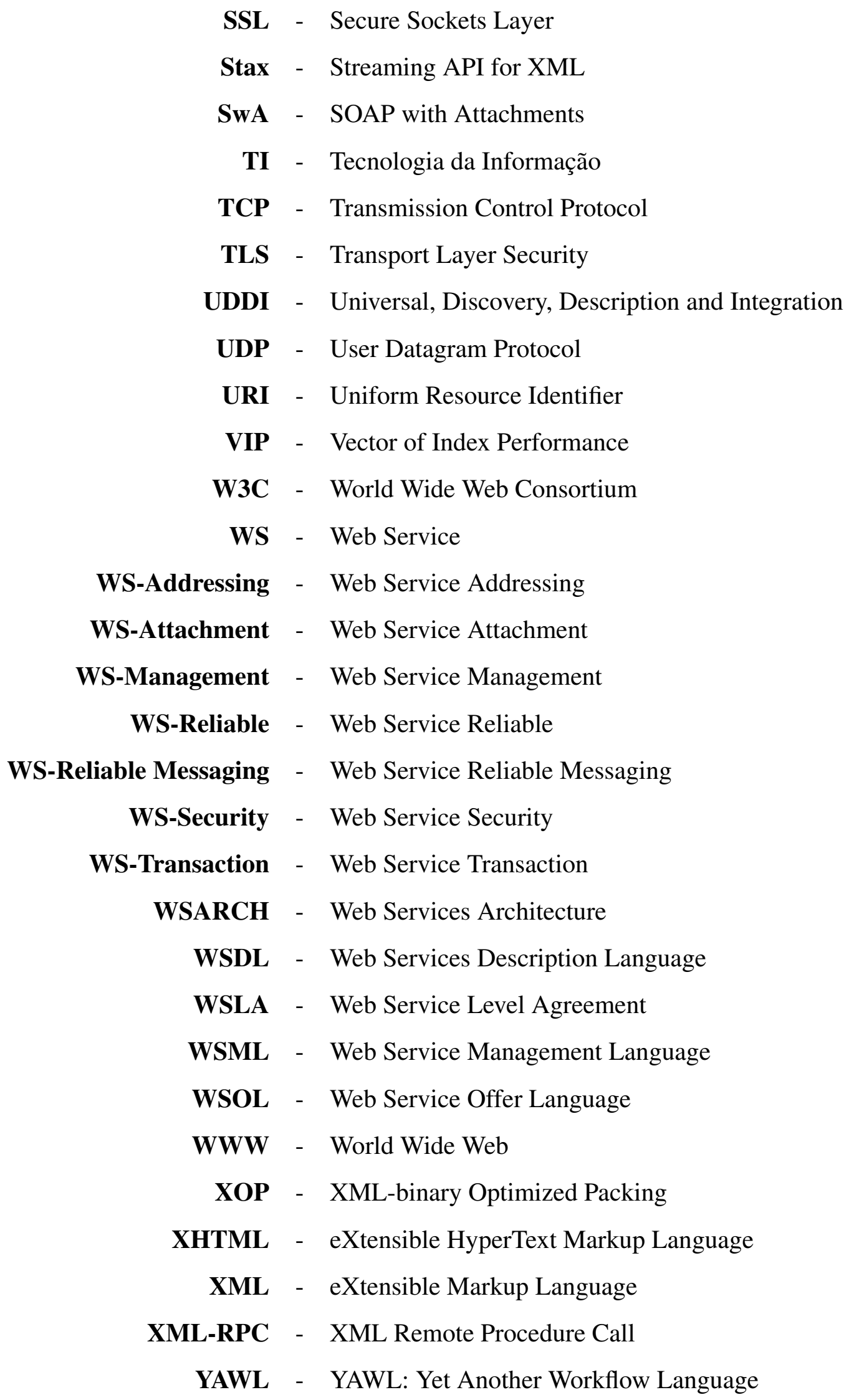




\subsection{Considerações Iniciais}

A Web, também conhecida como World Wide Web $(W W W)$, teve início em 1989 no CERN, o centro europeu para pesquisa nuclear, sendo concebida por Tim Berners-Lee (Berners-Lee e Fischetti, 1999). Nasceu da necessidade de fazer com que grupos de cientistas de diferentes nacionalidades pudessem colaborar uns com os outros por meio da troca de imagens, relatórios e outros documentos em formato digital. O primeiro protótipo da Web (no modo texto) já estava operacional no ano de 1991, durante uma demonstração pública na conferência Hypertext-91 em San Antonio, no Texas. Em 1994, o CERN e o MIT assinaram um acordo criando o World Wide Web Consortium (W3C), uma organização voltada para o desenvolvimento da Web, cujo objetivo era padronizar protocolos e incentivar a interoperabilidade. Desde então, centenas de universidades e empresas juntaram-se ao consórcio (Tanenbaum, 2002). Atualmente, a Web é amplamente utilizada para a veiculação de aplicações que envolvem comércio eletrônico, jogos online, aplicações multimídia, etc. Com o surgimento dos chamados Web Services tem sido possível que aplicações executando em diferentes plataformas e em diferentes linguagens de programação possam se comunicar pela Web por meio de uma interface denominada Web Services Description Language (WSDL), baseada em uma linguagem interoperável e independente de plataforma e sistema operacional denominada eXtensible Markup Language (XML). Os Web Services, oferecem características valiosas por meio do suporte ao desenvolvimento de sistemas distribuídos abertos, desenvolvido fora da composição de sistemas autônomos. No entanto, não basta que ocorra comunicação entre as diferentes aplicações distribuídas geograficamente. Essa comunicação deve ser acompanhada de características que envolvem critérios de qualidade de serviço. Com a crescente popularidade dos Web Services, 
um suporte geral à Quality of Service $(Q o S)$ (Erradi e Maheshwari, 2005) para esses é uma questão fundamental para o sucesso desta tecnologia emergente. Os ambientes de Web Services atuais não oferecem um suporte adequado à qualidade de serviço e apresentam diversas limitações (Atkinson et al., 2007), (Hicks et al., 2007). Como os Web Services podem ser aplicados em ambientes que envolvem aplicações de missão crítica e em cenários Business to Busissnes (B2B), uma melhor qualidade de serviço e entrega contínua de serviços tornam-se questões críticas para propiciar alta disponibilidade e confiabilidade apesar da falha e indisponibilidade de serviços participantes ou também da rede de comunicação (Erradi e Maheshwari, 2005). Poucos trabalhos relacionados (Marquezan et al., 2007), (Saez et al., 2004), (Suzumura et al., 2005), (Zhang et al., 2007) fazem menção a uma análise criteriosa em relação à avaliação de desempenho, visto que na maioria das vezes só há a proposição de arquiteturas e técnicas conceituais (Lo e Wang, 2007), (Serhani et al., 2008), (Tabein et al., 2008), (Tabein e Nourollah, 2008), (Pegoraro et al., 2008), (Yeom et al., 2009), (Yan et al., 2009), sem nenhum resultado satisfatório que permita afirmar que a provisão de $Q o S$ naquela arquitetura específica é ou não adequada. A próxima seção apresenta uma contextualização sobre os diversos aspectos que envolvem a tecnologia dos Web Services.

\subsection{Contextualização}

Web Services são uma realidade para a integração de aplicações Web, sendo um tópico amplamente pesquisado pela comunidade acadêmica e por empresas como IBM, HP - Hewlett-Packard, Microsoft (Siblini e Mansour, 2005). O surgimento dos Web Services têm provocado uma mudança de paradigma na integração de aplicações, onde serviços podem ser compartilhados para permitir a otimização de processos de negócios numa ampla estrutura de tecnologia de informação (TI). A adoção dos Web Services no mundo acadêmico e empresarial já é uma realidade, uma vez que as indústrias consideram duas frentes: padrões e produtos (Kreger, 2003). A IBM tem investido tempo, talento e dinheiro em ambas as frentes. O conceito de Web Services foi desenvolvido como um fundamento de uma nova geração de aplicações B2B e Enterprise Application Integration (EAI), bem como parte dos chamados componentes sob demanda, como Grids, Wireless e computação autônoma. Para isso, um conjunto de padrões e tecnologias tem sido desenvolvido e passado por constantes evoluções para permitir a interoperabilidade entre os componentes de uma arquitetura orientada a serviços. Os Web Services são capazes de integrar aplicações executando em diferentes plataformas, habilitar informações de uma base de dados de aplicações para serem disponibilizadas para outras, além de permitir que aplicações internas se tornem disponíveis na rede mundial de computadores, isto é, na Internet. Os benefícios trazidos pela utilização dos Web Services só têm se tornado possível em virtude da adoção de uma linguagem padrão da Web, como a XML e suas derivações como a WSDL, dentre outras. Há diversos problemas relacionados com a integração entre os Web Services que compõem um processo de negócios que requerem muita investigação. Como se trata de uma tecnologia que envolve diversos conceitos e aplicações de sistemas distribuídos, se faz necessária uma análise de problemas como disponibilidade, dependência 
e confiabilidade de Web Services, além da qualidade de serviço envolvida na comunicação das aplicações orientadas a serviços (não muito explorada pelos órgãos responsáveis pela padronização da tecnologia de Web Services). Alguns trabalhos (Chen et al., 2003), (Ludwig, 2003), (Wu et al., 2003), (Erradi e Maheshwari, 2005), (Tsai et al., 2006), (Badidi et al., 2006), (Tavares e Westphall, 2006), (D’Mello et al., 2008), (Zhao e Tan, 2009), tratam desses problemas com a proposição de arquiteturas isoladas. Assim, não se preocupam em considerar a possibilidade de utilização de recursos computacionais ociosos, que poderiam ser aproveitados para a execução de Web Services num ambiente globalmente distribuído. Há também esforços no sentido de aproveitar a ociosidade computacional em um contexto geral, com adoção de padrões como o Open Grid Service Architecture (OGSA) (Foster et al., 2002), culminando com o termo Grid Services, em que qualquer serviço possa ser oferecido aos clientes num ambiente de Grid.

\subsection{Motivação e Objetivos}

O objetivo desta tese de doutorado é o projeto e implementação de uma arquitetura orientada a serviços, denominada WSARCH - Web Services Architecture, que possibilita acesso a Web Services com Qualidade de Serviço $(Q o S)$. A arquitetura proposta neste projeto estende, com adaptações e sugestões de melhorias, outros modelos arquiteturais evidenciados na literatura de Web Services (Erradi e Maheshwari, 2005), (Benkner e Engelbrecht, 2006), (Sheth et al., 2002). O foco principal da WSARCH, que a torna diferente de outras arquiteturas, é o fato de ser uma arquitetura voltada à avaliação e oferecimento de desempenho e voltada à provisão de Web Services considerando atributos de qualidade de serviço. Para possibilitar o desenvolvimento dessa arquitetura torna-se necessário definir quais atributos devem ser considerados para esse fim. Desta forma, para o desenvolvimento da WSARCH é preciso identificar e mapear os atributos de $Q o S$ nos diversos componentes de uma arquitetura orientada a serviços e em particular à arquitetura proposta neste trabalho.

Um ponto importante para atingir os objetivos da WSARCH é sua arquitetura que considera a interação entre os componentes de uma arquitetura SOA (Service Oriented Architecture) tradicional e também um Broker de serviços responsável pelo escalonamento de mensagens SOAP entre cliente, provedor e registro de serviços.

Para alcançar os resultados desejados, deve-se avaliar cuidadosamente os aspectos relativos à QoS em Web Services, tais como o entendimento dos protocolos que compõem a arquitetura orientada à serviço, as arquiteturas propostas em trabalhos da área e a proposição de novas metodologias de $Q o S$.

A metodologia utilizada para o desenvolvimento do projeto é a implementação, através da construção de um protótipo da WSARCH. O protótipo deve ser desenvolvido de forma modular com o intuito de possibilitar que diferentes estudos de avaliação de desempenho possam ser realizados. 


\subsection{Estrutura}

No Capítulo 2 desta tese é apresentada uma revisão geral sobre Web Services, bem como dos protocolos da arquitetura SOA. Além disso, são discutidos os conceitos relacionados à $Q o S$ no nível de aplicação.

No Capítulo 3 é realizado uma análise crítica sobre os trabalhos relacionados a este projeto de doutorado, envolvendo as áreas de $Q o S$, arquiteturas orientadas a serviços e Web Services. Na análise serão abordadas características peculiares de soluções propostas para problemas dessas áreas, além de relacionar a provisão de $Q o S$ especificamente para Web Services. Ainda neste capítulo são abordadas as principais limitações de arquiteturas orientadas a serviços no contexto de desempenho, tais como: parsers XML, evolução e composição de serviços, segurança, Web Services attachments, compressão de mensagens, dentre outros, além dos desafios que precisam ser considerados para garantir que o desempenho geral de uma arquitetura $S O A$ seja adequado.

No Capítulo 4 é caracterizada a estrutura geral da arquitetura WSARCH, no qual serão discutidos seus módulos, sub-módulos, a interação entre seus componentes, e a relação dos atributos de $Q o S$ associados à arquitetura. Também serão discutidas todas as etapas da implementação e como as informações de $Q o S$ e mensagens $S O A P$ são propagadas entre cliente, Broker, Universal Description Discovery and Integration (UDDI), monitores de Web Services e provedores de serviços.

No Capítulo 5 é discutida a validação da arquitetura WSARCH por meio de uma avaliação de desempenho, o que envolve a configuração do ambiente para a avaliação, o planejamento de experimentos (escolha dos fatores para análise, níveis, etc.), variáveis de resposta, tais como: tempo de resposta médio, tempo de sobrecarga da arquitetura, tempo de processamento nos provedores de serviços, etc.

No Capítulo 6 são apresentadas as principais conclusões obtidas com o desenvolvimento deste projeto e também as contribuições geradas para a área com a apresentação do protótipo da WSARCH. Ainda nesse capítulo, será objeto de análise uma lista detalhada de projetos futuros que podem ser considerados a partir do desenvolvimento da arquitetura WSARCH. Finalmente no Capítulo 7 são apresentadas as referências. 


\section{2}

\section{SOA e Qualidade de Serviços}

\subsection{Considerações Iniciais}

A World Wide Web $(W W W)$ tem sido adotada por milhões de pessoas e milhares de empresas em todo o mundo. De natureza fracamente acoplada, esse sistema distribuído ainda necessita de melhor integração entre as aplicações (Brooks, 2002). Como resposta à melhoria na integração das aplicações surgiram em meados de 2002 os chamados Web Services. A proposta visa a realizar a convergência de inúmeras aplicações que hoje estão disponíveis na $W e b$, mas que não interagem entre si devido à algumas limitações como: falta de uma interface comum, independência de plataforma de hardware e de sistema operacional. O surgimento dos Web Services permite maior comunicação entre os sistemas, independente da linguagem em que eles foram escritos desde a sua criação. Neste capítulo, são apresentados conceitos de Web Services, seus protocolos e padrões, além de uma análise do tópico relacionado à qualidade de serviço (tanto em relação à rede de comunicação quanto em relação às aplicações), que é de essencial importância para o desenvolvimento do presente trabalho. Nesse contexto, na Seção 2.1 é realizado uma revisão sobre computação distribuída. Na Seção 2.3 são discutidos os conceitos primordiais relacionados a SOA e Web Services, incluindo a pilha conceitual dos Web Services e a descrição de cada uma das camadas dessa pilha. Na Seção 2.4 é abordado o tópico relacionado à qualidade de serviços do ponto de vista de aplicações incluindo os conceitos relacionados aos acordos de níveis de serviços. 


\subsection{Computação Distribuída}

A computação distribuída é uma referência para a computação paralela descentralizada, realizada por dois ou mais computadores conectados por meio de uma rede, cujo objetivo é concluir uma tarefa em comum (Tanenbaum, 2002). Dentre os modelos de computação distribuída mais difundidos destacam-se: o modelo cliente-servidor, o modelo peer-to-peer e o modelo de objetos distribuídos. Este último é semelhante ao modelo peer-to-peer, com a diferença de que há um middleware intermediando o processo de comunicação. Os protocolos representantes do modelo de objetos distribuídos mais amplamente utilizados são o Common Objetct Request Broker Architecture (CORBA) (OMG, 2001), Distributed Component Object Model (DCOM) (Hortsmann e Kirtland, 1997) e o Remote Method Invocation (RMI) (Sun, 2010). Embora esses protocolos permitam que aplicações distribuídas possam se comunicar tanto em uma rede local, quanto na Internet, eles apresentam os seguintes problemas (Brooks, 2002):

- Não são interoperáveis com outros protocolos;

- São dependentes de linguagem ou sistema operacional;

- Apresentam um modelo de objeto distribuído específico;

- Possuem um formato específico de serialização de mensagens utilizadas na troca de informações entre as partes comunicantes.

As limitações dos protocolos citados anteriormente e o crescimento da $W W W$, levou a necessidade de se estudar a criação de um novo modelo de computação distribuída dirigido ao consumidor final. Nesse novo modelo, chamadas distribuídas são feitas por meio de hiperlinks e codificadas em mensagens (HTTP) Hypertext Tranfer Protocol como requisições GET ou POST. Respostas geradas pelo servidor são enviadas em formato (HTML) HyperText Markup Language pelo protocolo HTTP e são exibidas imediatamente pelo browser. Ainda que chamadas distribuídas possam ser feitas por meio de hiperlinks, alguns pontos precisam ser considerados. O primeiro é que não há nenhum mecanismo padronizado para interrogar a Web diante de uma grande lista de serviços disponíveis, e muito menos um conjunto de interfaces padrão que mostre como os serviços disponíveis poderiam ser utilizados. Em (Ehnebuske et al., 2001) os autores apresentam um breve resumo das técnicas e tecnologias que têm sido utilizadas para tentar fazer Web Services baseados em HTML suportar um alto grau de interoperabilidade. Em geral, Web Services baseados em $H T M L$ e HTTP requerem um complexo processamento do lado do cliente, para entender e interpretar as mensagens dos servidores, além de serem inflexíveis. Nesse caso, a linguagem $X M L$ aparece para resolver alguns desses problemas. Ao permitir uma sintaxe de comunicação extensível e um conjunto de primitivas modulares denominada eXtensible HyperText Markup Language (XHTML), a interoperabilidade pode ser atingida. Uma questão fundamental é saber como os componentes de software podem descobrir e utilizar os Web Services, e como os dados de entrada e saída serão 
validados, além de questões envolvendo qualidade de serviços, confiabilidade e redundância. O segundo ponto, tão importante quanto o primeiro, é saber como se dará a comunicação entre os distintos Web Services, de forma que estes possam integrar os processos de negócios distribuídos, ao redor do mundo. Questões como essas têm sido investigadas pelos grupos de trabalho da W3C. Esses grupos são denominados Web Services Activity. Cada grupo de trabalho é constituído de membros da academia e da indústria da tecnologia da informação contribuindo por meio da publicação de especificações.

\subsection{SOA e Web Services}

Uma arquitetura orientada a serviço é uma maneira lógica de concepção de sistema de software para prover serviços para aplicativos ou usuários finais ou para outros serviços distribuídos em uma rede através de interfaces que possam ser publicadas e descobertas posteriormente. O principal problema com uma arquitetura SOA é que não houve preocupação em tratar questões tais como o gerenciamento de serviços, gerenciamento de transações, a orquestração de serviços, segurança e outros aspectos que se aplicam a todos os componentes de uma arquitetura orientada a serviços, como por exemplo: qualidade de serviço e desempenho. A abordagem arquitetural é aplicável quando há vários aplicativos em execução de diversas tecnologias e plataformas que precisam se comunicar uns com os outros. Um arquitetura SOA em sua concepção original é apresentada na Figura 2.1.

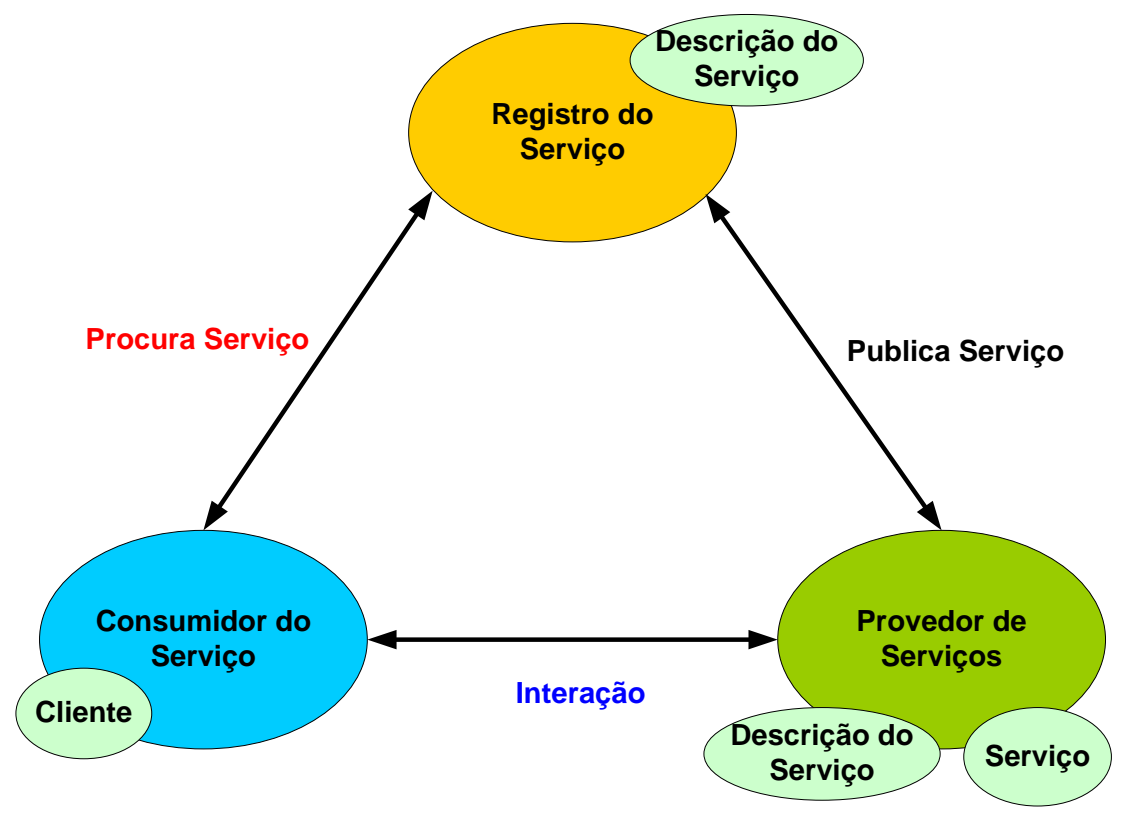

Figura 2.1: Arquitetura Orientada a Serviço

A implementação mais abordada para o conceito de arquiteturas orientadas a serviços são os chamados Web Services. O termo Web Service tem sido muito abordado nos últimos anos, com várias definições apresentadas pela literatura. Uma definição amplamente aceita apresenta Web 
Services como um componente, ou unidade lógica de aplicação, acessível por meio de protocolos padrões da Internet, possuindo uma funcionalidade que pode ser reutilizada sem a preocupação de como é implementada. Web Services são referenciados como uma implementação de uma arquitetura orientada a serviços - SOA (Erradi e Maheshwari, 2005). A W3C define o termo como uma aplicação identificada por um URI - (Uniform Resource Identifier), cujas interfaces e ligações são definidas, descritas e descobertas utilizando-se uma linguagem padrão como $X M L$ (Ferris e Farrell, 2003). As interações entre Web Services ocorrem tipicamente como chamadas SOAP, que é um protocolo de comunicação baseado em XML para a interação de aplicações (Papazoglou et al., 2007). SOAP é apresentado como um backbone para uma nova geração de aplicações de computação distribuída, independente de plataforma e de linguagens. Além disso, as descrições de interfaces dos Web Services são expressas usando uma linguagem denominada WSDL (Thomas et al., 2003). A pilha conceitual dos Web Services relaciona três camadas principais: camada física, camada de descrição, e camada de descoberta, mostradas na Figura 2.2.

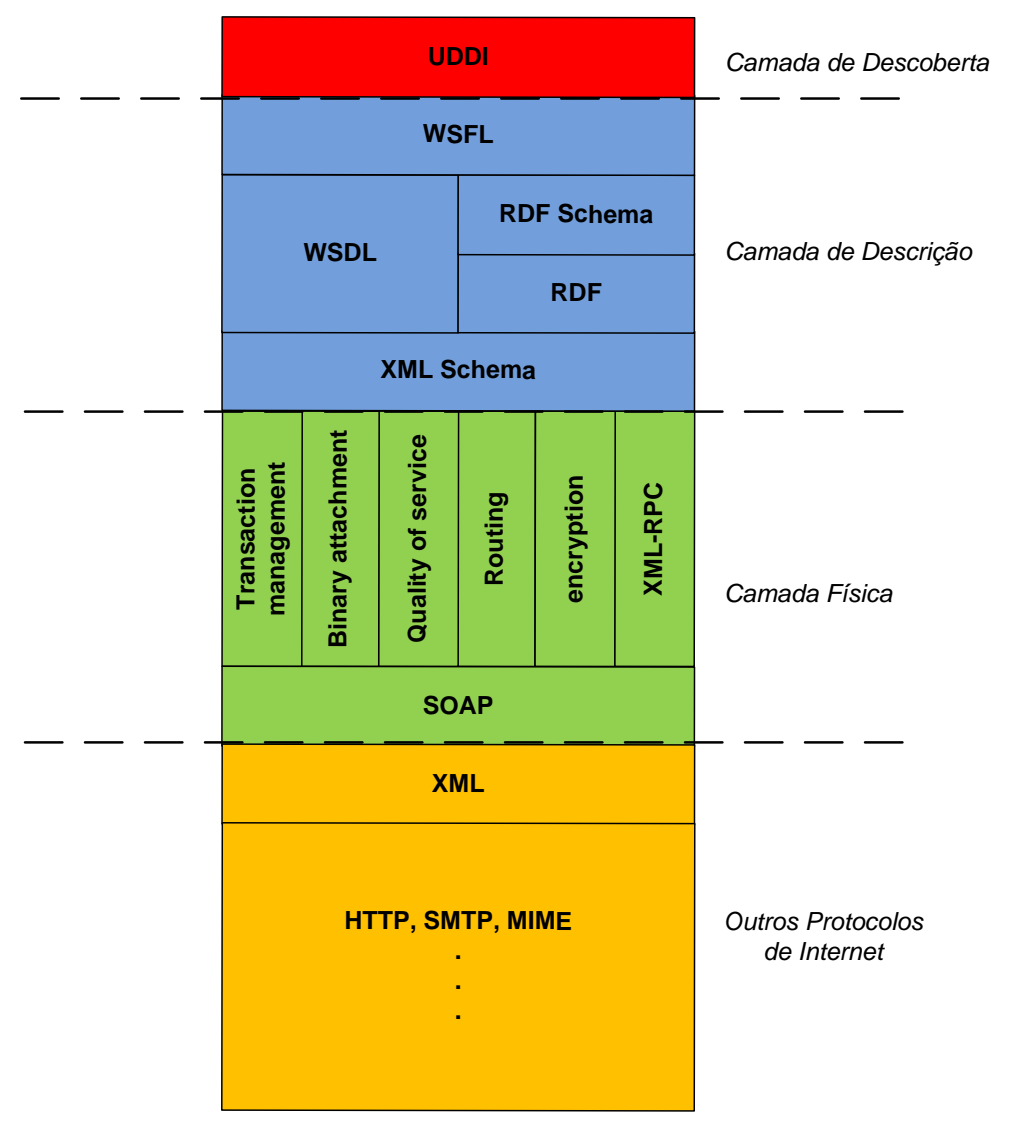

Figura 2.2: Pilha conceitual dos Web Services (Brooks, 2002)

Para a construção e utilização de Web Services é necessário considerar as seguintes especificações e tecnologias:

- Uma maneira de representar dados;

- Um formato de mensagens comum e extensível; 
- Um mecanismo para localizar os serviços presentes em Web sites específicos;

- Um mecanismo para descobrir os provedores de serviço.

Em resumo, um Web Service pode ser definido como um serviço de software publicado na Web por meio do protocolo SOAP (Gudgin et al., 2001b), (Gudgin et al., 2001a), descrito em uma interface WSDL e registrado num repositório denominado UDDI (Ehnebuske et al., 2001). Os protocolos relacionados a cada uma das camadas citadas serão objetos de estudo nas próximas seções.

\subsubsection{Camada Física}

Trata-se da camada mais baixa e a base de todo o desenvolvimento dos Web Services. É feita de componentes para suportar a troca de serviços em mais alto nível. Sendo assim, os componentes dessa camada podem ser chamados de descritores de sintaxe de baixo nível, que são necessários para passagem de mensagens. Assim, essa camada é responsável pela sintaxe do roteamento das mensagens, suporte à transações, qualidade de serviço no nível de mensagens, além de chamadas de procedimento. Com relação aos protocolos dessa camada, dois deles tem sido amplamente adotados. O primeiro é o eXtensible Markup Language - Remote Procedure Call (XML-RPC), que geralmente é adotado para serviços leves, que não necessitam de um roteamento complexo e de mecanismos de tipagem de dados. O segundo é o $S O A P$, que tem sido adotado para serviços mais pesados. Cada protocolo define um formato de mensagem baseada em $X M L$ e não necessita utilizar qualquer modelo de objeto específico, tal como coleta automática de lixo de forma distribuída. Ambos apresentam um número de implementações significativas e toolkits disponíveis, e são suportados por grandes empresas como IBM, Microsoft e Sun Microsystems.

\section{XML-RPC}

A especificação XML-RPC foi desenvolvida em 1999 como um protocolo de troca de informações para a Web. Foi construído sob o topo dos protocolos HTTP 1.1 (Fielding, 1999) e XML 1.0 (Apparao, 2001), tornando-o facilmente extensível para a maioria dos Servidores Web. A idéia é que cada requisição XML-RPC (Ibbotson, 2001) seja enviada como uma mensagem HTTP-POST, enquanto as respostas retornam como uma mensagem de resposta HTTP 200. Quando as falhas de processamento de baixo nível ocorrem, o Servidor Web consegue interpretar XML-RPC e rejeita a requisição. Toda mensagem $X M L-R P C$ deve possuir cabeçalhos HTTP que incluem os campos User-Agent, Content-Type e Content-Length, como descrito no RFC 2616 (Fielding, 1999). O campo Content-Type deve ser text-xml, e o campo Content-Length deve especificar o tamanho da mensagem. De acordo com a especificação da $W 3 C$ cada requisição $X M L-R P C$ é constituída de determinados elementos, onde cada elemento pode também conter outros elementos. Por exemplo, cada requisição pode começar com um elemento methodCall 
e este conter os elementos methodName. O elemento methodName por sua vez, identifica o serviço que está sendo invocado. Os parâmetros de cada método são codificados com um elemento param como um dos tipos básicos da especificação $X M L-R P C$. Além de tipos básicos não nomeados, XML-RPC também suporta um tipo básico nomeado por meio do elemento struct. Um struct é composto de um ou mais membros, cada um deles contendo um elemento nome, que distingue o nome do recurso, e um valor de elemento que distingue ambos os tipos e o valor do recurso. Outra característica da especificação $X M L-R P C$ também inclui um modo de representar um conjunto de recursos não-nomeado usando o elemento array. Um array contém um único elemento de dado com um conjunto de elementos de valor (os valores de elementos), cada qual contendo um tipo de recurso. Vetores podem ser recursivos e também incluir não somente o tipo básico, mas também structs.

\section{Simple Object Access Protocol (SOAP)}

O protocolo SOAP é uma especificação para requisitar métodos de negócio, como documentos XML e suporta outros protocolos como HTTP e Simple Mail Transfer Protocol (SMTP). O protocolo SOAP é o protocolo de comunicação para os Web Services. Dentre suas principais características destaca-se a definição do formato das mensagens XML. Uma mensagem SOAP nada mais é que um fragmento XML bem formado, encapsulado por um par de elementos SOAP. Há outras partes da especificação SOAP que descrevem como representar os dados do programa em $X M L$ e como usá-lo para fazer as chamadas de procedimento remoto. Tais partes opcionais da especificação são usadas para implementar as aplicações no estilo Remote Procedure Call (RPC). Neste caso, o cliente envia a mensagem SOAP contendo a chamada e os parâmetros da função, e o servidor retorna uma mensagem com os resultados da função executada. Ressalta-se que as implementações atuais do SOAP suportam aplicações RPC porque os programadores acostumados com as aplicações DCOM (Hortsmann e Kirtland, 1997) ou CORBA (OMG, 2001) aplicam esse estilo de forma adequada. Em contrapartida, o SOAP também suporta aplicações no estilo documento, onde a mensagem é apenas um envólucro de um documento $X M L$, sendo um estilo flexível, já que alguns Web Services o utilizam para implementar serviços que seriam difíceis de desenvolver usando chamada remota de procedimentos (Brooks, 2002). Outra parte opcional da especificação $S O A P$ define como é uma requisição HTTP que contém uma mensagem SOAP. Por ser o protocolo central da $W W W$ e por possuir características de segurança, monitoramento e balanceamento de carga, o HTTP tornou-se o protocolo padrão para o transporte de mensagens $X M L$, muito embora muitos outros protocolos tais como SMTP e File Transfer Protocol (FTP) possam ser utilizados.

\subsubsection{Camada de Descrição}

A camada de descrição contém uma semântica formal para descrever as mensagens que um Web Service pode entender, as restrições aplicadas aos dados dentro daquelas mensagens, as categorias ou ontologias as quais as mensagens pertencem, e o modo em que Web Services podem 
ser combinados com um outro para suportar fluxo de trabalho de negócios. Tipos de dados são manipulados pelo XML-Schema, enquanto semânticas para interfaces de Web Services são manipuladas pela WSDL. O Resource Description Framework $(R D F)$ é utilizado para criar ontologias para categorizar mensagens e serviços.

\section{XML-Schema}

XML-Schema (Lassila, 1999), (Leymann, 2001) é um mecanismo para a definição de tipos de dados complexos para documentos $X M L$. Ele permite a definição de novos tipos de dados e não força o usuário a adotar uma metodologia de programação específica. XML-Schema exclui a ambiguidade que pode ser trazida enquanto se usa o Document Type Definition (DTD), o mecanismo padrão de dados para documentos XML. Outra característica do XML-Schema é que ele tem sido amplamente adotado como um novo mecanismo de tipagem de dados para documentos $X M L$. Outro ponto é o suporte a extensões por meio do uso de namespaces $X M L$, além da provisão de um mecanismo para identificar instâncias de esquema individuais (Team et al., 2001). Podem ser definidos tipos de dados baseados em string simples ou tipos de dados de fragmentos de documentos $X M L$ mais complexos. Tipos de dados podem ser estendidos ou restringidos em razão do uso de 12 tipos de facetas de tipos de dados e 25 tipos de padrões de dados simples.

\section{Web Services Description Language (WSDL)}

O acrônimo $W S D L$ trata-se de um documento $X M L$ que descreve um conjunto de mensagens SOAP, a especificação de um serviço, e também a forma como as mensagens são trocadas entre clientes e provedores de serviços. As mensagens entre Web Services são quebradas em partes de elementos, representados por fragmentos de nomes de documentos. Operações são conhecidas como pontos de entrada em um Web Service e são descritos como elementos port Type. Fazendose uma analogia, o WSDL é para o SOAP o que a Interface Definition Language (IDL) é para o CORBA. Para os Web Services, o WSDL define quatro tipos diferentes de primitivas de transmissão descritas a seguir:

- One-Way: cliente envia com nenhuma resposta;

- Requisição/Resposta: cliente envia e recebe uma resposta do servidor

- Solicitação/Resposta: servidor (Provedor de serviços) envia e recebe a resposta do cliente.

- Notificação: servidor envia e nenhuma resposta é retornada.

\section{Resource Description Framework (RDF)}

O RDF é uma especificação produzida e recomendada pela W3C Semantic Web Activity. Seu objetivo principal é definir uma gramática que pode ser utilizada para marcar semanticamente 
recursos Web, isto é, criar um modelo simples de dados, com uma semântica formal, usar o vocabulário baseado em um $U R I$, uma sintaxe baseada em $X M L$ e suportar o uso de $X M L$. Os arquivos $R D F$ possuem três componentes básicos: recurso, propriedade e indicação, tornando a linguagem altamente escalável:

- Recurso: Qualquer objeto que pode conter um URI, incluindo as páginas da Web, assim como elementos de um documento $X M L$;

- Propriedade: Um recurso que tenha um determinado nome e que possa ser utilizado como uma propriedade;

- Indicação: Consiste na combinação de um recurso, de uma propriedade, e de um valor.

\subsubsection{Camada de Descoberta}

A camada de descoberta consiste de processos e protocolos pelos quais os Web Services podem ser descobertos por pesquisas por meio de seus metadados, cujo objetivo primariamente são as transações de negócios. Para que uma chamada a um Web Service seja realizada com sucesso, é necessário localizá-lo, descobrir a interface com a semântica da sua chamada, além de escrever e configurar o software local para colaborar com o serviço. O Universal Discovery Description and Integration (UDDI) (Ehnebuske et al., 2001) caracteriza-se por ser as páginas amarelas dos Web Services. Como as páginas amarelas de uma lista telefônica, é possível procurar por uma companhia que ofereça os serviços que você precisa, ler sobre o serviço oferecido dentre outras informações. Além disso, é possível oferecer o Web Service construído e registrá-lo no UDDI.

\section{Universal Description Discovery and Integration (UDDI)}

Enquanto não há nenhuma especificação padronizada pela $W 3 C$, o $U D D I$ é apropriado para suportar o mecanismo de descoberta. Essencialmente, o serviço UDDI é um repositório centralizado das especificações da camada de descrição, cuja construção é bastante parecida com o Domain Name System (DNS). Registros UDDI podem estar em escala global ou disponível em intranets locais. Entradas UDDI incluem pontos de entradas dos Web Services e metadados associados, publicados em uma ou mais taxonomias. Um diretório $U D D I$ é um arquivo $X M L$ que descreve o negócio e os serviços. O registro apresenta três partes:

- Páginas Brancas: descrevem a companhia (nome, endereço, contatos, etc.);

- Páginas Amarelas: incluem as categorias baseadas em taxonomias padrões;

- Páginas Verdes: descrevem a interface para o serviço, com detalhes suficientes para se escrever uma aplicação que utilize o Web Service. 


\subsection{Qualidade de Serviço}

O termo Qualidade de Serviço pode ser visto de diversas formas de acordo com a área de aplicação. Por exemplo, do ponto de vista de uma rede de comutação de circuitos, refere-se à probabilidade de sucesso em estabelecer uma ligação a um determinado destino. Do ponto de vista de uma rede de comutação de pacotes a Qualidade de Serviço $(Q o S)$ refere-se à capacidade de uma rede prover melhores serviços para um dado tráfego selecionado, podendo utilizar várias tecnologias incluindo Frame Relay, ATM, Ethernet, redes 802.11, SONET e redes IP (Vesegna, 2001). Dentre os parâmetros para descrever $Q o S$ destacam-se, largura de banda, utilização de buffers, atraso, jitter, prioridades, utilização de $C P U$, etc. No contexto deste trabalho de doutorado é importante destacar o termo $Q o S$ do ponto de vista de rede, uma vez que muitos dos conceitos aplicados na camada de rede de comutação de pacotes podem ser utilizados em aplicações Web atuais. Atualmente, o tráfego na rede é muito diversificado e cada tipo possui um requisito único em termos de largura de banda, atraso, perda e disponibilidade. Com o crescimento da Internet, a maioria das redes do momento é baseada no protocolo $I P$. O fato da pilha de protocolos padrão da Internet possuir um único protocolo de rede é benéfico, uma vez que a manutenção dos equipamentos de rede se torna menos complexa, resultando em custos operacionais mais baixos. No entanto, isso é contrastado pelo fato de que o IP é um protocolo sem conexões, isto é, os pacotes IP não possuem um caminho específico à medida que trafegam pela rede. Essa característica do protocolo IP sinaliza para uma qualidade de serviço inadequada em uma rede best effort (Networks, 2003). A pilha do protocolo IP básica fornece somente um serviço de melhor esforço. Nesse modelo, as requisições são processadas conforme a estratégia da primeira a chegar será a primeira a ser atendida. Isso significa que todas as requisições têm a mesma prioridade e são processadas uma após a outra sem nenhuma distinção. Em um cenário em que cada vez mais as pessoas e as empresas estão utilizando a Internet para entretenimento, para fins comerciais e para fins acadêmicos, a capacidade do canal de comunicação torna-se um assunto importante. Aplicações bem conhecidas do público da rede mundial de computadores como RealAudio, RealVideo, Internet Phone, Skype e sistemas de videoconferência fazem muito mais uso da largura de banda disponível que os aplicativos usados nos primeiros anos da Internet, tais como aplicativos de transferências de arquivos e de login remoto. O mesmo ocorre para aplicações da nova geração da Web, isto é a Web 2.0, tais como o YouTube, Revver, etc. Enquanto aplicativos tradicionais, tais como WWW e FTP não toleram perda de pacotes, mas são menos sensíveis aos atrasos variáveis, a maioria dos aplicativos em tempo real apresenta o comportamento oposto. Isso ocorre, pois, estes podem compensar uma quantidade razoável de perda de pacotes, mas são bastante críticos em relação aos atrasos variáveis. Diante dessa situação, na ausência de algum tipo de controle de largura de banda, a qualidade desses fluxos de dados em tempo real torna-se dependente de tal ausência (Ferguson e Huston, 1998). Apesar do aumento da largura de banda melhorar a interatividade das aplicações, ela não é suficiente para que a qualidade de serviço de uma determinada aplicação seja garantida. Essa insuficiência deve-se aos longos congestionamentos, aos atrasos inadmissíveis em 
redes compartilhadas por milhares de usuários e, na maioria das vezes, a longas distâncias. Há algumas formas de prover qualidade de serviço às aplicações críticas (voz e videoconferência, por exemplo), com destaque para os serviços integrados, serviços diferenciados e prioridade relativa. Pesquisas recentes, tais como as discutidas em (Benkner e Engelbrecht, 2006), (Liang et al., 2008), (Liang et al., 2009) têm mostrado que a $Q o S$ também pode ser obtida em nível de aplicação.

\subsubsection{Serviços Diferenciados em nível de aplicação}

A disponibilidade universal e a facilidade para utilizar a interface provida pelos Web browsers, juntamente com o crescimento do número de usuários da Internet, têm motivado empresas de grande porte a migrar serviços de missão crítica para a Web. Bancos online, livrarias, reservas de passagens são exemplos de serviços que estão sendo oferecidos via Web front-ends. Tais características são uma tendência na Web, de modo que as considerações de qualidade de serviço têm ganho importância. Por exemplo, o tempo de resposta elevado, por parte de um site da Web, é um dos problemas enfrentados pelos usuários finais (Srinivas et al., 2000). Enquanto prever a demanda e aumentar a capacidade dos servidores em geral pode permitir a um site da Web descobrir as expectativas de $Q o S$ dos usuários, saber com certeza a demanda de novos usuários é mais custoso e apresenta mais dificuldades. A alternativa para o tratamento desse problema tem sido a provisão de qualidade de serviço em servidores Web, de modo que quando um servidor esteja sobrecarregado, este tenha a habilidade para estabelecer prioridades dentre as requisições que a ele chegam e, seletivamente, processar aquelas que são consideradas mais importantes segundo determinado critério. Para o usuário final, deve haver um limite no tempo de resposta às resquisições enviadas a um cluster de servidores Web. Se o tempo de resposta exceder um determinado limiar, o usuário tende a ficar insatisfeito com o serviço oferecido. Por isso são necessários algoritmos de balanceamento de carga, como sugerem os trabalhos de (Ho et al., 2004) e (Chen e Chen, 2004), para permitir alta disponibilidade dos servidores, evitar a sobrecarga, além de possibilitar uma resposta rápida aos clientes. Outros trabalhos que merecem destaque nesta área, incluem (Pai et al., 1999), (Crovella et al., 1999), (Cherkasova e Phaal, 2002), (Eggert e Heidemann, 1999), (Chen e Mohapatra, 1999), (Blanquer et al., 2004), (Bhinder et al., 2004), (Andreolini et al., 2004). Todos, de uma forma geral abordam a problemática de se tratar a diferenciação de serviço no nível da aplicação, utilizando técnicas de balanceamento de carga, escalonamento, controle de admissão, middleware, etc. Como complemento à diferenciação de serviços em servidores Web, muitas são as discussões em torno da qualidade de serviços relacionadas aos Web Services tais como as evidenciadas em (Liang et al., 2008), (Liang et al., 2009), (Qiqing et al., 2009), (Sha et al., 2009), (Huang e Nie, 2010). As questões relacionadas às garantias fundamentais de $Q o S$ tais como: disponibilidade, acessibilidade, integridade, desempenho, confiabilidade e segurança (Jensen et al., 2007) ainda são incipientes. Esforços de pesquisadores e empresas têm originado resultados importantes. Um modo para a provisão de qualidade de serviço em Web Services é a utilização de protocolos que realizam o transporte confiável das mensagens trocadas entre as aplicações envolvidas num pro- 
cesso de comunicação. No entanto, alguns estudos têm sido conduzidos para o desenvolvimento de outras especificações que garantam melhor QoS para os Web Services. Um comitê técnico da W3C trata desse assunto, e desenvolveu uma especificação de Web Services confiável denominada WS-Reliability (Leavitt, 2004). Destaca-se também suporte para a descrição de camadas de acordos de níveis de serviços, denominadas Web Service Level Agreements (WSLA). Atualmente, ainda não foi adotada nenhuma especificação padrão para a utilização de Web Services com qualidade de serviço. Por isso, enquanto não há uma sólida especificação padrão de QoS para Web Services, os trabalhos relacionados na literatura da área refletem diversos cenários, principalmente porque garantir qualidade de serviço é um grande desafio devido a heterogeneidade e a natureza imprevisível dos serviços (Farkas e Charaf, 2003), (Skorin-Kapov et al., 2007), (Nemati e Takizawa, 2008), (Gardasevic e Bojkovic, 2009), (Liang et al., 2009).

\subsubsection{Service Level Agreements (SLA)}

O termo Service Level Agreements (SLA) é baseado no conceito de serviços fixos e acordos de desempenho entre clientes e provedores de serviço, criando uma transparência para ambas as partes em termos de desempenho e custos. Acordos de níveis de serviços específicos são usados para definir o tipo, o escopo, a qualidade de serviços, e para verificar que especificações são conhecidas. Como tais acordos também incluem sanções potenciais para o evento que aceitou os parâmetros de serviços que não são conhecidos, as especificações fazem com que elas tenham um efeito significativo no sucesso comercial de uma companhia, provendo serviços para seus clientes (Schmietendorf et al., 2004). No contexto de arquiteturas orientadas a serviço, os benefícios de gerenciamento de níveis de serviço são descritos abaixo: O número de situações de conflito entre provedor e cliente podem ser reduzidos, resultando na melhoria da satisfação do cliente; Os recursos utilizados para melhorar o serviço (hardware) podem ser distribuídos num nível detalhado pelo provedor de serviços e, por isso, usados para otimizar os custos; Problemas podem ser identificados rapidamente pelo monitoramento de nível de serviço e a causa associada pode ser determinada; Custos podem ser mais transparentes - por um lado, o consumidor (cliente) quer somente pagar pelo serviço que ele utiliza, por outro lado, um preço adequado pode ser garantido;

Como parte do gerenciamento de acordo de nível de serviço para Web Services baseados em aplicações, um acordo deve ser concluído para prover o Web Service. As especificacões discutidas em (Keller e Ludwig, 2003) são apresentadas a seguir:

- Partes envolvidas e a validade de um acordo, isto é, o período sobre o qual o serviço será provido;

- Especificação de componentes de contrato e procedimentos para qualquer modificação necessária;

- Especificação de um escopo funcional e qualidade de serviço a ser provida;

- Definição de parâmetros de SLA com a qual a provisão do serviço será efetuada; 
- Especificação do procedimento para determinar/calcular os parâmetros de SLA.

De acordo com (Schmietendorf et al., 2004) os conteúdos descritos para um acordo de nível de serviço podem variar significativamente em termos de precisão de detalhes. No caso de aplicações baseadas em Web Services, é essencialmente necessário manter o relacionamento entre os Web Services envolvidos em prover o serviço e promover uma padronização de possíveis SLAs. Tanto o aspecto semântico quanto o sintático podem ser negociados usando $X M L$. A padronização de aspectos semânticos ainda está em fase inicial. Um exemplo disso, é a tarefa de interpretar a disponibilidade de um Web Service que é especificado como 98 por cento. Usuários podem questionar se o tempo de manutenção é levado em consideração, e como seria tratado um possível downtime do sistema. Esta flexibilidade deve ser explicitamente levada em conta durante o desenvolvimento, e a interface do Web Service deve ser tratada com esta informação. Além disso, o monitoramento deve ser suportado por pontos de medidas adequadas, de modo que potenciais gargalos do SLA possam ser identificados. Em geral, qualidade de serviço se refere às propriedades não funcionais de Web Services, tais como: desempenho, confiabilidade, disponibilidade, throughput, tempo de resposta, latência, acessibilidade, robustez, flexibilidade, integridade, reputação e segurança, (Kalepu et al., 2003). Em (Bouch et al., 2000) são discutidas que as métricas tradicionais de $Q o S$ tais como tempo de resposta e retardo não são suficientes para descrever totalmente a qualidade de serviço percebida pelos usuários. Outro fator, é que ao se levar em consideração determinados quesitos de $Q o S$, alguns trabalhos abordam o melhor modo possível de descobrir a WSDL mais apropriada que defina um serviço (Erradi e Maheshwari, 2005), (Ludwig, 2003). Na busca pela WSDL mais adequada, um suporte à $Q o S$ deve responder a questões principais: Qual a latência envolvida e qual o round-trip-time (retardo de ida e volta) aceitável (Kalepu et al., 2003). Essa é uma das vertentes de pesquisas de $Q o S$ em Web Services. Outras buscam melhorar a interação entre aplicações modificando protocolos, tal como o HTTP, e os adequando às características dos Web Services (Banks et al., 2002). Soma-se a isso, proposições de arquiteturas para prover $Q o S$ entre os Web Services, com a inclusão de Brokers (responsáveis por procurar pelo melhor repositório que contém a WSDL para um determinado Web Service requisitado pelo cliente) (Farkas e Charaf, 2003). Alguns trabalhos também têm se concentrado na proposição de novas métricas para melhorar a $Q o S$ numa arquitetura orientada à serviço (Kalepu et al., 2003), (Kalepu et al., 2004), (Taher et al., 2005), (Thio e Karunasekera, 2005), (Sha et al., 2009), (Liang et al., 2009). Em resumo, de acordo com uma análise da literatura da área, verifica-se que a área de qualidade de serviço em Web Services apresenta uma quantidade considerável de trabalhos, mas parte deles apenas enfatizam linguagens, arquiteturas e métricas de $Q o S$ para Web Services, e poucos trabalhos evidenciam de forma sucinta os benefícios da provisão de $Q o S$, por meio de resultados e da análise de desempenho, tópico que deve ser enfatizado no desenvolvimento deste projeto de doutorado. 


\subsection{Considerações Finais}

Este capítulo abordou a caracterização dos Web Services, incluindo protocolos, padrões e as técnicas utilizadas atualmente para a construção de aplicações envolvendo serviços Web. Um destaque maior foi dado ao tópico relacionado à qualidade de serviço em especial no nível de aplicação, com os esforços de diversos grupos de trabalho para a provisão de $Q o S$ em Web Services. A Web tem se tornado nos últimos anos um canal para troca de informações, negócios e comércio eletrônico, sendo necessário, portanto, um tratamento diferenciado para as aplicações que recebem solicitações de clientes ou sistemas distintos. Soma-se a isso, a adoção da idéia de que tudo na Web se torne um serviço e que a utilização de determinada funcionalidade de um sistema, principalmente das grandes empresas, esteja disponível para a interação com outros sistemas de outras empresas e até mesmo centros de pesquisas. Nesse sentido, para que os problemas de interação sejam diminuídos, faz-se necessária a adoção de métricas de qualidade de serviço. No próximo capítulo serão abordados os principais trabalhos relacionados envolvendo composição de serviços, desempenho e qualidade de serviços em Web Services. O Capítulo 3 também destaca as principais limitações de uma arquitetura orientada a serviços no contexto atual, e de que forma essas limitações podem degradar o desempenho do ponto de vista dos componentes participantes de uma arquitetura $S O A$. 



\subsection{Considerações Iniciais}

O objetivo deste capítulo é apresentar uma discussão em torno dos trabalhos relacionados ao desempenho em arquiteturas orientadas a serviços e qualidade de serviço em Web Services. Essa discussão e uma análise cuidadosa desses trabalhos são de fundamental importância para se situar nas áreas de pesquisa em questão e também para sugerir possíveis melhorias para a comunidade científica, sendo, portanto, referências para o desenvolvimento deste projeto de doutorado. Nesse contexto, na Seção 3.2.1 são discutidos diversos trabalhos relacionados ao tópico de composição de Web Services, o qual tem sido amplamente pesquisado pela comunidade acadêmica nos últimos anos. Na Seção 3.2.2 são abordados trabalhos relacionados à qualidade de serviço em especial voltado para arquitetura SOA e Web Services. As principais limitações do paradgmina de arquiteturas orientadas a serviços, incluindo protocolos, dispositivos móveis, XML parser, dentre outros, são apresentadas na Seção 3.3. Na Seção 3.4 são apresentados trabalhos relacionados a criação de índices de desempenho, de modo que esses pudessem ser utilizados no protótipo da arquitetura WSARCH. 


\subsection{Trabalhos Relacionados}

\subsubsection{Composição de Web Services}

Pesquisas efetuadas de acordo com a literatura sobre Web Services têm demonstrado um grande interesse dos pesquisadores em investigar como prover qualidade de serviço durante a troca de mensagens entre duas partes comunicantes. Uma referência importante relatando os problemas, os desafios e as iniciativas da área de computação orientada a serviço são apresentadas em (Papazoglou et al., 2007), (Papazoglou et al., 2006) e também em (Papazoglou, 2003). Em (Papazoglou et al., 2007) a temática é o paradigma de computação que utiliza serviços como elementos fundamentais para o desenvolvimento de aplicações/soluções. O autor argumenta que os Web Services requerem considerações especiais para interações entre os serviços. A arquitetura original SOA não se preocupa com detalhes como: gerenciamento, coordenação e segurança. O artigo também relaciona a interação entre Web Services (cujo foco é a neutralidade de plataformas computacionais, descoberta e invocação de serviços) e grades (com foco na dinâmica de serviços e uso eficiente de recursos computacionais distribuídos). Em (Papazoglou e van den Heuvel, 2005) os autores discutem o relacionamento de gerenciamento de sistemas distribuídos com o gerenciamento de Web Services explorando diversas abordagens e conceitos arquiteturais. Em (Menasce, 2004) o autor trata dos problemas de composição de Web Services. Analisa essa problemática por meio de um exemplo e destaca atenção para o tópico: "Como os diferentes atributos de $Q o S$ devem ser combinados para realizar uma composição de serviços mais elaborada?" Destaca, de maneira formal, alguns tipos de composição de serviço, tais como:

- Invocação probabilística: deve ocorrer quando há dois serviços disputando para fazer parte da composição e somente um deles é selecionado probabilisticamente;

- Invocação Paralela: numa situação em que $S$ é um serviço composto e A e B são seus sucessores, para que a composição seja efetivada com sucesso, todos os sucessores de $\mathrm{S}$ precisam ser invocados em paralelo;

- Ativação Sequiencial: os caminhos que conduzem ao serviço S são mutuamente exclusivos. Isso significa que se um deles completar, o serviço S se inicia;

- Ativação do mais rápido predecessor: a execução de $S$ se inicia tão logo a execução do primeiro predecessor esteja completa;

- Ativação Sincronizada: a execução de todos os serviços predecessores precisam ser completadas antes de S ser iniciado.

Outro desafio mencionado pelo autor, mas não caracterizado com um exemplo, é a composição dinâmica de serviços. O ponto positivo desse trabalho é a discussão em torno da composição de 
serviços. Mostra um exemplo teórico de composição estática e alguns tipos de composição de serviços. Sobre a composição dinâmica, que é um tópico relativamente complexo (Yang et al., 2005), não é abordada com maior profundidade e não são apresentados exemplos. O trabalho de (Wang et al., 2004) apresenta uma engine denominado D3D-Serv para implementar a funcionalidade de composição de serviços que é utilizada para compor serviços de diferentes requerimentos e lógicas de negócio. A idéia é discutir uma estratégia de seleção e execução de serviços (de modo eficiente) baseada em teoria de filas e que pode prover garantias de $Q o S$ sobre recursos limitados dos provedores. A composição de serviços é um tópico de pesquisa bastante discutido e cuja característica é a modelagem de processos de negócios complexos. Por exemplo, em um sistema de logística a integração complexa de várias aplicações deve envolver muitas companhias, consumidores, fornecedores, provedores e clientes. O artigo descreve um framework para composição dinâmica de serviços. Neste framework a idéia é que os serviços sejam definidos sob demanda, selecionados de acordo com critérios de $Q o S$ e executados de forma dinâmica. Dado o problema de composição, estudam uma estratégia de seleção de provedores de serviços garantindo uma determinada $Q o S$. A estratégia de seleção é uma abordagem dinâmica e adaptável ao ambiente dinâmico da Web. Os autores modelaram o problema do ambiente dinâmico da Internet e utilizaram a vantagem oferecida da teoria de redes de filas para o processo de seleção e escalonamento de serviços. Sugerem que a abordagem por eles oferecida permitem ganhos de desempenho em ambientes sobrecarregados e com limitação de recursos. A abordagem é interessante, inclusive no que diz respeito ao mecanismo de funcionamento do engine. Os algoritmos também são devidamente explicados. Os gráficos com os resultados sinalizam o entendimento dos mecanismos sugeridos pelo artigo. No entanto, como boa parte dos artigos, falha em não mostrar de forma clara como foi feita a simulação, quais ferramentas foram utilizadas e como foi feita a composição. A composição dinâmica é abordada na escrita do artigo, mas nenhum resultado relacionado é apresentado.

Em (Jaeger et al., 2005), os autores abordam a seleção de Web Services para o processo de composição e como considerar diferentes categorias de $Q o S$ para determinar os candidatos mais adequados para tal processo. Como ponto positivo, o artigo demonstra o modo de calcular a qualidade de serviço de uma composição de Web Services, agregando a $Q o S$ a cada serviço individual e também sinaliza para alguns algoritmos que permitem a seleção de candidatos para otimizar a composição. Em (Ardgna e Pernici, 2005), por sua vez, é discutido o processo de composição de serviço como um problema de otimização linear, isto é, uma abordagem matemática da composição de serviço. Ainda com relação ao processo de composição de serviços, em (Kalepu et al., 2003) é apresentada uma métrica para quantificar a composição e seleção de um Web Service. A utilização da métrica deve ser voltada aos provedores de serviços de modo a verificar se estes estão cumprindo os acordos de níveis de serviços com os usuários (clientes). Esse esforço é válido, visto que, há problemas em selecionar o Web Service mais adequado em razão da grande quantidade de provedores de serviços. Por isso, existe a necessidade de delimitação de qualidade de serviço para diferenciar os provedores e responder a seguinte pergunta: Há o cumprimento dos acordos de níveis de serviços com os usuários? Uma questão é a necessidade do usuário, outra está rela- 
cionada ao que o provedor de serviços pode oferecer. Para os autores, a proposição de uma métrica para quantificar qual o melhor provedor de serviço a ser escolhido deve levar em consideração aspectos como a replicação de serviços, distribuição de carga, redirecionamento de servidores e medida dos atributos de $Q o S$. Além disso, alguns autores fazem alusão ao termo de Reputação em Web Services, que permeiam questões como (Kalepu et al., 2004): como escolher o serviço correto e em que parâmetros se basear. Um ponto negativo destacado em (Kalepu et al., 2003) é o de apresentar a métrica mas não correlacioná-la com uma abordagem prática ou simulada. Apresenta a arquitetura proposta, mas não uma avaliação quantitativa.

\subsubsection{Qualidade de Serviço}

Muitos trabalhos relacionados não consideram avaliação de desempenho em Web Services. Com a integração de Web Services como uma solução de negócios em muitas aplicações empresariais, a qualidade de serviço apresentada pelos Web Services está se tornando a preocupação tanto dos provedores de serviços quanto dos clientes. Provedores precisam especificar e garantir a $Q o S$ de seus Web Services para se manterem competitivos e realizarem o melhor atendimento de seus processos de negócios. Por outro lado, os clientes objetivam que os serviços solicitados tenham bom desempenho (alta disponibilidade, baixo tempo de resposta, baixa latência). Em (Comuzzi e Pernici, 2005), os autores trabalham na criação de uma abordagem automática para a negociação de Web Services. A negociação é realizada por um Broker no qual ambos o provedor e o consumidor do serviço podem notificar suas preferências de $Q o S$ e negociar estratégias especificando o valor de um conjunto de parâmetros. A idéia é que o Broker tenha um modelo de decisão de cada provedor, de modo que o cliente faça a interação diretamente com o Broker. O Broker pode simular o comportamento do provedor no processo de negociação sem ter contato com o provedor toda a vez que o usuário faz um novo oferecimento de $Q o S$.

Em (Orta et al., 2009) é apresentado um modelo de simulação relacionado ao gerenciamento de capacidade de Web Services. A principal finalidade do modelo é ajudar a gerir a capacidade de Web Services atribuídas pelos provedores de serviços aos seus clientes com o objetivo de assegurar o cumprimento de um acordo de nível de serviço (SLA - Service Level Agreements). Questões de $Q o S$ têm recebido atenção durante os últimos anos, a maioria em rede de comunicação e também em comunidade de middleware (Tian et al., 2004) em que métricas locais foram definidas sem a preocupação com métricas para serviços fim-a-fim. Tem sido difícil encontrar propostas para negociação direta de $Q o S$ em ambientes de Web Services, especialmente quando consideram estratégias com aspecto fundamental em definir um framework de negociação automatizada.

Em (Thio e Karunasekera, 2005), é discutido como fazer medidas de $Q o S$ tanto do lado do cliente quanto do servidor. Qualidade de serviço de um Web Service é um fator importante que diferencia serviços similares oferecidos pelos vários provedores. Tal medida permitiria a um cliente de um Web Service escolher e ligar um Web Service adequado em tempo de execução (baseado em atributos de $Q o S$ ). Alguns pesquisadores têm proposto a integração de medidas de 
$Q o S$ no diretório do servidor do Web Service. Este artigo propõe um mecanismo dessa natureza, isto é, um mecanismo para manter métricas de $Q o S$. Esse mecanismo deve envolver medidas automáticas de atributos de $Q o S$, tanto do lado do cliente quando do lado do servidor, quando o serviço está sendo usado e atualizando o diretório baseado em $Q o S$, com esta informação. As propriedades de $Q o S$ podem ser representadas como atributos dos serviços e conseqüentemente a consulta do cliente pode ser baseada nessas propriedades. O modo como o autor apresenta as técnicas para avaliar o desempenho em Web Services, poderá ser considerado para definir o que foi avaliado na implementação deste projeto de doutorado. Em (Sheth et al., 2002) é proposto um middleware de alto nível para a arquitetura orientada a serviço e a composição de um modelo de QoS levando em conta as seguintes dimensões: tempo, custo, confiabilidade;

As definições das dimensões segundo o trabalho citado são:

- Tempo de resposta: o tempo estimado entre a chegada de uma requisição de serviço e o processamento daquela requisição;

- Custo: custo associado com a execução de Web Services;

- Confiabilidade: probabilidade que um serviço atenda às necessidades de quem deseja utilizálo. Ou seja, a taxa de execuções escalonadas/executadas com sucesso.

- Fidelidade: usada para indicar quão bem um serviço atende as expectativas dos usuários. Tratada como um vetor composto de atributos de fidelidade. Cada atributo se refere a uma propriedade/característica do produto/serviço criado, transformado ou analisado.

Outras questões importantes abordadas em (Sheth et al., 2002) são como determinar as estimativas para as propriedades de $Q o S$ de um Web Service. Neste caso pode-se ter:

- Uma combinação de estimativas de projetistas (da aplicação);

- Estimativas de $Q o S$ são paramétricas. Como por exemplo, o tempo de resposta de um serviço que obtém um documento $X M L$ como entrada, dependerá do tamanho do documento;

- A especificação do comportamento de execução de um Web Service pode ser feita utilizandose 2 classes:

- Básica: associa a cada dimensão de $Q o S$ do Web Service um valor mínimo, médio e máximo. Os valores especificados nesta classe são empregados por métodos matemáticos para computar métricas de $Q o S$. Por exemplo: a dimensão do custo corresponde a um valor mínimo, médio e máximo associada com a execução de uma tarefa.

- Distribucional: corresponde à especificação de uma constante ou de uma função de distribuição (exponencial, lognormal, normal, etc.) que estatisticamente descreve o comportamento da tarefa em tempo de execução. Os valores são apresentados por meio de simulação para computar o fluxo de trabalho de $Q o S$. 
O aspecto positivo do trabalho de (Sheth et al., 2002) é a abordagem sobre gerenciamento de $Q o S$ de modo efetivo e eficiente, além da integração de Web Services, grades e redes peer2peer. Produtos e serviços devem ser disponíveis aos consumidores com especificações bem definidas para preencher expectativas dos clientes. Cita uma ferramenta para simulação (JSIM) (Miller et al., 1997) e outra para criação de fluxo de trabalho de $Q o S$. Aborda que resultados estatísticos podem ser coletados e mostrados indicando o fluxo de trabalho de $Q o S$. Em (Woodside e Menasce, 2006), os autores defendem que muitos projetos de aplicações para sistemas distribuídos falham porque não abordam aspectos de qualidade de serviço. Soluções baseadas na atualização de hardware não resolvem o problema causado por componentes de software inadequados e por construções erradas de arquiteturas de software. Abordam algumas técnicas para o desenho de $Q o S$ :

- Evolution: baseada nas características de desempenho anteriores para a tomada de decisão.

- Precision Design: explora modelos de carga, comportamento e recursos para obter $Q o S$ adequada.

- Flexible Design: trabalha com características para lidar com as incertezas da carga de trabalho e criar softwares escaláveis que (dado um conjunto suficiente de recursos) podem operar eficientemente para uma vasta gama de cargas de trabalho.

Em (Woodside e Menasce, 2006) é reiterado que a qualidade de serviço resulta da interação entre a demanda do usuário, o comportamento do sistema sobre essa demanda e os recursos que esse comportamento requer. Se tais fatores não forem considerados, a tendência é o mal uso de recursos e uma $Q o S$ não controlada. O ponto principal deve ser o conhecimento do comportamento das aplicações e suas demandas por recursos. Um problema freqüentemente enfrentado é a dificuldade de descobrir esse comportamento. O trabalho de (Taher et al., 2005) tem como objetivo prover suporte à seleção de Web Services baseado em critérios de $Q o S$ em um framework denominado QoS Information and Computation $(Q o S-I C)$. O destaque é para o mapeamento de $Q o S$ para consumidores (clientes) com a informação de $Q o S$ publicada pelos provedores de serviço. Os autores criticam o mecanismo atual de seleção de Web Services em registros de serviços pelo fato daquele ser baseado somente nas informações publicadas no documento WSDL, ou seja, somente nas informações funcionais. Os clientes precisam de um mecanismo baseado numa informação funcional e também não funcional (tempo de resposta, disponibilidade, confiabilidade, etc.). A contribuição dada pelo artigo são as discussões sobre como selecionar Web Services de um provedor de serviços. Os autores utilizam uma técnica de otimização para tal finalidade. Apresenta de forma clara e transparente a metodologia e descreve matematicamente todo o procedimento. O ponto negativo é que os autores não exploram questões de avaliação de desempenho e simulação/implementação.

Outra técnica para a melhoria da provisão de $Q o S$ é a utilização de um mecanismo que reduza o tempo de transmissão e de resposta das mensagens trocadas entre Web Services (Wu et al., 
2003), por meio da compressão de mensagens a serem enviadas do consumidor para o provedor de serviços. Durante o desenvolvimento desse projeto de doutorado foi proposta uma heurística que pode ser usada para decidir se uma mensagem SOAP deve ou não deve ser compactada. Uma simulação foi realizada para determinar a eficiência da heurística, e os resultados mostraram que ela pode ajudar na redução do tempo de resposta do serviço em uma variedade de cenários. Os resultados obtidos são apresentados em (Estrella et al., 2008a).

Em (Ludwig, 2003) são evidenciados tópicos relacionados as semânticas dos parâmetros de QoS (entendimento dos parâmetros de $Q o S$ pelos usuários e Web Services). "Onde as medidas devem ser realizadas? Rede, Cliente, Servidor de Aplicação?” É importante considerar os aspectos relacionados ao desempenho dos sistemas envolvendo Web Services, tais como: gerenciamento de desempenho, gerenciamento de carga, escalonadores, controle de resposta de sistemas individuais, etc. Técnicas de avaliação de desempenho não são mostradas, apesar das discussões sobre o tema serem mapeadas adequadamente. Para (Farkas e Charaf, 2003), em geral, o modelo básico de Web Services não contém informações sobre medidas de qualidade. Dentre as desvantagens desse modelo, os autores citam:

- Baixa qualidade;

- Pouca confiabilidade;

- Tamanho das mensagens $X M L$ : é necessário melhorar o desempenho com técnicas de compressão de mensagens;

Citam ainda que os fatores de qualidade para a escolha do melhor Web Service devem envolver o tempo de resposta, carga da rede, custo para acessar o melhor serviço.

O trabalho proposto em (Chen et al., 2003) destaca uma arquitetura de $Q o S$ utilizando um Broker entre clientes, Web Services e provedores de serviço. Análise de desempenho também é um tema abordado. Além disso, mostra quais as garantias que as aplicações precisam possuir quando estão trocando informações (mensagens). Dentre os componentes de controle de $Q o S$ foram citados: poder de processamento do servidor e entrega do serviço. De acordo com estudo dos autores os parâmetros de $Q o S$ que podem ser coletados do sistema avaliado, com a vantagem de não apresentar nenhuma intervenção do usuário são:

- Tempo de resposta;

- Custo do serviço;

- Largura de banda;

- Disponibilidade do serviço; 
Além das abordagens anteriormente descritas o artigo também mostra como classificar os Web Services de acordo com suas funcionalidades, separando-os em grupos de serviços. Neste caso os clientes teriam os mesmos critérios de $Q o S$. Apresentam também, dois algoritmos de reservas de alocação de recursos para se ter uma qualidade de serviço adequada. Apesar das boas discussões em torno do tema de $Q o S$, os autores não sinalizam no artigo como foram realizados os testes desses algoritmos, isto é, em que condições, quais as ferramentas para implementação ou simulação, etc.

Em (Jaeger et al., 2005) também são apresentadas técnicas para composição de Web Services por meio de modelos. Por meio de uma ferramenta de simulação são gerados exemplos de composições e candidatos de Web Services para avaliar possíveis substituições. As características de $Q o S$ tais como custo, disponibilidade, tempo de execução e reputação também são analisadas. Em (Aiello et al., 2009) é proposto um algoritmo que, dada a funcionalidade desejada, retorna uma composição de serviços a partir de um repositório com o ótimo tempo de resposta ou throughput. Os serviços são compostos, levando em consideração uma ontologia de nomes de operações expressas em Web Ontology Language (OWL). Outra questão abordada é em relação aos serviços que precisam ser substituídos em um fluxo composto. Essa preocupação é importante, pois, serviços do fluxo podem falhar e causar degradação na qualidade de serviço final. Nesse sentido, em (Yin et al., 2009) é proposto uma nova abordagem para os serviços substitutos de um fluxo composto. O serviço de destino pode ser substituído individualmente, ou pode ser substituído por seus serviços relacionados na composição como um todo por um serviço mais complexo. Desta forma, muito mais opções estarão disponíveis para reparar a composição. É também apresentado um mecanismo para selecionar o serviço ideal para a substituição baseada em $Q o S$ em duas fases: a pré-seleção e classificação.

Em (Yu e Lin, 2004), os autores discutem os principais parâmetros que devem ser considerados na proposição de um algoritmo de seleção de serviços, isto é, aqueles que podem ser coletados sem a intervenção do usuário. Entre tais parâmetros, são citados: custo do serviço, tempo de resposta, carga do servidor/provedor, atraso da rede, etc. $\mathrm{O}$ artigo também destaca especial atenção ao tópico de composição de serviços. Para os autores, os Web Services requisitados por um cliente podem ser divididos em duas categorias. Uma delas é a dos serviços simples, ou seja, quando uma requisição pode ser cumprida por um serviço individual. A outra é a categoria de serviços compostos, para o qual uma requisição deve ser completada por um conjunto de serviços individuais (por exemplo, quando um usuário quer fazer um plano de viagem que inclui a seleção do vôo, a reserva do hotel, o aluguel do carro, etc). Há dois tipos de serviços compostos dependendo da quantidade de caminhos de execução que um serviço composto possa ter:

- Pipeline Simples: Uma estrutura de serviço composto com um único caminho de execução;

- Estrutura de Grafo: Possui múltiplos caminhos de execução. O Broker ou o responsável pela seleção, deve escolher o caminho ótimo dentre os apresentados. 
Em contrapartida, o trabalho de (Liu et al., 2005b) tem como objetivo a apresentação de um plano de composição automático e dinâmico de Web Services. A abordagem de composição de Web Services, e particularmente como tal composição é feita, é mostrada segundo o algoritmo a seguir:

- Computar uma rede reduzida (de serviços);

- Encontrar todos os planos de composição para uma saída dada pelo usuário final;

- Obter todos os planos de composição para todas as saídas dada pelo usuário final;

- Encontrar o plano de composição com qualidade de serviço ótima.

Os autores ainda consideram como relevantes os atributos de $Q o S$, preço, disponibilidade, confiabilidade, duração e reputação. Eles não mencionam se a abordagem foi implementada ou simulada. Não são apresentados resultados. Em (Estrella et al., 2008b) diversos atributos de qualidade de servico são mapeados para entidades participantes de uma SOA, visando definir como pode ser avaliado o desempenho de um Web Service. Pontos como o que deve ser avaliado e a maneira como deve ser avaliado em um Web Service, são abordados neste artigo, além de uma arquitetura utilizada para exemplificar como os atributos de $Q o S$ definidos podem ser utilizados no oferecimento de Web Services.

O trabalho de (Huang, 2005) mostra um modelo de como formatar e resolver o problema de alocação de capacidade de recursos computacionais para as aplicações, como um problema de otimização linear, juntamente com contratos de $Q o S$. O trabalho proposto pelos autores retrata um modelo de redes de fila para a resolução do problema de capacidade de alocação de recursos. Neste modelo, máquinas são estações de serviços compartilhadas e aplicações de negócios são filas associadas com essas estações. Os jobs são instâncias dos processos de negócio. O método de alocação de capacidade leva em consideração os seguintes fatores:

- Chegadas aleatórias de instâncias de processos de negócios;

- Flutuações no tempo de serviço das aplicações de negócios;

- Requerimentos de $Q o S$ das aplicações;

- Estrutura de composição do processo.

Além disso, relatam que utilizam distribuições para simular o tempo de serviço e também entre as chegadas de requisições. O mesmo ocorrendo para aproximações de tráfego pesado. Segundo os autores, cada atividade em um processo de negócios representa um determinado tipo de tarefa a ser completada. Para completar um processo de negócios, aplicações que controlam aplicações individuais precisam ser requisitadas de forma correta de acordo com a estrutura seqüencial (padrão 
de composição do processo). Para analisar o desempenho de um processo de negócios, saber a estrutura do processo não é suficiente; é preciso conhecer o desempenho de cada atividade dentro do processo, ou mais precisamente, o desempenho de aplicações de negócios que controlam essas atividades. Em (Xia, 2006) a articulação gira em torno do seguinte ponto: mesmo com os acordos de níveis de serviço, a qualidade do serviço não é garantida na prática, devido a infra-estrutura heterogênea da Internet. $\mathrm{O}$ desempenho da composição não tem sido considerado na maioria das técnicas existentes na literatura. O mesmo autor apresenta trabalhos em que o foco é a implementação de algoritmos genéticos e otimização para selecionar os melhores serviços. A avaliação de desempenho não é tratada pelo autor. Para serviços em tempo real, a falha na composição de um serviço agregado e a não entrega deste num tempo adequado pode causar grandes perdas para as aplicações de negócios e aplicações Web em geral. Para garantir a qualidade de serviço, a execução dos serviços compostos precisa ser monitorada constantemente. Segundo (Xia, 2006) o ambiente de composição baseado em $Q o S$ deve considerar:

- Seleção e execução de serviços baseado em $Q o S$;

- Monitoramento de $Q o S$;

- Adaptação baseada em $Q o S$.

O problema de adaptação baseada em $Q o S$ é tratado em (Dorn et al., 2009). Os autores abordam o problema de auto-adaptação em sistemas orientados a serviços de larga-escala. Os serviços precisam se adaptar, selecionando da melhor forma os melhores serviços vizinhos apenas com base em algumas informações. Em geral as informações são locais e limitadas, o que não é adequado se forem considerados sistemas complexos. Nesses sistemas, o significado global dos parâmetros de seleção muda dinamicamente. Por isso, os autores introduzem uma nova métrica para medir a distribuição e o impacto potencial das propriedades do serviço que afetam esses parâmetros de seleção e apresenta também um formalismo para identificar as propriedades mais importantes de interação com base em dados agregados de serviço. Para a concretização desse ambiente é necessário:

- Um modelo de $Q o S$ quantitativo;

- Um compositor de serviço baseado em $Q o S$;

- Um motor (engine) de execução em $Q o S$;

- Um monitor que verifique a qualidade dos componentes do serviço do provedor.

Em (Maheshwari et al., 2004) é exemplificada a construção de um middleware orientado a mensagens, cujo objetivo é aumentar a confiabilidade dos Web Services. Os autores discutem vários fatores, dentre eles: tipos de mensagens, status dos Web Services, eficiência e como priorizar a execução de um Web Service. Web Services tem ganhado popularidade nos últimos anos ao permitir 
que aplicações de diferentes provedores sejam publicadas como serviços e sejam compostas como uma parte de uma grande tarefa. Como um fator essencial para a computação orientada a serviço (Ludwig, 2003), QoS tem-se demonstrado um fator difícil de se gerenciar devido as diferenças das organizações, e também devido à localização dos Web Services. Para resolver este problema, pesquisadores propõem um mecanismo de composição baseado em $Q o S$ para melhorar a seleção do serviço e gerenciar atributos de $Q o S$ por meio do ciclo de vida dos serviços. Suporte à $Q o S$ para Web Services está entre um dos tópicos bastante pesquisados no momento, atraindo tanto pesquisadores da academia quanto de empresas. Durante o surgimento da tecnologia dos Web Services, pesquisadores focaram mais nos aspectos funcionais e de interfaces (UDDI, WSDL, etc.), não se preocupando com qualidade de serviço. A qualidade do serviço analisada pelo cliente, por exemplo, pode ser afetada por muitos fatores, incluindo: o desempenho do próprio Web Service, a plataforma do provedor que o hospeda e a própria rede de comunicação. O gerenciamento de $Q o S$ tem sido extensivamente estudado em aplicações multimídia baseada na rede, bem como baseada em aplicações Web. No contexto de Web Services (Papazoglou et al., 2007), (Orta et al., 2009), (Liang et al., 2009), as pesquisas estão em constante evolução.

\subsection{Limitações do Paradigma de Arquiteturas Orientadas a Serviço}

Para permitir que os sistemas troquem informações com um mínimo de qualidade, é fundamental que as questões de desempenho sejam levadas em consideração. No entanto, o desempenho esperado pelo cliente de um Web Service nem sempre é possível. No universo dos Web Services, isso ocorre devido a falha nas especificações de arquiteturas que se concentram mais em como o serviço pode ser acessado e não sobre questões de qualidade, ou seja, o foco está mais para os aspectos funcionais do que para os aspectos não-funcionais de serviços. A concepção de um arquitetura $S O A$ e suas extensões, permitiu a interação entre os diversos sistemas, mas ainda carece de critérios mínimos de qualidade de serviço. Na literatura de Web Services e qualidade de serviço, foram identificadas lacunas que precisam ser devidamente tratadas para trazer benefícios para áreas de pesquisa e também para aqueles que querem se aproveitar da arquitetura orientada a serviços, como forma de integrar aplicações e processos empresariais. Os problemas de arquitetura orientadas a serviços do ponto de vista de desempenho são descritos nas próximas seções deste trabalho. Em resumo, existem particularidades de motores de processamento de mensagens SOAP (algumas delas em $\mathrm{C}$ e outras em linguagem Java), protocolos e limitações de hardware, o $X M L$ como formato de mensagem, parser XML, mensagens SOAP com anexos de dados e também problemas de segurança. 


\subsubsection{Protocolos e Limitações de Hardware - Dispositivos Móveis}

Embora o HTTP seja o protocolo mais utilizado na $W W W$, em (Phan et al., 2006) os autores argumentam que a utilização de mensagens SOAP sobre o Tranmission Control Protocol (TCP) ou HTTP são ineficientes devido a grande sobrecarga e latência de rede. Se os Web Services são uma forma de integrar os processos, equipamentos e dispositivos, há um interesse para estender aplicações Web tradicionais para ambientes móveis (Phan et al., 2006). Este interesse esbarra em questões como as limitações de protocolos de rede e protocolos de aplicação como o protocolo SOAP. O SOAP pode ser usado para fornecer a interoperabilidade entre sistemas de diferentes plataformas e dispositivos, mas foi originalmente concebido para rede cabeada e sistemas de grande escala. No âmbito dos dispositivos móveis como handhelds, celulares dentre outros, podemos listar alguns desafios:

- Comunicação sem fio: aplicações móveis apresentam requisitos específicos de domínio (segurança, agilidade e disponibilidade de serviços). Segurança em Web Services é um temachave também estudado na literatura, como mostrado em (Silva et al., 2004) e (Jensen et al., 2007).

- Limitações de recursos: baixo poder de processamento, restrições de memória e tempo de duração da bateria.

- Informação resumida: se um Web Service for construído para trocar informações entre dois sistemas (por exemplo, duas bolsas de valores), tem-se uma situação em que esses sistemas apresentam menos limitações em relação ao processamento da $C P U$ e visualização de informações. No âmbito de dispositivos móveis, é preciso considerar a utilização de um servidor proxy, a fim de extrair apenas as informações necessárias que possam ser processada pelo dispositivo móvel, principalmente porque este dispositivo apresenta limitação de processamento de informações;

- Os dispositivos móveis precisam se mudar para redes diferentes a fim de obter as informações solicitadas.

Algumas soluções envolvendo a mudança do protocolo de ligação (binding protocol) usado para transportar mensagens são apresentadas em (Phan et al., 2006), (Engelen e Gallivan, 2002), (Cafaro et al., 2007). Os autores desses trabalhos sugerem o uso do protocolo UDP. O UDP apresenta alguns benefícios como pacotes menores que o TCP, natureza multicast e menor uso de largura de banda (Mahlo et al., 2005). Se por um lado, o UDP apresenta benefícios de desempenho, por outro lado, ele possui algumas limitações. Por exemplo, não há nenhum mecanismo de recuperação de pacotes caso algum problema ocorra na rede durante a transmissão. Para os sistemas que não precisam de algum tipo de confirmação e pouca sobrecarga e quando a alta transferência de dados se sobrepõe à confiabilidade, o uso do UDP pode ser aplicável. Como exemplo desses cenários destacam-se stream de dados e aplicações em tempo real. 


\subsubsection{XML como Formato de Mensagem, XML Parser e Mensagens SOAP}

Em (Andresen et al., 2004) os autores concluem que o maior custo da codificação e decodificação do $X M L$ está na complexidade estrutural dos elementos, ao invés de dados das mensagens. Eles mencionam que uma grande percentagem do tempo gasto pelo provedor é na codificação da mensagem XML, no processo de marshalling (o processo de transformar a representação em memória de um objeto para um formato de dados adequado para o armazenamento ou transmissão). Os autores mostram uma lista de verificação que é importante considerar, principalmente se o foco é a construção ou integração de sistemas com restrições de avaliação de desempenho. É importante considerar esta listagem e também as medidas relacionadas ao processamento de mensagens SOAP (Andresen et al., 2004):

- Chamadas SOAP têm uma grande sobrecarga, devido ao tempo de execução considerável exigido para processar mensagens $X M L$.

- Não há equilíbrio entre a velocidade de execução e interoperabilidade.

- Cinqüenta por cento do tempo de execução é gasto na codificação de dados $X M L$ e na criação de uma conexão HTTP. A codificação XML envolve: preparação da carga útil SOAP e a serialização e marshalling da carga útil antes desta ser transmitida para o provedor de serviços.

- SOAP é ineficiente em comparação com CORBA e RMI, em computação distribuída

- Falta de otimização com dados $X M L$

- Codificação de dados binários na forma de resultados XML e uma sobrecarga de processamento

Também é importante mencionar que a sobrecarga de processamento de mensagens $S O A P$ pode estar relacionada a:

- Velocidade de codificação e decodificação: Conversão de dados binários para o padrão American Standard Code for Information Interchange (ASCII) e vice-versa é um dos principais custos relacionados ao processamento de dados $X M L$. Particularmente o alto custo em relação ao desempenho ocorre para valores de ponto flutuante e matrizes de grandes dimensões (Ying et al., 2005).

- Alto Custo da Rede de Transmissão: Os dados ASCII resultantes da decodificação são maiores que o dado binário original. Para transferir dados binários por meio de mensagens SOAP são usados algoritmos de codificação binária como o base64. A conversão dos arquivos binários em caracteres sinaliza mais tempo de $C P U$, uso intensivo de memória e mais 
largura de banda necessária para a transmissão de dados (Zhang et al., 2007). Um cenário típico onde conversão é usada, é na transferência e gestão de dados de experimentos científicos, que geram grandes quantidades de dados. A transferência de dados binários usando um algoritmo de codificação pode degradar o desempenho do sistema. Em um estudo de avaliação de desempenho foi possível identificar os principais aspectos relacionados à transferência de dados binários dentro de mensagens SOAP utilizando três diferentes técnicas (Binário Puro, e SWA/MTOM), apresentado em (Estrella et al., 2009).

- Tamanho da mensagem: O tamanho da representação de dados SOAP é tipicamente cerca de 10 vezes o tamanho da representação binária equivalente. Isso ocorre particularmente devido aos custos associados à codificação e decodificação de valores de ponto flutuante.

Em (Alodib e Bordbar, 2009) é apresentado um método de criação de arquiteturas que permitem a monitoração da ocorrência de falha em arquiteturas orientadas a serviço (SOA). A abordagem apresentada abrange técnicas de sistemas de eventos discretos para produzir um método de criação automatizada de diagnóstico do serviço que monitora a interação entre os serviços para identificar se uma falha ocorreu e qual é o tipo da falha. Além dos requisitos de segurança e tolerância a falhas, o aspecto desempenho precisa ser considerado em função dos problemas discutidos. Na integração de sistemas em tempo real, por exemplo, a utilização de SOAP e XML não são a melhor opção (Kohlhoff et al., 2004). O uso de SOAP e XML incorrem em uma penalidade de desempenho em comparação com os protocolos binários. Para completar os problemas discutidos em (Andresen et al., 2004), outros fatores podem afetar o desempenho dos Web Services, tais como o desenho e implementação de serviços. Alguns deles são listados em (Mani e Nagarajan, 2002), (Kohlhoff et al., 2004):

- XML Parser: Diferenças em relação à eficiência da memória, velocidade computacional e facilidade de uso. Os parsers se encaixam em duas categorias: baseado em árvore (por exemplo, Document Object Model (DOM) ou baseado em eventos (por exemplo, Stax). Em um parser push-based, o próprio parser tem o controle do fluxo de dados e decide o que fazer com a informação. Em um parser pull-based a aplicação "puxa"os dados do fluxo de dados $X M L$ de acordo com sua conveniência. A aplicação e não o parser está no controle, o que dá a aplicação o poder para filtrar, manter tags ou parar o parser a qualquer momento. Em parsers do tipo DOM, todo o conteúdo do documento $X M L$ é lido na memória e uma transformação do objeto desse conteúdo é produzida. O principal problema de parsers DOM é a ineficiência do uso de memória, pois toda a informação é analisada. Algumas aplicações não precisam de todas as informações representadas na memória, mas apenas parte dela. Carregar grandes documentos na memória também pode causar problemas de segurança como será discutido mais adiante neste documento. Pull parser é mais eficiente com relação ao uso de memória, pois o código da aplicação controla diretamente o parser iterando sobre o documento usando o leitor de stream baseado em Stax. Outra questão importante é o 
papel do parser XML no desempenho do protocolo SOAP. Parsers XML causam uma elevada utilização de recursos computacionais quando mensagens $X M L$ são processadas.

- WSDL: A interface que permite a descrição de um Web Service específico para o mundo exterior, também apresenta problemas que precisam ser investigados. A WSDL se preocupa apenas com aspectos funcionais e de sintaxe, mas não verifica se a semântica do documento está correta ou se as normas mínimas de $Q o S$ podem ser alcançadas. Devido à ausência de tais características, o desenvolvedor precisa compreender as características de $Q o S$ dos Web Services, desenvolvendo aplicativos que dependem de Web Services. A WSDL também expõe as operações em um domínio sem se preocupar com a segurança, sendo assim suscetível a ataques, conforme descrito em (Jensen et al., 2007).

- Cálculo do Tamanho da Mensagem: Conhecer dinamicamente o conteúdo de uma mensagem SOAP é difícil sendo necessário na maioria dos casos a utilização de buffers.

- Custos de Estabelecimento de Conexão: Uma nova conexão HTTP para cada operação degrada o desempenho, devido a interação com determinadas características do TCP como: handshake de três vias e algoritmo de partida lenta. O HTTP 1.0 não é a melhor escolha. A melhor maneira é utilizar o protocolo HTTP 1.1 com buffering pipelining, porque a conexão por si só não é suficiente para melhorar o desempenho.

- Canal de Comunicação: Um fator limitante no desempenho de Web Services é o canal de comunicação. Deve-se ressaltar que os Web Services atingiram certa maturidade devido ao fato de que a comunicação entre serviços ser feita por meio da Internet. No entanto, detalhes como baixa latência, baixo congestionamento e garantia de entrega devem ser considerados na transmissão de mensagens. Talvez esses detalhes pudessem ser garantidos se uma rede global fosse construída exclusivamente para a Web Services.

- Protocolo de Vinculação de Rede (Binding Protocol): O uso do HTTP deveria ser restrito somente para a comunicação estilo mensagem, uma vez que o HTTP é um protocolo do tipo requisição-resposta. Em sistemas de tempo real, o HTTP não é uma solução adequada. Os problemas discutidos a seguir podem aparecer em algumas das etapas que envolve o processamento de uma mensagem SOAP tanto no cliente como no provedor de serviços (Andresen et al., 2004):

- Recepção da requisição pelo roteador

- Identificação do provedor e o despacho da chamada para o provedor de serviços

- Despacho da chamada para o serviço atual e a recepção da resposta subsequente

- Marshalling do envelope

- Marshalling da resposta 
Há outras abordagens na literatura para melhorar o desempenho dos Web Services. As técnicas vão desde o mecanismo de desserialização que reutiliza regiões correspondentes obtidas de objetos previamente desserializados de mensagens anteriores (Suzumura et al., 2005), a implementação do protocolo SOAP utilizando um mecanismo de cache no provedor de serviços (Andresen et al., 2004), dentre outras. Técnicas para enviar dados binários encapsulados em mensagens SOAP (Heinzl et al., 2006) também são discutidas.

\subsubsection{Evolução de Web Services}

Em (Papazoglou, 2008) os autores discutem a dificuldade em lidar com as mudanças nos serviços (infra-estrutura, protocolos de negócios, comportamento, política operacional) tornandose difícil estabelecer um acordo de nível de serviço (SLA). Um SLA deve considerar as mudanças nos serviços e nas decisões a este respeito. Entre eles estão, como o sistema irá responder a uma mudança de serviço, se as mudanças são funcionais (específicas de serviço) ou não funcionais. Outra questão é em relação às versões de serviços. As novas versões precisam considerar as características do antigo e ao mesmo tempo, introduzir novas características que refletem a mudança no serviço. $\mathrm{O}$ artigo trata das mudanças que possam ocorrer durante o ciclo de vida de serviços. Tais alterações podem ser de dois tipos:

- Shallow: Envolve mudanças estruturais e mudanças no protocolos de negócios. Ocorre geralmente em serviços simples e de processos de negócio.

- Deep: Envolve alterações determinadas pelas mudanças nas políticas e comportamento operacional. Ocorre em processos de negócios. As mudanças profundas são as mais difíceis para lidar, porque envolve problemas como:

- Serviços de Fluxo

- Controle de Serviços

- Sobreposição de Serviços

- Funcionalidades de Serviços conflitantes

- Serviços de entrada e saída

Há uma forte relação entre a evolução de um serviço e o desempenho de um sistema. Portanto, é essencial considerar os aspectos de desempenho para: analisar o sistema, controlar o sistema e também para a melhoria dos processos de negócios. Questões como a evolução dos serviços e gestão de mudanças também precisam ser consideradas. Esses aspectos são importantes na avaliação do desempenho de um sistema. É também necessário lidar com contratos de serviços (exigências funcionais, requisitos não-funcionais, políticas - acordos e suporte). 


\subsubsection{Composição de Web Services}

Em uma arquitetura orientada a serviços, Web Services funcionalmente equivalentes com qualidade diferente podem ser selecionados para juntos realizar uma tarefa de forma dinâmica. Os Web Services devem ser escolhidos por requisitores com base em suas necessidades. Nesse sentido, a utilização de SLAs pode satisfazer a exigência do solicitante e ser utilizado em um fluxo de composição de Web Services. Em (Dong e Jiao, 2008) os autores propõem um mecanismo de composição de serviços orientados à $Q o S$ e estabelecem uma relação entre o espaço vetorial $S L A$ e constroem um serviço composto baseado numa análise funcional dos atributos de $Q o S$. A composição de Web Services é um tema importante na literatura uma vez que um único Web Service tem funcionalidade limitada, se comparada com um processo de negócio complexo. Um processo de negócio geralmente envolve mais de uma organização independente que possui serviços que precisam ser integrados e, em seguida, fornecer aos clientes um resultado desejado. Portanto, há uma demanda crescente em pesquisas que envolvem a composição de Web Services e QoS, e como esta parceria pode proporcionar aos clientes um resultado satisfatório para suas necessidades e requisitos para a utilização de um Web Service.

Um dos principais conceitos utilizados para a integração dos processos dentro de Business Process Management (BPM) é a composição de Web Services, em que as linguagens Business Process Execution Language (BPEL) (Decker et al., 2007) e Yet Another Workflow Language (YAWL) (van der Aalst e ter Hofstede, 2005) são baseadas. Um aspecto importante do modelo de serviço é que os novos serviços podem ser criados a partir da existência dos outros, sem descuidar do paradigma da arquitetura orientada a serviços (Weerawarana et al., 2005). As dificuldades para a operação dos Web Services em larga escala esbarra em questões tais como: diferentes estratégias de composições e linguagens diferentes para concepção da execução de um fluxo. Para lidar com um fluxo de composição complexa (Dustdar e Schreiner, 2005) os autores consideram seis questões essenciais na composição de Web Services: a coordenação, a transação, o contexto, conversação, execução e infra-estrutura. Por exemplo, a execução de um fluxo composto pode ser centralizada ou distribuída, a abordagem composta pode ser estática ou dinâmica, em tempo de design ou tempo de execução, orientado a modelos ou orientado a regras de negócio, automático ou manual. Outros desafios incluem: descoberta de serviços, seleção de serviços e mudanças nos serviços. Essas discussões, algumas especificamente relacionadas com a composição de serviços, para não mencionar outras, traz uma reflexão aos muitos desafios pela frente para alcançar um equilíbrio entre desempenho e eficiência tanto para o provedor quanto para o cliente do serviço.

Para a composição de Web Services ser uma ferramenta computacional eficaz é essencial que as interfaces de serviços (WSDL) e motores de processamento de mensagens considerem a semântica dos dados. Composição de Web Services é um tema crucial e tem um grande impacto em diferentes áreas de pesquisa (Dustdar e Schreiner, 2005). O número crescente de dispositivos conectados e os recursos de cliente heterogêneos necessitam que as informações dos serviços sejam acessíveis a partir de qualquer dispositivo (Dustdar e Schreiner, 2005), (Keidl e Kemper, 2004). Muitas são 
as vantagens de ocultar a natureza heterogênea dos dados e fornecer uma interface bem definida para o acesso aos dados, principalmente para dispositivos móveis e sistemas pervasivos (Dustdar e Schreiner, 2005). No entanto, como informações sobre o contexto de serviços tornam-se fundamentais em futuras aplicações Web, é importante o uso de técnicas que garantam um mínimo de desempenho e qualidade de serviço $(Q o S)$. Por exemplo, o uso de agentes móveis para monitorar o status dos Web Services para verificar a sua disponibilidade e notificar os participantes, e também a tomada de decisão quando ocorre algumas mudanças, quando propagá-las, pois as mudanças podem ocorrer antes ou durante a invocação do serviço.

\subsubsection{Segurança em Web Services}

Aplicações orientadas a serviços são altamente distribuídas e dinâmicas. Uma vez que a procura por um Web Service se baseia na interface disponível para acessá-lo e esta apenas possui propriedades funcionais do Web Service, a qualidade de serviço pode sofrer degradação. Portanto, há muitas possibilidades de mal funcionamento, o que pode causar perdas significativas para as empresas, organizações e sistemas que utilizam o conceito de arquiteturas orientadas a serviços. Neste contexto, é importante considerar a segurança como uma questão essencial na construção de Web Services, tanto para clientes quanto para provedores de serviços. É essencial avaliar as principais opções de segurança para Web Services, considerando algoritmos de criptografia, técnicas de assinaturas digitais, entre outros. Atualmente não há boas razões para determinar quais especificações de segurança computacional no contexto de Web Services impõem o mínimo de impacto em termos de desempenho (Jensen et al., 2007). Diferentes opções devem ser avaliadas a fim de determinar quais ou qual a combinação delas são suficientes para garantir a segurança ponto a ponto no contexto das mensagens trocadas entre os participantes em uma arquitetura orientada a serviços (os clientes, provedores de serviços, registro de serviços e barramento de serviços Enterprise Service Bus (ESB).

Para que um mínimo de segurança seja alcançada entre a troca de mensagens, algumas propriedades clássicas devem ser garantidas: confidencialidade, integridade, disponibilidade, autenticidade e não-repúdio. Assim, os principais problemas de segurança em Web Services são para garantir que as aplicações se comuniquem de forma segura e fim-a-fim. Em (Alrouh e Ghinea, 2009) os autores argumentam que os mecanismos de segurança dos Web Services apresentam preocupações devido ao conteúdo de segurança adicional nas mensagens $S O A P$, o maior número de troca de mensagens $S O A P$ para estabelecer a confiança entre as entidades comunicantes, bem como o tempo extra de $C P U$ para processar a sobrecarga gerada pelos mecanismos de segurança. São realizados testes para comparar o desempenho dos diversos mecanismos de segurança aplicado em um Web Service simples com diferentes tamanhos de mensagens. O roteamento entre múltiplos Web Services é comumente usado para obter escalabilidade e também para atuar como uma ponte entre diferentes protocolos. 
Alguns protocolos (como, por exemplo, TLS/SSL) (Freier et al., 1996), (Dierks e Rescorla, 2008) garantem a confidencialidade entre as duas partes, mas não fornecem segurança ponto a ponto. Isto implica que, se a segurança ocorre só em termos da camada de transporte dos nós intermediários, estes irão permitir o acesso ao provedor de serviços ou alguma outra entidade. Para enfrentar esse desafio, os princípios de segurança devem ser aplicados a diferentes contextos, nos quais é essencial considerar uma configuração ponto a ponto e fim a fim. Outra importante discussão é que os padrões como XML, SOAP, UDDI e WSDL abordam os conceitos básicos de serviços inter-operáveis, mas para Web Services outras regras devem ser adicionadas. Como exemplos destacam-se: (i) WS-Security, um padrão da Organization for the Advancement of Structured Information Standards (OASIS), que garante integridade e confidencialidade de mensagens SOAP. (ii) Security Assertion Markup Language (SAML), um outro padrão da OASIS baseado em XML para troca de informações de segurança (K. e Fung, 2007), (Nordbotten, 2009). Além dos Web Services estarem expostos a ataques conhecidos a protocolos da Internet, eles também estão expostos a ataques específicos, como os listados na Tabela 3.1 .

Tabela 3.1: Ataques e impactos da segurança no desempenho de Web Services Adaptado de (Jensen et al., 2007)

\begin{tabular}{|c|c|}
\hline Ataque & Impacto no Desempenho \\
\hline DoS - Denial of Service & Sobrecarga CPU e memória \\
\hline Coercive Parsing & Sobrecarga de CPU \\
\hline SOAP Action Spoofing & Sobrecarga de CPU \\
\hline XML Injection & Acesso a conteúdo proibido \\
\hline WSDL Scanning & Acesso a conteúdo proibido \\
\hline Metadata Spoofing & Escuta ou modificação de dados \\
\hline Attack Obfuscation & Sobrecarga de CPU \\
\hline Oversized Cryptography & Sobrecarga CPU e memória \\
\hline BPEL State Deviation & Sobrecarga de CPU \\
\hline Instantiation Flooding & Sobrecarga de CPU \\
\hline Indirect Flooding & Sobrecarga CPU e memória \\
\hline Workflow Engine Hijacking DoS & Sobrecarga CPU e memória \\
\hline \hline
\end{tabular}

Os métodos de ataque listados na Tabela 3.1 ocorrem, em geral, porque ainda não há um padrão de fato para a segurança em Web Services (Jensen et al., 2007). Se as especificações atuais de segurança para os Web Services forem utilizadas indevidamente podem degradar ainda mais uma arquitetura $S O A$, tanto em termos de segurança quanto em termos de desempenho. Para lidar adequadamente com as vulnerabilidades de segurança em Web Services, é necessário combinar as técnicas de segurança já estabelecidas nos protocolos de rede e de protocolos de aplicação, e também os mecanismos específicos para Web Services, como o WS-Security, WS-Encryption, etc. Uma descrição mais detalhada dos métodos de ataques pode ser apreciada em (Jensen et al., 2007). 


\subsubsection{Web Services Attachments}

Com a utilização dos Web Services, é possível enviar qualquer tipo de informação, sob qualquer forma de codificação. Há três técnicas para enviar dados em conjunto com um documento XML:

- Binário Puro: A incorporação desses dados em XML como texto codificado com o tipo octects xs:base64Binary ou xs:hexBinary. A principal desvantagem desta abordagem é encapsular a mensagem no envelope $S O A P$, uma vez que essa técnica causa sobrecarga de custos de transformação de dados, especialmente quando ocorre a decodificação de volta para o formato binário.

- Utilizar uma $\boldsymbol{U R I}$ do tipo xs : anyURI no documento $X M L$ de forma a referenciar para os dados binários que estão fora do corpo da mensagem (SWA e MTOM são duas técnicas que utilizam referências externas para o conteúdo do corpo da mensagem $S O A P$ ). Os dados são externos ao documento $X M L$, sendo necessário fornecer um conjunto de soluções para o componente $X M L$ dos seus dados e outro conjunto de soluções para os componentes externos (DIME e MIME). Outra questão é sobre os problemas de interoperabilidade, porque não há um modelo padrão que determina como provedores de mensagens SOAP intermediários irão processar os dados referenciados (Young, 2007).

\section{Message Transmission Optimization Mechanism (MTOM)}

Message Transmission Optimization Mechanism (MTOM) é um método eficiente de envio de dados binários por meio de Web Services. Sua base é o XML-binary Optimized Packaging (XOP), um protocolo utilizado para transmitir dados binários em mensagens SOAP. XOP é uma alternativa de serialização XML que apenas ocorre com pacotes MIME multipart/related, com um documento $X M L$ como a parte da raiz. A parte raiz do documento só difere da codificação base 64, porque os dados são substituídos por uma referência a uma das partes MIME que não está codificado na base 64 . Na seqüencia serão demonstrados todos os passos do uso do XOP:

1. $X O P$ extrai dados binários em um documento $X M L$

2. $X O P$ serializa documentos $X M L$ em pacotes localizados dentro de um pacote de formato extensível, como MIME Multipart/Related.

3. O novo documento $X M L$ marca a localização dos pacotes de dados binários com elementos especiais que contêm $U R I$, identificando a localização correspondente.

As diferenças entre $M T O M$ e $X O P$ é que o primeiro é apenas uma descrição de como XOP é encapsulado em uma mensagem SOAP para posterior transporte pelo protocolo HTTP. MTOM especifica ainda uma implementação concreta do mecanismo de binding do SOAP via HTTP. MTOM 
usa XOP para otimizar a transmissão de mensagens SOAP com anexos. Ele descreve como serializar um envelope SOAP usando o formato XOP e pacote MIME Multipart/Related (note que MIME Multipart/Related não é exigida no XOP). É importante mencionar que o XOP somente otimiza elementos de dados base64 (Nottingham, 2004). XOP e MTOM são padrões W3C desde 2005 e não são propostos como parte da especificação SOAP original. Para identificar MTOM em uma transmissão de mensagens SOAP sobre HTTP é necessário verificar quatro atributos (Young, 2007):

1. Presença da mídia applicationx/xop +xml

2. Tipo de mídia da mensagem HTTP precisar ser Multipart/Related

3. Tipo de mídia da parte raíz do pacote MIME Multipart/Related é appli cation/xop+xml

4. Parâmetro start-info indica um tipo de conteúdo application/soap+xml

\section{SOAP with Attachments (SWA)}

Define como um binário ou uma mensagem SOAP pode ser composto em uma mensagem MIME do tipo Multipart/Related. Cada parte da mensagem é separada por um delimitador de sequiência único definido no início da mensagem. A diferença entre o SWA e MTOM é que SWA não mostra a referência do objeto no corpo da mensagem SOAP como um InfoSet XML como faz o MTOM. A representação do conteúdo binário anexado com SWA não é um XML formatado. A vantagem do SWA é que ele não converte dados binários em caracteres utilizando algoritmos de codificação. Ele ainda economiza recursos do sistema e a transmissão de dados binários é mais eficiente (Zhang et al., 2007). No entanto, o SWA apresenta suas limitações, especialmente a implementação do mecanismo no motor de processamento Apache Axis2. MIME não permite acesso aleatório aos elementos arbitrários da mensagem, sem prévia recepção da mensagem inteira. Um Web Service não pode decidir quais objetos binários são transferidos como um todo, usando o protocolo de transferência. Isso significa que a ordem de envio do anexo não pode ser escolhida sobrepondo-se à execução de serviço e impedindo que a transmissão de dados seja possível.

Em um cenário onde tem-se um cliente e um provedor, o provedor tem que esperar pela transmissão de todo o conteúdo da mensagem pelo cliente antes que ele possa decodificar cada parte anexada. Outra conseqüência é que a transmissão de anexos de grandes dimensões pode demorar muito tempo, porque o processamento de anexos requer grande utilização de memória (Heinzl et al., 2006). Resultados recentes sobre o desempenho de Web Services com anexos de dados binários são discutidos em (Estrella et al., 2009). Os autores avaliaram as três técnicas de anexos de Web Services (binário puro, MTOM, SWA), considerando a influência da rede e diferentes tamanhos de arquivos além de apresentar uma ferramenta de apoio para este estudo. Os resultados deste estudo culminaram com a implantação de um sub-módulo no Broker da WSARCH para tratar especialmente da transmissão de mensagens SOAP com anexos. Essa nova funcionalidade foi testada e avaliada em outro projeto de mestrado associado à arquitetura WSARCH (Toyohara, 2010). 


\subsubsection{Registro UDDI}

Obter informações sobre Web Services nem sempre é uma tarefa trivial. Especialmente quando se trata de uma arquitetura distribuída em que os Web Services estão localizados em um domínio e as informações sobre esses Web Services foram armazenados em um local diferente. Alguns trabalhos na literatura abordam a necessidade de um registro de serviço mais confiável e, ao mesmo tempo de forma consistente, de modo que a busca de determinado serviço seja realizada em menor tempo. Em (Pilioura et al., 2004), os autores apostam na Web semântica para tentar endereçar Web Services de forma apropriada, por meio de repositórios UDDIs confiáveis, e da proposição de uma infra-estrutura para publicação e descoberta de Web Services. As promessas vão desde a publicação e descoberta de serviços baseada na sintaxe e semântica, o uso de $Q o S$, o uso de uma infra-estrutura escalável que organize registros com base em domínios e permita que usuários acessem múltiplos registros sob uma única visão, juntamente com a descoberta de serviços por usuários finais e desenvolvedores. Os autores sinalizam para os pontos negativos da especificação UDDI, tais como:

- Descrição deficiente do serviço;

- Descrição deficiente para atender as necessidades do solicitante do serviço;

- Filtragem adicional feita de modo manual;

- Falta de uma interface amigável com o usuário final;

- Problemas de escalabilidade devido à centralização do UDDI;

- Informações armazenadas no UDDI são semanticamente diferentes. Não há um padrão específico. A infra-estrutura deveria acomodar diferentes mecanismos da publicação e descoberta;

- A distribuição física não é transparente ao usuário.

O funcionamento da arquitetura proposta não é apresentado. As demonstrações da mesma são feitas teoricamente utilizando ontologias. Soma-se a isso a ausência total de aspectos de avaliação de desempenho. Informações armazenadas no UDDI são semanticamente diferentes. Não há um padrão específico. A infra-estrutura deve acomodar diferentes mecanismos de publicação e descoberta. A distribuição física deve ser transparente para o cliente (visualizar como uma coleção de serviços sem saber de onde vem). Embora o artigo demonstre o funcionamento por meio de ontologias, não há nenhuma discussão sobre a forma como esta arquitetura funciona na prática, nem algum impacto sobre a avaliação de desempenho.

Em (Banerjee et al., 2005) é discutido o problema de escalabilidade no gerenciamento de grandes quantidades de dados de diferentes fontes. Os autores propõem o desenvolvimento de 
uma arquitetura para a descoberta de Web Services. As limitações do UDDI levam a pensar na proposta de um registro $U D D I$ distribuído. Os autores não relatam como foi avaliada a eficácia do esquema proposto e também quais técnicas serão utilizadas para essa finalidade. Estes pontos estão abertos e não são discutidos no artigo. O registro UDDI precisa fornecer alto throughput, tempo de resposta baixo, alta disponibilidade e acesso aos dados consistentes. Uma maneira de satisfazer essas necessidades é utilizando replicação, como demonstrado no trabalho apresentado em (Sun et al., 2004).

Muitos pesquisadores investigam mecanismos para melhorar o acesso à interface UDDI para a pesquisa de Web Services. Poucos estudos, no entanto, se preocupam com o impacto do UDDI no desempenho da invocação de um Web Service, como caracterizado em (Saez et al., 2004). A questão de como invocar um Web Service com base em informações contidas no registro UDDI é considerada em (Yu e Lin, 2004). Eles mencionam que, em um ambiente real é difícil invocar dinamicamente Web Services que têm a mesma funcionalidade entre muitos existentes em um grande banco de dados de informações. Os autores propõem um framework que estende o registro $U D D I$ e analisa a aplicabilidade e as características deste framework, mas não se preocupa com as questões gerais de desempenho. Em (Kumar et al., 2005) a proposta é uma abordagem generalizada para construir um registro $U D D I$ baseado em $Q o S$, cujo objetivo é tornar a busca de informações mais eficiente.

Em (Liu et al., 2005a) é proposto um registro UDDI orientado a domínio. Nesta proposta, um banco de dados de informação centralizada e externo é usado para armazenar os serviços nãofuncionais e suas relações. O trabalho discutido em (Blake et al., 2007) propõe um método para avaliar os modos de operação em um ambiente de computação orientada a serviço. Os autores avaliaram o desempenho de algumas implementações do UDDI e incorporam os resultados de desempenho em um software de simulação. Usando esse software, foram avaliados dois modos de operação que suportam o uso do UDDI a fim de permitir a confiabilidade em um cenário de processos de negócio.

Em (Peterkin et al., 2007) é apresentado um sistema para controlar o acesso ao UDDI. A idéia é limitar a busca de informações por meio de um controle de acesso que garanta um desempenho adequado. Nenhuma avaliação de desempenho é discutida. Em (Liu et al., 2007b), os autores caracterizam como grafos de Web Services podem ser suportados pelo registro UDDI, acrescentando-lhe uma estrutura de dados auxiliar. Embora a conclusão do artigo mencione algumas experiências, nenhuma delas está associada à avaliação de desempenho. A falta de recursos adicionais que possam estar presentes no UDDI também é estudada na literatura.

O trabalho discutido em (ShaikhAli et al., 2003) propõe a implementação de um registro UDDI com algumas extensões, denominado UDDIe. Dentre as deficiências identificadas no UDDI padrão destaca-se que as páginas são baseadas em alguns atributos e não apresentam um mecanismo de atualização do Web Service armazenado. Assim, a busca de um determinado serviço é restrita aos atributos listados, podendo haver serviços que não estão mais disponíveis e com sua especificação desatualizada. As soluções propostas pela implementação de UDDI estão além das páginas 
brancas, amarelas e verdes. Algumas extensões acrescentam as chamadas páginas azuis que estão relacionadas com as propriedades associadas a um serviço. Os serviços permanecem armazenados por um período de tempo limitado, a fim de evitar a inconsistência dos dados. Assim, tem-se as seguintes extensões para o UDDI:

- Leasing: serviços com tempo limitado

- Extensão da classe businessService com a entidade propertyBag: busca por outros atributos.

- Extensão do método de pesquisa: permite resultados por faixas lógicas ou numéricas.

Para finalizar, o artigo explica as extensões propostas pelo modelo estendido e exemplifica um serviço publicado usando essas extensões. Como ponto negativo não apresenta as métricas para justificar todas as proposições, uma vez que é apenas baseado em conceitos. É difícil fazer alguma consideração sobre o desempenho do registro $U D D I$, principalmente porque o número de trabalhos na literatura é limitado e porque alguns deles lidam apenas com questões de desempenho de uma maneira superficial.

Poucos trabalhos como o caracterizado em (Saez et al., 2004) estão preocupados com o desempenho do registro UDDI. O desempenho de todas as interações em uma arquitetura orientada a serviços pode ser afetada se o UDDI não possui mecanismos adequados para a busca de Web Services. Para desenvolvedores, a característica mais importante em um motor de pesquisa de informação é a velocidade e a facilidade de uso. Neste aspecto, o trabalho apresentado em (Kawamura et al., 2005) mostra um mecanismo que usa a Web semântica para permitir que os Web Services sejam descobertos com base em características específicas.

Além disso, há estudos que tentam incluir em um registro UDDI mecanismos baseados em grafos, de modo que os Web Services sejam agrupados, facilitando assim a construção de processos de negócio baseado em um fluxo de informações interligadas (Liu et al., 2007b). Os autores argumentam que escolher o melhor serviço na Internet para compor um processo de negócio não é um tarefa trivial, especialmente quando as questões de $Q o S$ são predominantes. A otimização da busca de informações utilizando-se de algoritmos eficientes também é um assunto tratado em (Hicks et al., 2007). Apesar de todos os benefícios que o paradigma SOA trouxe para o desenvolvimento de aplicações, a tarefa de encontrar e validar adequadamente os Web Services é ainda um dos principais desafios envolvidos na construção de um repositório eficiente de informações de serviços (Atkinson et al., 2007).

\section{4 Índices de Carga e de Desempenho}

Um sistema computacional serve para auxiliar no processamento de inúmeras tarefas. No entanto, para que as tarefas sejam executadas em tempo apropriado, é necessário considerar o 
desempenho de cada parte que compõe um sistema, além do desempenho global caso determinada máquina faça parte de um cluster por exemplo. Métricas precisam ser definidas para aferir e quantificar as cargas de trabalho submetidas a cada recurso dos elementos de processamento (se está sobrecarregado, moderado ou ocioso). Na literatura especializada, as métricas são chamadas de índice de carga. Além do índice de carga também pode ser utilizado um índice de desempenho, que difere do primeiro por analisar além da heterogeneidade das configurações, a heterogeneidade arquitetural e temporal do ambiente avaliado (Branco et al., 2006).

Na próxima seção serão definidos índices de carga e um índice de desempenho os quais são parte da implementação da arquitetura WSARCH. Índices de carga foram implementados na arquitetura para que o Broker os utilize na tomada de decisão na seleção de provedores de serviços de acordo com as requisições de determinadas classes de clientes.

\subsection{1 Índices de Carga}

O índice de carga caracteriza-se por ser uma métrica que quantifica a carga de trabalho submetida a um recurso de determinado sistema (Ferrari e Zhou, 1988), (Kunz, 1991). O objetivo da métrica é indicar os estados de um recurso, tal como: se está ocioso, moderado, ou sobrecarregado (Branco, 2004). O índice de carga está relacionado ao desempenho de roteamento/escalonamento de mensagens e à coleta das informações de carga do sistema, bem como à periodicidade com as quais tais informações são coletadas. Esses fatores podem influenciar na eficiência do balanceamento de cargas.

Neste trabalho de doutorado foram obtidas diversas informações sobre o estado de uma máquina atuando como provedor de serviços utilizando uma ferramenta de monitoração de carga denominada Ganglia (Massie et al., 2004). Em geral, um índice de carga é definido na literatura especializada como uma variável numérica, inteira e não negativa que possui valor zero quando o recurso está ocioso. A medida que a carga do recurso aumenta, o seu valor também é acrescido (Ferrari e Zhou, 1988), (Kunz, 1991),(Branco, 2004).

Em sistemas distribuídos é preciso ser prudente em relação à comunicação das informações dos índices de carga para os componentes participantes. As informações de carga dos recursos não podem ser atualizadas frequentemente, pois uma sobrecarga na rede de interconexão pode degradar o desempenho do sistema. Por outro lado, se tais informações são pouco atualizadas, algoritmos de balanceamento podem utilizar informações incorretas e também prejudicar o desempenho (Branco, 2004). Pode se utilizar também o índice de carga para prever o comportamento futuro das cargas, com base no comportamento atual/passado, e fornecer essa informação para o Broker da WSARCH, para que o roteamento/balanceamento de carga seja efetuado.

Diversos índices de carga são definidos e utilizados na literatura (Ferrari e Zhou, 1988), (Zhou et al., 1993), (Branco, 2004), os quais são divididos em grupos baseados no tamanho da fila de acesso ao recurso (comprimento da fila da $C P U$ (instantâneo), comprimento médio da fila da $C P U$ 
em um determinado tempo), no percentual de utilização do recurso e no tempo de execução/resposta (normalizado), taxa de mudança de contexto e quantidade de memória disponível.

Dentre os índices de carga existentes na literatura grande parte destina-se a ambientes formados por configurações e arquiteturas homogêneas. De um modo geral, a literatura apresenta poucos trabalhos sobre índices de carga para ambientes com homogeneidade arquitetural e heterogeneidade configuracional, e até mesmo para ambientes totalmente heterogêneos (Branco, 2004). Um tratamento diferenciado é exigido na heterogeneidade configuracional e arquitetural para a utilização de índices de carga. Para compreender essa afirmação, pode-se utilizar o seguinte exemplo na literatura: um ambiente composto de dois computadores com potências computacionais diferentes e que possuam cargas semelhantes (Branco, 2004). Em determinado instante, um dos computadores apresenta dois processos de baixa ocupação em sua fila de $C P U$, e o outro, um processo que ocupa cerca de $99 \%$ da $C P U$. Na técnica de índice de carga baseado no comprimento da fila de processos, o resultado no primeiro computador citado é um índice de valor 2 , e no segundo é um índice de valor 1 . Por ter obtido um menor índice, o segundo computador recebe os novos processos mesmo não possuindo recursos disponíveis; enquanto isso, o primeiro computador encontra-se semi-ocioso, o que degradará o desempenho do sistema como um todo.

\subsection{2 Índices de Desempenho}

Para suprir a lacuna encontrada na literatura no tocante ao índice de carga para ambientes heterogêneos, (Branco, 2004) propôs um índice de desempenho que fornece informações da carga de trabalho e da situação de operação de cada um dos hosts do sistema, levando em consideração as heterogeneidades configuracional, arquitetural e temporal (Branco et al., 2006), como pode ser observado na Figura 3.1.

Um bom índice de desempenho, assim como os índices de carga, deve possuir meios de estimar o futuro por meio de valores atuais e fatores do passado. Portanto, para que se possa obter um bom índice de desempenho, sua base deve estar fundamentada nos índices de carga. Outra característica importante do índice de desempenho é seu tempo de uso. As cargas são voláteis; consequentemente, os índices de cargas e de desempenho também o são. Na Figura 3.2, apresentase uma visão macroscópica do Modelo De Índice de Desempenho em Ambientes heterogêneos (MEDIDAh) proposto por Branco (Branco, 2004).

Nota-se que, para a compreensão e a obtenção do MEDIDAh, faz-se necessário um conhecimento prévio a respeito dos diferentes tipos de aplicações e do hardware envolvido bem como dos índices de carga existentes. Na Figura 3.3 é apresentada uma estratégia para obtenção do índice de desempenho.

O índice de desempenho proposto em (Branco, 2004) baseia-se na distância euclidiana entre o ponto de origem (onde a máquina está ociosa) e o ponto resultante entre os valores de carga da máquina antes de receber uma determinada aplicação e o vetor da carga imposta por essa aplicação. A máquina mais adequada para receber a aplicação é a que obtém a menor distância euclid- 


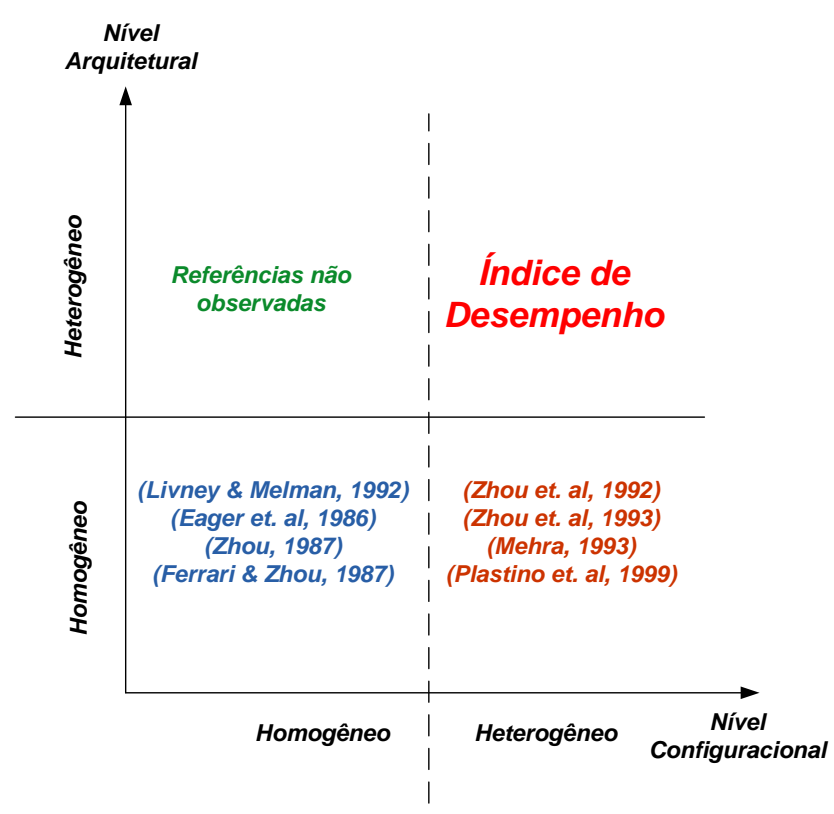

Figura 3.1: Lacuna existente na literatura quando levado em consideração os níveis arquiteturais e organizacionais (Branco, 2004)

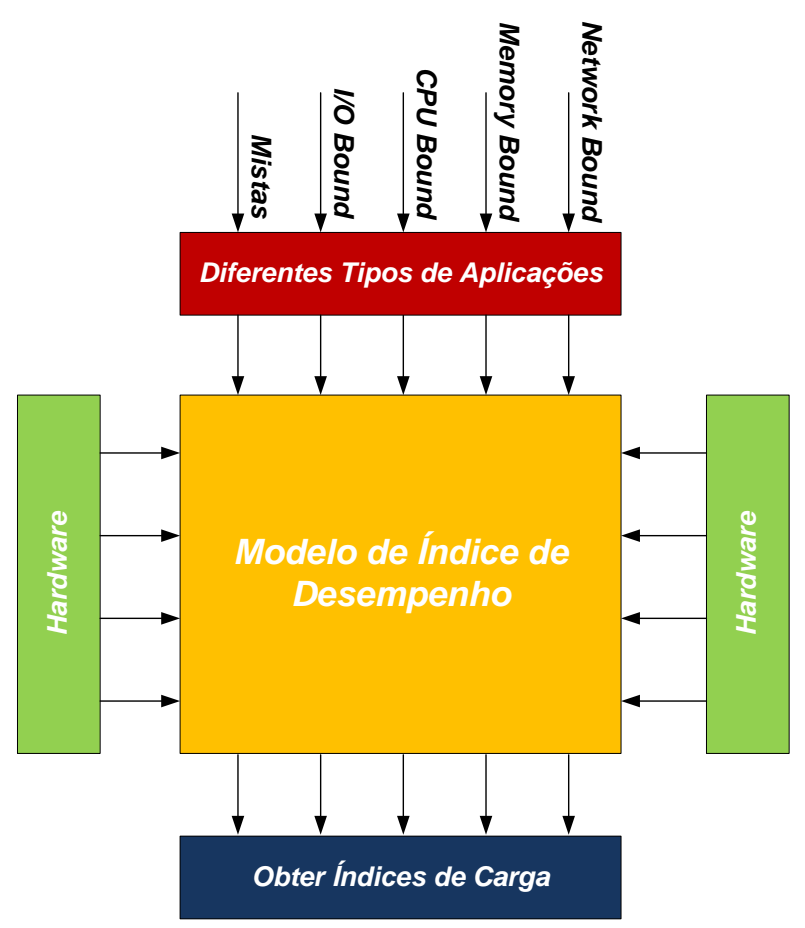

Figura 3.2: Visão macroscópica do projeto de um índice de desempenho (Branco, 2004)

iana (Branco, 2004), (Branco et al., 2006). Denomina-se (Vector for Index of Performance) (VIP) o índice baseado em vetor de carga. Considerando a relação existente entre os diferentes recursos que compõem uma máquina e permitindo que a alocação dos processos se efetue de maneira equilibrada, é possível obter o índice de desempenho (ID) como visto na Equação 3.1. 


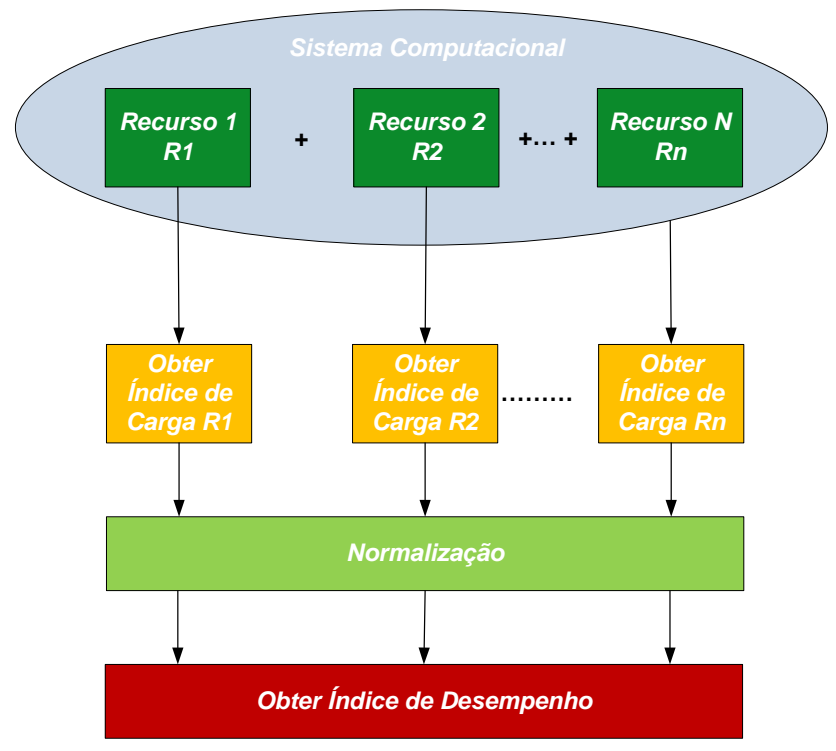

Figura 3.3: Estratégia para obtenção do índice de desempenho (Branco, 2004)

$$
I D=\sqrt{I_{C P U}^{2}+I_{M E M}^{2}+I_{N E T}^{2}}
$$

Nessa equação o ID representa o valor do índice de desempenho e o I refere-se ao índice de carga de cada um dos recursos. No exemplo utilizado em (Branco, 2004), ilustrado na Figura 3.4, adotam-se duas máquinas distintas, mas que estão igualmente carregadas. O recurso 1 está mais carregado na máquina M1, enquanto o recurso 2 está mais carregado na máquina M2 em termos de utilização. Um processo P, que utiliza apenas o recurso 1, pode ser alocado para M1 e M2. Para determinar em qual situação se obtém melhor resultado, pode ser adotada a distância Euclidiana entre o ponto e a origem, isto é, o comprimento do vetor da origem ao ponto. Dessa forma, obtêm-se os vetores $\mathrm{C} 1$ e C2, e o resultado do comprimento C2 é menor que o de C1. Por conseguinte, o processo P deve se alocado em M2. Embora as máquinas estejam igualmente carregadas, a distinção de carga quanto aos recursos que estão sendo utilizados, e o tipo de tarefa que será alocada, permitem uma melhor alocação da tarefa (Branco et al., 2006).

\subsection{Considerações Finais}

Este capítulo apresentou de forma detalhada os principais conceitos e técnicas de qualidade de serviço relacionados com Web Services. O estudo bibliográfico permitiu observar as principais melhorias sugeridas e algumas desenvolvidas para tratar do tópico de qualidade de serviço, este, um dos maiores desafios na área de Web Services. O estudo também permitiu identificar quais as lacunas que precisam ser exploradas em relação a $Q o S$ em Web Services e também uma revisão sobre índices de carga e desempenho, tópico que servirá de base para a construção de um índice utilizado na prototipação da WSARCH. Como citado anteriormente, há diversas propostas de pro- 


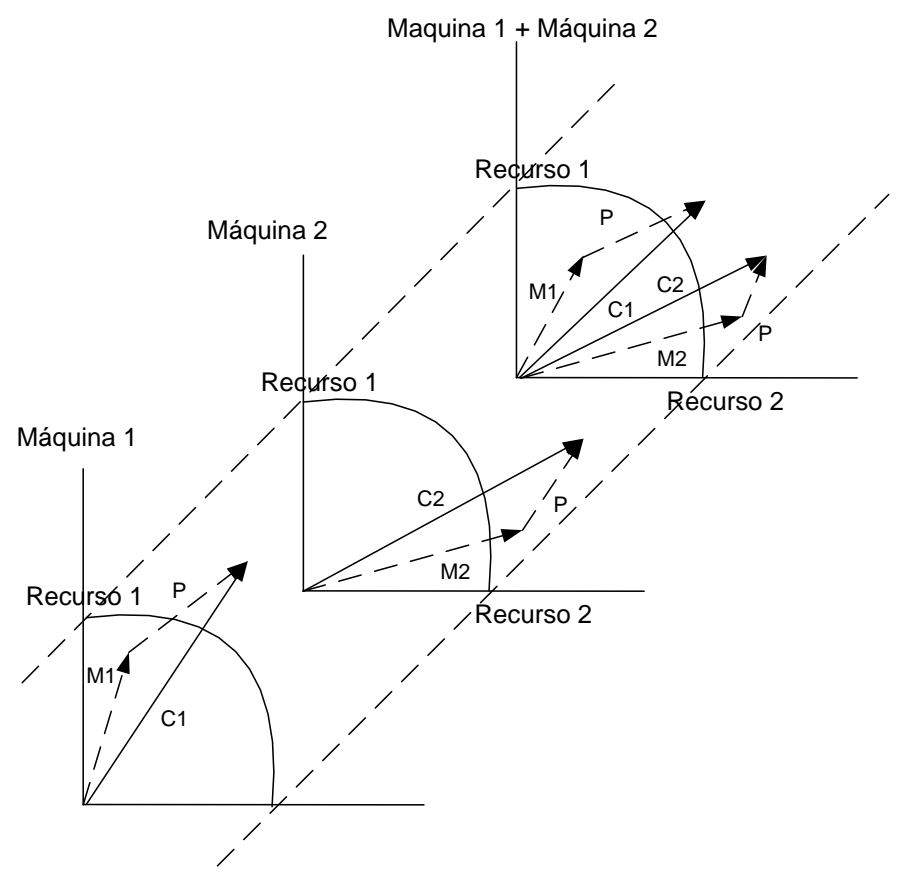

Figura 3.4: Exemplo de utilização do índice de desempenho (Branco, 2004)

visão de $Q o S$ para Web Services, no entanto poucas consideram a avaliação de desempenho de forma consistente. O próximo capítulo apresenta uma proposta de arquitetura cujo objetivo é a provisão de Web Services com qualidade de serviço. A arquitetura, seus componentes e o que deve ser avaliado serão apresentados de forma detalhada. 



\subsection{Considerações Iniciais}

Este capítulo tem por objetivo descrever a proposta de uma arquitetura para a provisão de Web Services com qualidade de serviço. Serão apresentadas todas as etapas para o desenvolvimento, bem como cada componente da arquitetura. Também será objeto de estudo, como ocorreu a interação entre cada módulo da arquitetura, visto que tal estudo é importante para a avaliação de desempenho dos serviços oferecidos pela arquitetura proposta. Nesse sentido, na Seção 4.2 é descrita a arquitetura WSARCH. Na Seção 4.3 é discutido o funcionamento da arquitetura, seus módulos e sub-módulos. Na Seção 4.4 um relacionamento dos atributos de $Q o S$ com os componentes da arquitetura são apresentados. Na Seção 4.5, por sua vez, são abordados todas as fases da arquitetura incluindo como ocorreu a monitoração dos provedores, a comunicação das informações de $Q o S$ entre os componentes da WSARCH, o desenvolvimento dos algoritmos de roteamento/escalonamento de mensagens no Broker, a implementação dos provedores e a descrição das categorias de aplicações e controle de erros. Na Seção 4.6 é descrito como aplicações compostas podem ser integradas e testadas na arquitetura WSARCH.

\subsection{A Arquitetura WSARCH}

Uma arquitetura orientada a serviços ( $S O A)$ é essencialmente uma coleção de serviços, os quais se comunicam uns com os outros. Um serviço é uma função bem definida e que não depende do estado ou contexto de outro serviço. A comunicação entre eles pode envolver ou um simples dado ou 
mais serviços coordenando alguma atividade (Nickull, 2005). Como os Web Services implementam uma arquitetura orientada a serviço, o seu maior foco é fazer com que blocos funcionais sejam acessíveis sobre protocolos padrões da Internet que são independentes de plataforma e linguagem de programação. Esses serviços podem ser novas aplicações ou sistemas já existentes que venham a ser habilitados para serem acessados de qualquer lugar do mundo por meio de interfaces bem definidas baseadas em $X M L$. Uma arquitetura orientada a serviço é essencialmente dividida em três blocos: um provedor de serviços, um cliente que faz o acesso ao serviço e um repositório que armazena informações sobre os serviços. Embora a interoperabilidade entre os sistemas possa ser alcançada por meio do uso de interfaces bem definidas dos serviços, a comunicação entre os blo$\cos$ da $S O A$ precisa ser feita de forma que pelo menos alguma forma de qualidade de serviço possa ser oferecida ao consumidor do serviço, seja esse um cliente Web, um outro serviço ou conjunto de serviços. No entanto, uma arquitetura padrão como a $S O A$ em sua especificação, não apresenta preocupação com qualidade de serviço. Em contraste com a arquitetura original de Web Services, o modelo de arquitetura WSARCH proposto neste trabalho deve permitir melhor provisão de qualidade de serviço entre as mensagens trocadas entre as aplicações. Para isso, alguns módulos de $Q o S$ serão considerados nesta arquitetura, além de um estudo de avaliação de desempenho. $O$ trabalho mencionado em (Benkner e Engelbrecht, 2006) não descreve como é realizada a interação com um registro de serviços como o UDDI. Soma-se a isso a ausência de informações de como é feito o casamento de informações de $Q o S$ solicitadas pelo cliente do serviço com aquelas fornecidas pelo provedor de serviço. Para essa questão em específico a WSARCH trabalha com duas possibilidades: 1) Gerenciar a $Q o S$ de forma paralela (um serviço Web ser invocado exclusivamente para essa finalidade); 2) Alterar em última instância os protocolos SOAP e WSDL para contemplar aspectos relativos à qualidade de serviço. Neste caso, primeiramente deveria ser escolhida uma implementação livre do SOAP (tal como o Apache Axis2), dada a diversidade de implementações por empresas como IBM, Microsoft, dentre outras. Outra diferença da WSARCH em relação a outros trabalhos da literatura, é que a arquitetura proposta nesta monografia terá seu foco voltado para a avaliação de desempenho, tópico pouco explorado na maioria dos trabalhos relacionados estudados, tais como (Maheshwari et al., 2004), (Tian et al., 2003), (Comuzzi e Pernici, 2005), (Benkner e Engelbrecht, 2006), (Taher et al., 2005), (Liu et al., 2007a), (Zilora e Ketha, 2008).

Um modelo de alto nível da WSARCH é mostrado na Figura 4.1. Nesse modelo, observam-se os componentes da arquitetura proposta:

- Cliente: A aplicação cliente faz requisições ao Broker informando a qualidade de serviço requisitada;

- Broker: Este módulo é composto por outros sub-módulos e será responsável por oferecer informações sobre $Q o S$ para os clientes. Um acordo de nível de serviço entre o Broker e o cliente pode ser estabelecido de modo que o Broker faça uma requisição ao melhor provedor de serviços de acordo com o que foi solicitado pelo cliente; 


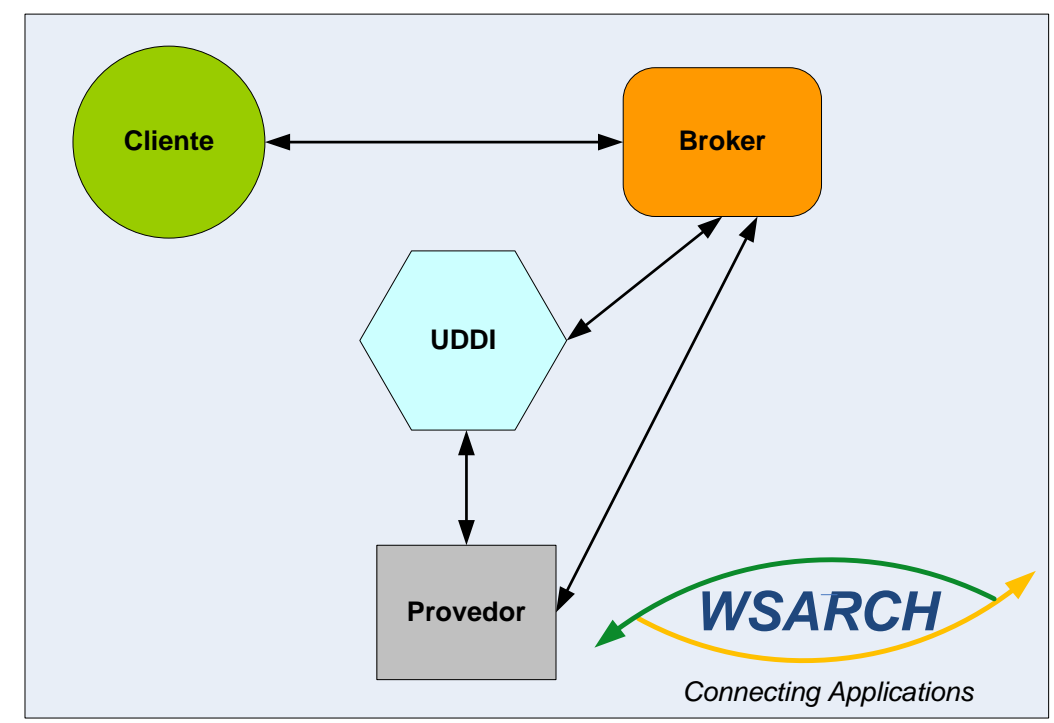

Figura 4.1: WSARCH - Modelo Abstrato

- Provedor: Contém os Web Services que serão requisitados pela aplicação cliente. Possui também um módulo de informações de $Q o S$ que envia mensagens ao UDDI.

- UDDI: O registro UDDI em sua forma original é responsável por armazenar informações funcionais sobre os Web Services cadastrados nos provedores de serviços. Para os propósitos da WSARCH o UDDI foi modificado para incluir informações não funcionais dos Web Services.

O detalhamento do objetivo da arquitetura, os problemas envolvidos na sua composição, dentre outras características, serão apresentados nas próximas seções.

\subsection{Funcionamento e Sub-Módulos da WSARCH}

A arquitetura WSARCH, seus componentes e as possíveis interações entre eles são apresentados de modo simplificado na Figura 4.2. As seguintes etapas são necessárias para a execução de uma requisição:

1. Cliente faz requisição ao Broker, o qual possui informações atualizadas do provedor do serviço (carga, tipo de serviço, classe de cliente, etc.);

2. Com base nas informações de $Q o S$ solicitadas pelo cliente do serviço, o Broker realiza uma busca num repositório de serviços com o objetivo de encontrar o serviço mais adequado;

3. Broker obtém a especificação do serviço apropriado e as respectivas informações de $Q o S$ do provedor; 


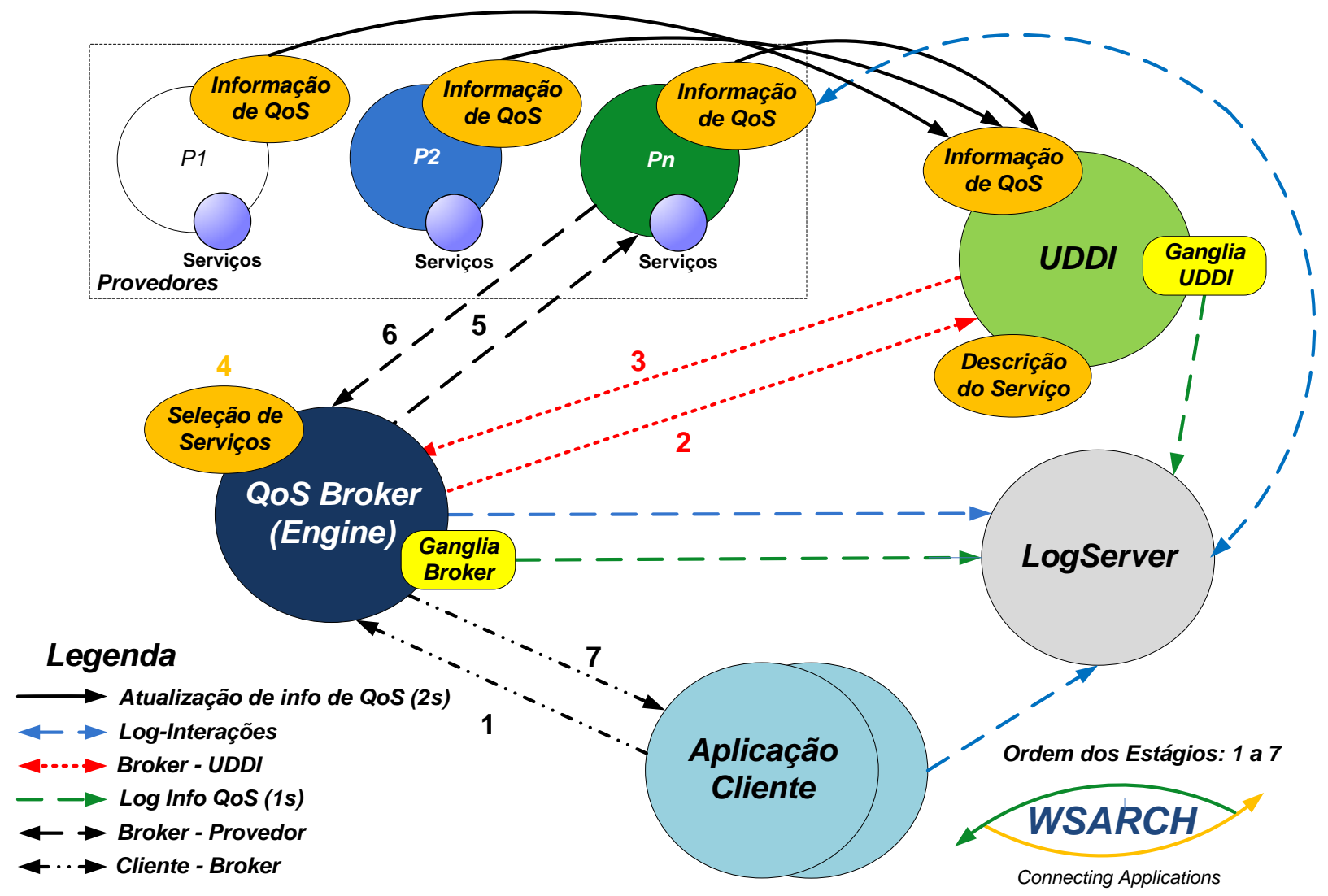

Figura 4.2: WSARCH - Modelo Simplificado

4. Com a localização do serviço apropriado no repositório de serviços, e já de posse das informações dos provedores de serviços (essas informações de $Q o S$ são propagadas periodicamente), o Broker escolhe o melhor provedor candidato (Seleção de Serviços)

5. Após a execução da função de seleção de serviços, o Broker realiza a requisição (invocação do Web Service) no provedor de serviços;

6. Depois de executada a requisição, a resposta é retornada diretamente ao Broker da WSARCH;

7. Finalmente a resposta é encaminhada ao cliente que inicialmente solicitou o Web Service.

Além das etapas referentes a uma requisição de serviço, é importante destacar que outras atividades ocorrem em paralelo a uma requisição de um cliente do serviço. As informações de $Q o S$ dos provedores de serviços são atualizadas periodicamente a cada 1s no registro de serviço para cada um dos provedores cadastrados. Essa propagação de informações ocorre em função da utilização de uma aplicação de monitoração presente nos provedores de serviços e no UDDI, denominada Ganglia (Massie et al., 2004). Os provedores de serviços possuem monitores escravos que enviam as informações para um monitor mestre no registro UDDI, de modo que o Broker da WSARCH possa utilizar a informação de $Q o S$ (índice de desempenho) para a seleção do melhor provedor de serviços em determinada ocasião. Como a arquitetura proposta é utilizada também para 
avaliar desempenho de Web Services um novo componente denominado LogServer foi adicionado à WSARCH. Esse componente é opcional e utilizado para armazenar dados sobre o desempenho dos vários componentes da WSARCH. Para uma melhor explanação da arquitetura WSARCH, será detalhado nesta Seção cada um dos sub-módulos referentes ao cliente, Broker e provedor de serviços, como mostra a Figura 4.3.

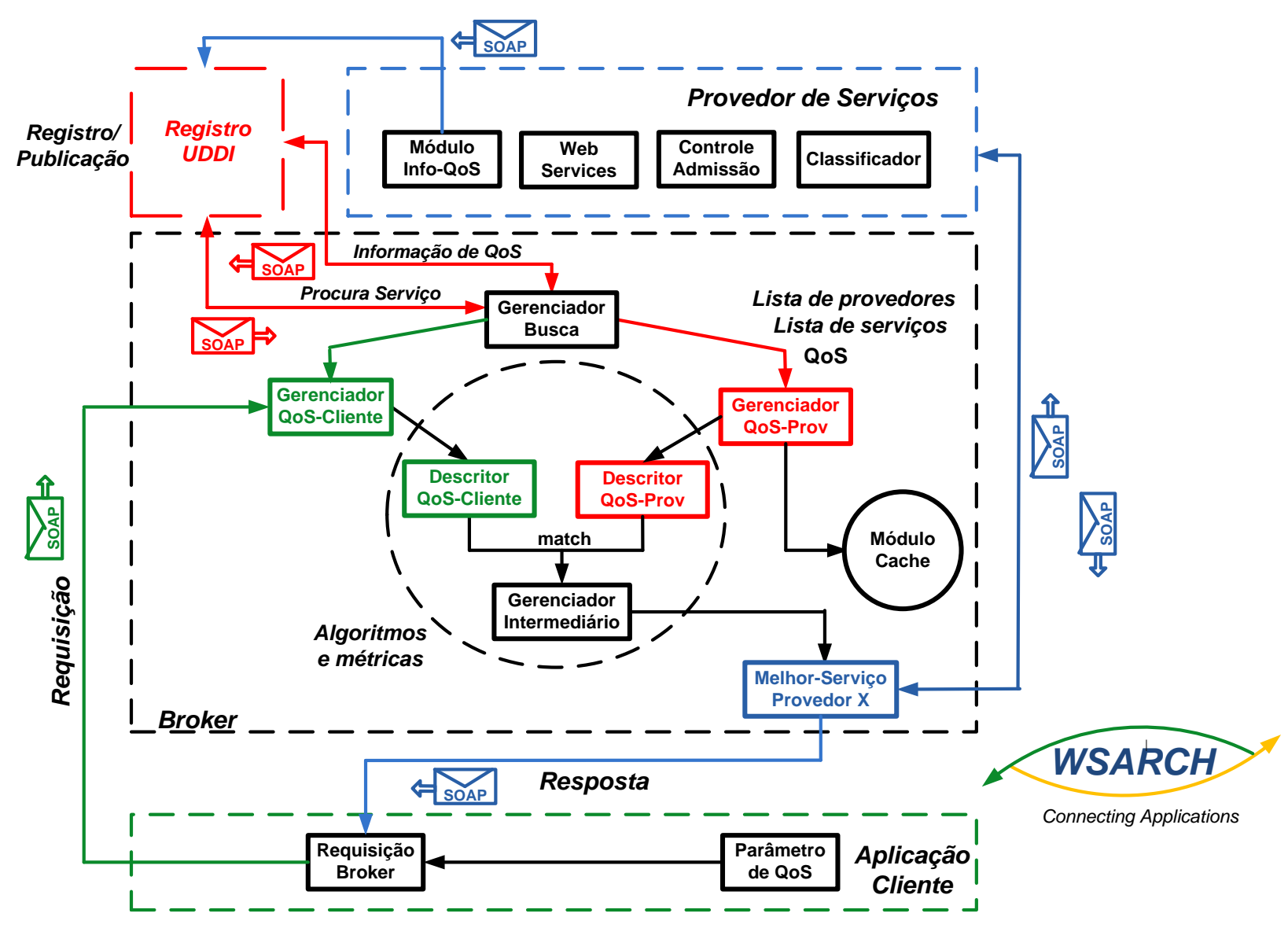

Figura 4.3: WSARCH - Modelo Atual

\section{Broker}

- Gerenciador de QoS-Cliente: Deve receber uma requisição de serviço levando em consideração parâmetros de qualidade de serviço determinados pela aplicação cliente;

- Gerenciador de Busca: Deve gerenciar as pesquisas efetuadas ao registro UDDI, na busca pelo tipo de serviço solicitado pela aplicação cliente. Outra função deste gerenciador deve ser a solicitação de informações de qualidade de serviço (índice de desempenho) do provedor de serviço e se esse possui o serviço adequado.

- Gerenciador de $Q o S$-Provedor: Receberá informações de $Q o S$ (processador, carga de $C P U$, memória, ocupação de disco) do provedor de serviços por meio do gerenciador de 
busca. Essas informações serão utilizadas pelo módulo gerenciador intermediário para posterior análise;

- Módulo Cache: Esse módulo deverá armazenar informações temporárias do provedor e seus serviços. A vantagem na utilização de um cache é que um serviço anteriormente consultado e com informações já caracterizadas, não necessita ser buscado novamente no registro UDDI;

- Descritor de QoS-Provedor: Informações de desempenho em formato padronizado, obtidas e filtradas pelo gerenciador de $Q o S$ do provedor de serviços;

- Descritor de $Q o S$-Cliente: Informações de $Q o S$ obtidas e filtradas pelo gerenciador de $Q o S$ do cliente do serviço;

- Gerenciador Intermediário: Funcionará como um agente otimizador com o objetivo de realizar as seguintes tarefas:

- Fazer a associação do serviço (e suas características) solicitado pelo cliente, com as informações sobre a disponibilidade de recursos computacionais dos provedores candidatos à execução daquele serviço;

- Oferece métricas e algoritmos utilizando as informações dos descritores de $Q o S$ do cliente e do provedor para selecionar o melhor serviço possível nos casos em que existam vários provedores candidatos para execução de um mesmo serviço.

- Melhor - Serviço Provedor X: Esse oferecimento de $Q o S$ deve incluir o serviço adequado que será invocado pelo Broker da WSARCH.

\section{Cliente}

- Parâmetros de QoS: Requisição (mensagem) contendo as informações (parâmetros) exigidos pelo cliente, de modo que o serviço solicitado seja cumprido adequadamente;

- Requisição Broker: Invocação, pelo cliente, do serviço propriamente dito.

\section{Provedor de Serviços}

- Módulo Info QoS: Coletar informações sobre o desempenho dos provedores de serviços, em determinados períodos (memória utilizada, ocupação da $C P U$, tipo de serviço em execução);

- Web Services: Os serviços que serão invocados pelo cliente;

- Controle de admissão: Deverá controlar o acesso ao serviço no provedor em situações de sobrecarga;

- Classificador: Utilizado para classificar as requisições de acordo com o tipo de serviço requisitado, os critérios de $Q o S$ solicitados, etc. 


\section{UDDI}

Para os propósitos da WSARCH, o UDDI foi modificado para armazenar dinamicamente informações não-funcionais. Este tipo de informação pode ser um atributo de $Q o S$ usado para descrever alguma característica de uma entidade ou componente. A ferramenta de monitoração Ganglia é utilizada para coletar parâmetros relacionados a ocupação de $C P U$ e memória. Os valores de $C P U$ e memória obtidos pela ferramenta de monitoração são processados e normalizados para compor um índice de desempenho. A normalização permite que novos índices de carga possam ser parte do índice de desempenho. $O$ índice de desempenho deve estar entre 0 (zero) e 1 (um) o que significa que quanto mais próximo de 0 (zero) estiver o índice menor é a sobrecarga no provedor de serviços e quanto mais próximo de 1 (um) maior será a sobrecarga nos provedores. Periodicamente, o índice é enviado ao UDDI e associado com a WSDL do provedor de serviços anteriormente cadastrado. Assim, o índice pode ser utilizado pelo Broker para selecionar o melhor Web Service de acordo com o critério desejado pelo cliente do serviço. O índice de desempenho usado nos experimentos da arquitetura é simples e válido somente para ambientes homogêneos. No entanto, já está implementado no Broker da WSARCH um novo índice de carga para ambientes heterogêneos baseado nos estudos de (Branco, 2004), pronto para ser utilizado em experimentos futuros.

\section{Observações Importantes}

Algumas observações adicionais também serão levadas em consideração com a proposição dessa arquitetura:

- O descritor de $Q o S$ do provedor poderá ser parametrizado para cada tipo de aplicação, visto que cada aplicação possui um requisito de qualidade de serviço - $Q o S$ particular. A arquitetura proposta pode apresentar métodos genéricos para negociação de $Q o S$.

- O módulo gerenciador de $Q o S$ do cliente receberá como entrada uma requisição contendo informações de $Q o S$ de um cliente em particular ou de uma classe de serviços. A idéia é que a requisição de $Q o S$ seja um documento $X M L$ que possua as informações necessárias para que o serviço solicitado pelo usuário seja cumprido obedecendo determinados critérios (tempo de resposta, etc.).

- A proposta é que a arquitetura seja capaz de negociar dinamicamente com os clientes, garantias de $Q o S$ e contratos de serviços, na forma de acordo de níveis de serviço.

- O UDDI deve possuir uma lista de provedores de serviço e os serviços que cada um deles suporta, bem como informações atualizadas sobre o desempenho (índice de carga e índice de desempenho).

- Todas as interações de um cliente com o serviço serão iniciadas pelo cliente. 
- Possibilidade de expor aplicações executando em clusters ou hardwares paralelos, como serviços, sem se preocupar com os detalhes de baixo nível de Web Services.

- Explorar possibilidades de alterações no servidor de aplicações Tomcat juntamente com o motor de processamento de mensagens SOAP denominado Axis2 (Axis2, 2010), de modo que seja viável garantir $Q o S$.

\subsection{Relação de Atributos de QoS com a WSARCH}

Em (Thio e Karunasekera, 2005) é discutido como realizar medidas de $Q o S$ tanto do lado do cliente quanto do provedor. Qualidade de serviço de um Web Service é um fator importante que diferencia serviços similares oferecidos pelos vários provedores. Tal medida permitiria a um cliente de um Web Service escolher e acionar um Web Service adequado em tempo de execução, baseado em atributos de $Q o S$. A seguir, os atributos de $Q o S$ são relacionados com os módulos participantes da arquitetura WSARCH proposta. Inicialmente é discutida a perspectiva de qualidade de serviço para cada um dos módulos.

\subsubsection{QoS e Módulos da WSARCH}

Cada uma das partes envolvidas na arquitetura SOA e suas extensões possuem uma perspectiva distinta de qualidade de serviço. A seguir serão discutidas as perspectivas de $Q o S$ para cada um dos módulos da arquitetura proposta.

\section{Cliente}

Geralmente, para um cliente, o atributo primordial em termos de qualidade de serviço é o tempo de resposta. Isso significa que o principal modo de um usuário aferir a qualidade de um serviço prestado por uma provedor é verificar se a resposta à sua solicitação foi atendida em um tempo adequado. Quando se considera a comunicação entre aplicações independentes de linguagens de programação, como é o caso dos Web Services, outros fatores que contribuem para o aumento ou diminuição do tempo de resposta precisam ser considerados: o processamento de mensagens $X M L$, a possibilidade de compressão de mensagens visando diminuir o tempo de resposta, o tempo de acesso para recuperação de informação de uma base de dados (caso as mensagens trocadas entre as aplicações façam uso de um repositório de dados) e atraso da rede.

\section{Provedor}

O provedor de serviços precisa ser eficiente ao prover um serviço requisitado pelo cliente. A seleção e a execução devem ser realizadas em tempo hábil de modo a evitar degradação no tempo de resposta. Por isso, é importante considerar: 
- As estimativas de tempo de execução de uma aplicação baseadas nas características da aplicação (enviadas por meio de uma requisição Web na forma de mensagens $S O A P$ );

- A divisão das aplicações em classes, de modo a determinar um tratamento diferenciado no atendimento. Por exemplo, um serviço multimídia requer alta vazão (a quantidade de serviços que o provedor atende por segundo, por exemplo), baixos atrasos, jitter, enquanto um serviço bancário online requer segurança e qualidade de serviço transacional;

- Se o serviço requisitado deve fazer parte de um processo de composição de serviços e se a composição será feita de forma centralizada, isto é, no próprio provedor. Um exemplo de composição ocorre quando um usuário precisa fazer a reserva de uma viagem via Web. Neste caso, ocorrerá a interação entre o sistema de reserva do hotel, a verificação da entidade certificadora do cartão de crédito e também a disponibilidade do vôo para o destino que o cliente solicitou. É importante salientar que esse processo, também conhecido como processo de negócios, somente finaliza se os participantes trocarem dados de forma correta. Em resumo, tal processo de negócios também pode contribuir para um impacto significativo no tempo de resposta percebido pelo cliente;

- O cache de requisições pode permitir que haja uma diminuição no tempo de resposta percebido pela aplicação cliente. Este mecanismo pode ser configurado nos motores de processamento de mensagens SOAP, como por exemplo o Apache Axis2.

- O balanceamento de carga. O objetivo é permitir que as requisições sejam encaminhadas para provedores de serviços menos sobrecarregados, o que permite melhorar a provisão de $Q o S$ oferecida aos clientes dos Web Services.

\section{Broker de QoS}

O Broker deve fazer o papel de intermediador entre o cliente e o provedor de serviços e interagir ativamente com diversos provedores em busca de serviços similares. Sua função é interceptar as requisições de um cliente em particular e tentar oferecer a esse o melhor serviço disponível de acordo com a sua solicitação. O Broker deve se preocupar com questões como:

- Gerenciar as solicitações feitas pelo cliente e iniciar a interação com os possíveis provedores na busca do melhor serviço;

- Estimativa do tempo para o cruzamento de informações entre o que o cliente deseja e o que o provedor de serviços pode oferecer;

- Prover a interação com um repositório de serviços para realizar a seleção do serviço adequado. Isso deve envolver tempo de busca e tempo de acesso; 
- Oferecer uma lista de provedores sobrecarregados e que apresentam Web Services que causam sobrecarga de comunicação gerada pelo processamento de mensagens SOAP.

Na implementação da arquitetura WSARCH os atributos de $Q o S$ considerados são relacionados com os módulos participantes. Esse relacionamento é apresentado na Tabela 4.1.

\begin{tabular}{|l|c|c|c|c|}
\cline { 2 - 5 } \multicolumn{1}{c|}{} & \multicolumn{4}{c|}{ Módulos da Arquitetura } \\
\hline \multicolumn{1}{|c|}{ Atributos de QoS } & Cliente & Provedor & Broker de QoS & UDDI \\
\hline Tempo de Resposta & $\mathrm{X}$ & & & \\
\hline Vazão & & $\mathrm{X}$ & $\mathrm{X}$ & $\mathrm{X}$ \\
\hline Memória Principal & $\mathrm{X}$ & $\mathrm{X}$ & $\mathrm{X}$ & $\mathrm{X}$ \\
\hline Compressão de Mensagens & $\mathrm{X}$ & $\mathrm{X}$ & & \\
\hline Atraso da Rede & $\mathrm{X}$ & $\mathrm{X}$ & $\mathrm{X}$ & $\mathrm{X}$ \\
\hline Composição de Serviços & $\mathrm{X}$ & $\mathrm{X}$ & $\mathrm{X}$ & \\
\hline Disponibilidade & & $\mathrm{X}$ & $\mathrm{X}$ & $\mathrm{X}$ \\
\hline Custo do Serviço & & & $\mathrm{X}$ & \\
\hline Confiabilidade & & $\mathrm{X}$ & $\mathrm{X}$ & $\mathrm{X}$ \\
\hline Classe do Serviço & & $\mathrm{X}$ & $\mathrm{X}$ & \\
\hline Carga do Servidor & & $\mathrm{X}$ & $\mathrm{X}$ & $\mathrm{X}$ \\
\hline Latência & & $\mathrm{X}$ & $\mathrm{X}$ & $\mathrm{X}$ \\
\hline Reputação & $\mathrm{X}$ & & $\mathrm{X}$ & \\
\hline Segurança & $\mathrm{X}$ & $\mathrm{X}$ & & $\mathrm{X}$ \\
\hline Atomicidade & & $\mathrm{X}$ & & $\mathrm{X}$ \\
\hline Consistência & & $\mathrm{X}$ & & $\mathrm{X}$ \\
\hline Isolamento & & $\mathrm{X}$ & & $\mathrm{X}$ \\
\hline Durabilidade & & $\mathrm{X}$ & & \\
\hline
\end{tabular}

Tabela 4.1: Relação dos atributos de QoS com os módulos da WSARCH

Baseando-se nas perspectivas de $Q o S$ foram definidos os atributos de $Q o S$ que podem ser considerados na implementação da arquitetura WSARCH e apresentados a seguir. Esses atributos são definidos e relacionados com os módulos participantes (Estrella et al., 2008b).

\section{Atributos de QoS}

- Tempo de resposta (Cliente): Muito importante quando se pretende avaliar qual o impacto visto pelo cliente em relação ao desempenho do sistema e também características da rede de comunicação. O tempo de resposta pode ser o tempo de resposta total, envolvendo rede de comunicação em conjunto com a aplicação, ou somente o tempo necessário para que determinado serviço seja finalizado;

- Vazão (Provedor, Broker, UDDI): Representa a capacidade que um determinado provedor de serviço apresentará em termos de serviços executados por unidade de tempo. Esse atributo depende de outros fatores, tais como a capacidade de processamento, de memória disponível, velocidade do disco, característica da aplicação, etc.; 
- Memória principal (Cliente, Provedor, Broker, UDDI): Outro componente que tem papel importante no tempo de execução de serviço e no tempo de resposta resultantes para as diferentes aplicações;

- Compressão de mensagens (Cliente, Provedor): Deve-se considerar as diferentes técnicas de compressão de mensagens que podem ser consideradas de modo que o tempo de transmissão das mensagens e o tempo de resposta trocadas entre as partes comunicantes sejam reduzidos (Wu et al., 2003).

- Atraso da rede (Cliente, Provedor, Broker, UDDI): O tempo de transmissão requerido para receber o serviço. Componente importante para serviços com conteúdo multimídia tal como vídeo ou gráficos. O atributo largura de banda é também essencialmente importante para o Broker porque irá decidir se um serviço deve ser invocado, se um cliente está utilizando uma largura de banda inferior, etc.

- Composição de serviços (Cliente, Provedor, Broker): Em função da natureza dinâmica dos Web Services e de inúmeros serviços que dependem um do outro para compor um serviço maior, é importante caracterizar e aplicar técnicas para seleção dos serviços mais apropriados baseados em requisitos de $Q o S$;

- Disponibilidade (Provedor, Broker, UDDI): A indisponibilidade de um serviço pode conduzir a problemas durante a composição de serviços. Por exemplo, para finalizar um serviço composto, com a melhor $Q o S$ possível, é necessário que determinado serviço esteja disponível. A indisponibilidade pode ser tanto de software, quanto de hardware. Para melhorar a disponibilidade de serviços em software é necessária a utilização de algoritmos de otimização de rotas. Em relação a indisponibilidade de hardware, esse problema pode ser amenizado utilizando técnicas como Linux-HA (Linux High Availability) (HA, 2010). Linux-HA provê capacidade básica de alta disponibilidade (failover) em uma gama grande de plataformas, suportando milhares de Web sites em missão crítica no mundo;

- Custo do serviço (Broker): A análise do custo é um quesito fundamental para verificar o quão viável será determinar uma qualidade de serviço para uma aplicação em particular. Os Web Services possuem características diferentes e o custo para a computação de cada serviço pode depender dessas características;

- Confiabilidade (Broker, Provedor, UDDI): Seleção de um serviço que melhor se adequa às necessidades da aplicação;

- Classe de serviço (Provedor, Broker): Uma classe de serviço é uma coleção de Web Services individuais com funcionalidades comuns, mas com diferentes propriedades nãofuncionais. Por exemplo, dois serviços podem realizar a mesma tarefa, mas diferem em relação a um valor de determinado atributo de $Q o S$; 
- Carga do servidor (Provedor, Broker, UDDI): Quantidade de serviços presente no provedor e quantidade de requisições simultâneas para cada tipo de serviço. A qualidade de serviço percebida pelo cliente pode sofrer degradação se não houver mecanismos que controlem a quantidade de requisições suportadas por um provedor de serviços;

- Latência (Provedor, Broker, UDDI): Tempo gasto entre a chegada da requisição e o envio da resposta.

- Reputação (Cliente, Broker): Medida de confiabilidade do Web Service que pode ser calculada pela experiência dos clientes;

- Segurança (Cliente, Provedor, Broker, UDDI): Este atributo pode ser utilizado nas interações em que os componentes da WSARCH troquem informações seguras. O uso inadequado de medidas de segurança ou a ausência delas pode degradar o desempenho do sistema.

\section{Atributos Transacionais de QoS}

Qualidade de serviço transacional refere-se ao nível de confiabilidade e consistência em que as transações são executadas. Segundo (Mani e Nagarajan, 2002) são fundamentais para manter a integridade de um Web Service.

- Atomicidade (Provedor, UDDI): Em uma transação atômica, todas as fases necessárias para sua execução devem ser concluídas, caso contrário a transação não é finalizada;

- Consistência (Provedor, UDDI): Uma execução correta da transação deve levar o sistema de um estado consistente a outro;

- Isolamento (Provedor, UDDI): Uma transação não deveria deixar sua utilização visível para outras transações até que ela realmente seja executada. Ou seja, a transação deve executar como se não soubesse da ocorrência de outras;

- Durabilidade (Provedor): Uma vez que uma transação finaliza, as mudanças finalizadas nunca devem ser perdidas no evento de qualquer falha.

\subsubsection{Fatores relacionados à interação entre os módulos da WSARCH}

O projeto e desenvolvimento da arquitetura WSARCH visam o oferecimento de qualidade de serviço com foco em desempenho para os clientes participantes. Desta forma, torna-se necessário definir um procedimento para avaliar o desempenho da diversidade de interações que podem ocorrer entre os componentes da arquitetura proposta. Para isso, alguns parâmetros de qualidade de serviço e fatores devem ser considerados nas interações. Devido a natureza dinâmica da Internet e 
o surgimento cada vez maior de diferentes aplicações disponíveis na Web é preciso um estudo que defina quais atributos analisar e em que situação essa análise deve ser feita. O critério para a escolha dos atributos de $Q o S$ deve ser baseada na característica das aplicações. Por isso, é importante identificar as necessidades de $Q o S$ dessas aplicações e descobrir que parâmetros são mais adequados e como eles serão correlacionados. Por exemplo, um serviço multimídia requer alta vazão, enquanto um serviço bancário requer segurança e qualidade de serviço transacional. A seguir são levantados alguns fatores que devem ser considerados nas interações entre os diferentes módulos e sub-módulos para avaliar o desempenho da arquitetura WSARCH.

\section{Interação Cliente x Broker}

- Influência dos parâmetros de $Q o S$ enviados ao Broker;

- Deve ser considerada uma avaliação baseada em características de determinadas aplicações, cada uma com requisitos de $Q o S$ diferentes;

- Determinar o preço dessa interação.

\section{Interação Broker x Registro de Serviços}

- Considerar o tempo gasto para o Broker fazer uma solicitação ao registro de serviços e também o tempo que o registro de serviços levará para encontrar o serviço mais adequado (com base nas informações de $Q o S$ do cliente).

- No caso da busca no registro de serviços, determinar os algoritmos/heurísticas visando a diminuição do tempo de resposta global.

\section{Interação Broker x Provedor de Serviços}

- Tempo necessário para o provedor de serviços selecionar o serviço requisitado e retornar tal informação para o Broker;

- Considerar o tempo de resposta do provedor de serviços de acordo com a solicitação feita pelo Broker;

- No Broker deve ser considerado o tempo para fazer o "casamento" entre a QoS solicitada pelo cliente e a $Q o S$ retornada pelo provedor do serviço;

- O provedor também pode trabalhar com uma cache de requisições e balanceamento de carga, o que faria com que o tempo para a consulta aos serviços mais acessados diminuísse. Ao provedor também é permitido:

- Categorizar o tráfego do Web Service pelo volume de tráfego; 
- Categorizar o Web Service pelo tráfego de diferentes categorias;

- Categorizar o Web Service pelo tráfego de diferentes fontes.

\section{Interação Cliente x Provedor de Serviços}

- Tempo de invocação do serviço pelo cliente;

- Tempo para o processamento do Web Service no provedor;

- Tempo de resposta.

\section{Interação LogServer x Demais componentes}

- Considerar o impacto no tempo de resposta ao utilizar um servidor de Log para a coleta de dados para avaliação de desempenho.

\section{Interação Provedor x Registro UDDI}

- Considerar o impacto de se utilizar um monitor de desempenho/recursos computacionais.

O detalhamento das possíveis interações entre os componentes da arquitetura é importante pois permite detectar quais parâmetros podem ser considerados durante a fase de avaliação de desempenho da WSARCH.

\subsection{Implementação}

Conforme apresentado na Seção 4.2, a WSARCH é composta por quatro componentes: aplicação cliente, Broker, UDDI e provedores de serviços. O LogServer é um componente adicional que foi incorporado à arquitetura para fins de armazenar informações dos testes de desempenho da arquitetura. Nesta Seção, são descritas quais ferramentas e tecnologias são utilizadas para a implementação de cada um desses componentes. Para atender os requisitos especificados para a WSARCH, é necessário ainda a comunicação entre todos os componentes e um sistema de obtenção de informações a serem utilizados para as tomadas de decisão. Para a obtenção das informações e posterior comunicação para os componentes da arquitetura, é utilizado um módulo de monitoração denominado Ganglia, já citado anteriormente nesta tese. A Seção 4.5.1 detalha a utilização do Ganglia na WSARCH. A forma de comunicação entre os componentes da arquitetura é apresentada na Seção 4.5.2 As seções 4.5.3 à 4.5.6 detalham a implementação de cada um dos componentes da arquitetura. A Seção 4.5.3 descreve o Broker de serviços e os algoritmos implementados para o roteameto/escalonamento de mensanges. A Seção 4.5.4 descreve como o UDDI é implementado e como foi alterado para estender suas funções visando oferecer informações sobre a qualidade de serviço obtida dos provedores. A Seção 4.5.5 apresenta a implementação dos 
provedores de serviços e a Seção 4.5.6 as categorias de aplicações utilizadas para um teste inicial da WSARCH. A Seção 4.5.7 mostra a implementação do LogServer e a Seção 4.5.8 quais os problemas de instabilidade aos quais os componentes da arquitetura estão suscetíveis.

\subsubsection{Monitoração dos Provedores de Serviços}

A monitoração dos provedores de serviços é realizada por meio da utilização de um módulo de monitoração denominado Ganglia. O Ganglia se comporta como um monitor de sistemas escalável para computação de alto desempenho. Ele foi projetado para ser utilizado em clusters e em estruturas de clusters trabalhando como federações. A comunicação entre nodos mestre e escravos é realizada de forma multicast. Para a comunicação entre federações o Ganglia usa uma comunicação ponto-a-ponto em forma de árvore, tornando-a apta a passar pela maioria das estruturas de rede (Matos, 2009). Os dados dos nodos são publicados utilizando como padrão o formato de dados $X M L$. Os dados obtidos por meio da monitoração devem ser acessados de forma transparente pelo Broker da WSARCH. A escolha do Ganglia se deve a flexibilidade por ele proporcionada e por apresentar as características necessárias para o desenvolvimento do trabalho. Segundo os desenvolvedores, ele pode ser usado em clusters com até 2000 nós, em função das estruturas de dados e algoritmos utilizados, que causam baixa sobrecarga. Mesmo diante de todo o poder para monitoração de grandes estruturas, o Ganglia é de fácil instalação e configuração, e funciona adequadamente também em pequenas estruturas. Basicamente, o Ganglia é composto por um núcleo e algumas ferramentas auxiliares. O núcleo do Ganglia é formado pela ferramenta gmond, um daemon que deve estar presente em todos os nós do cluster, coletando as informações sobre sua carga. Para os propósitos da arquitetura WSARCH, os gmonds escravos são configurados em cada provedor de serviços e o gmond mestre (que concentra as informações de carga dos provedores) é configurado no registro UDDI, como mostra a Figura 4.4.

As métricas sobre a configuração de cada provedor, uso do processador, memória, rede e disco estão presentes no próprio provedor. $\mathrm{O}$ daemon obtém ainda os dados de carga do provedor (métricas referentes à quantidade de processos ativos, esperando $E / S$, etc.). Além disso, o uso do daemon permite a configuração do tempo de atualização e propagação dos dados coletados, com uma periodicidade pré-definida. O gmond decide se deve ou não propagar as informações com base nos dados coletados, e também em suas configurações. Para que a propagação das informações não afete diretamente a escalabilidade, é preciso obedecer alguns parâmetros. A monitoração pode ser feita por mudança de estado ou de forma periódica. No caso da WSARCH, a monitoração é feita de forma periódica. Este valor deve ser definido de forma que mantém informações atualizadas sem comprometer o funcionamento da arquitetura visto que um intervalo muito pequeno entre coletas pode causar sobrecargas na rede de comunicação. Uma possibilidade é adotar uma forma híbrida para atualização dos dados, onde é definido um intervalo e um valor limite para a mudança. Caso ocorra de um valor mudar mais que o valor determinado pelo administrador dentro de um intervalo de tempo, propaga-se a informação. Caso essa situação não ocorra, o valor só será enviado quando 


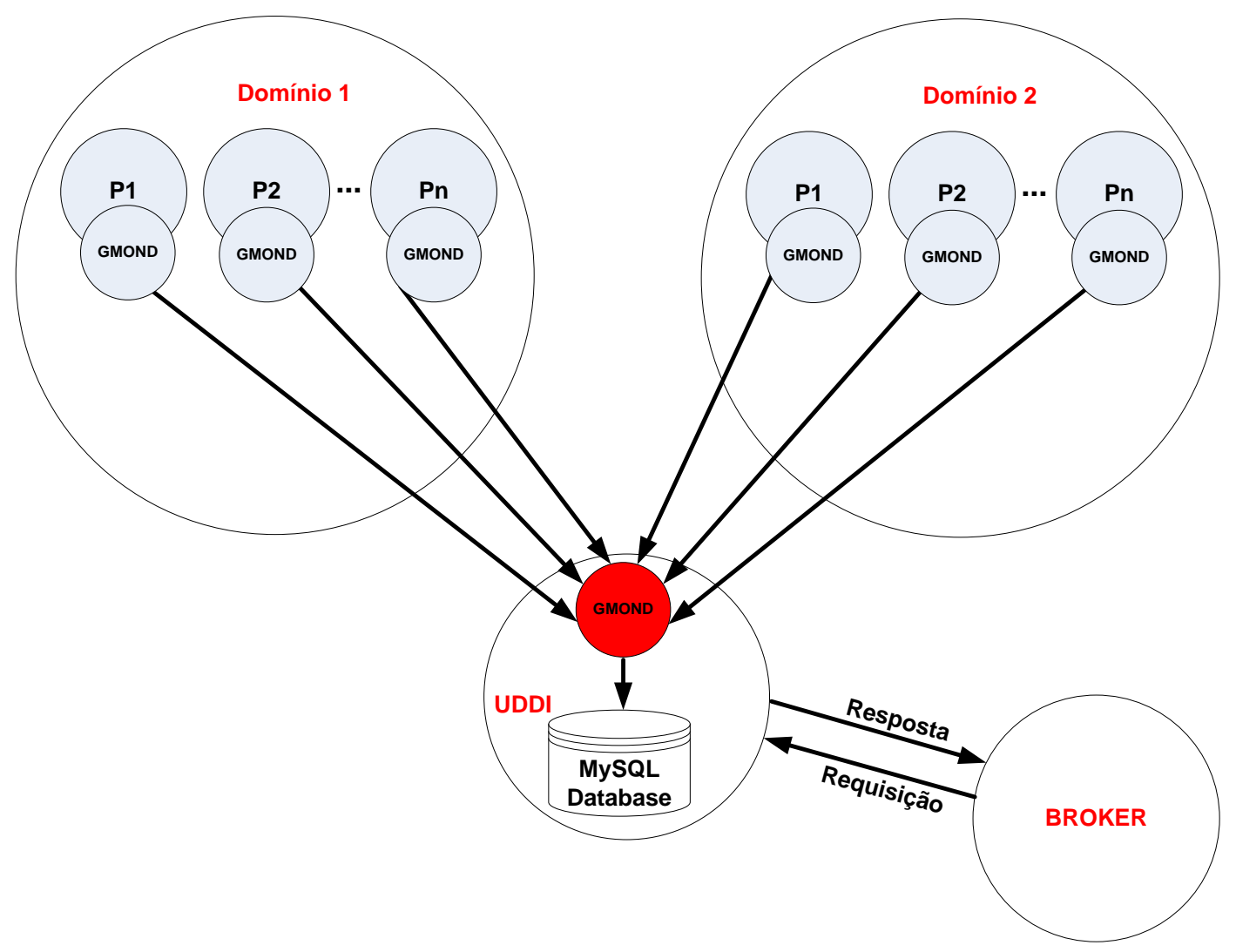

Figura 4.4: Funcionamento do Ganglia na WSARCH

finalizado o intervalo de tempo definido. Para a obtenção das informações, o gmond realiza uma consulta mediante uma conexão em uma porta configurada. Quando ele recebe uma conexão, ele envia todas as informações codificadas dentro de um documento XML. Essa característica simplifica o acesso de informações por programas externos, somente utilizando uma conexão TCP e um processador (parser) XML. Em complemento ao gmond, o Ganglia utiliza o gmetric. Este permite que sejam adicionadas mais métricas em tempo real. O gmetric é um comando que pode ser executado manualmente dentro de qualquer um dos nós, e isso requer que sejam informados o nome de um dado a ser propagado, seu valor e o tipo de dado. Assim, o gmetric conecta-se ao gmond e passa esse novo dado. O novo dado é então propagado por meio do gmond tornando-se acessível para todos os gmonds e programas que dele obtém informações. Nesse sentido, podem ser utilizadas ferramentas externas escritas em scripts Bash, Perl, Python que coletam informações úteis que não foram inicialmente concebidas nos módulos do Ganglia. No caso da WSARCH o gmetric foi utilizado para propagar novas informações sobre a ocupação de $C P U$ uma vez que o valor que o Ganglia obtém dos hosts não é o valor correto. Sendo assim um script foi produzido para coletar as informações corretas e repassadas ao gmetric que por sua vez propagou essa informação ao gmond de cada nó provedor. Além do gmetric, o Ganglia contém uma ferramenta chamada gmetad (também um daemon). Esta ferramenta apresenta como característica a capacidade de consultar o gmond e armazenar as informações coletadas. Assim, é possível obter um histórico sobre a situ- 
ação dos nós monitorados. Para obter as informações de diversos nós é preciso que o gmetad se conecte a um único gmond. Depois de obter as informações, estas são armazenadas em um banco de dados chamado Round-Robin Database (RRD). Uma das características que fazem do Ganglia um monitor de dados hierárquico é que os gmetads podem conectar-se a outros gmetads para buscar informações, ou seja, não fica restrito somente aos gmonds.

\subsubsection{Comunicação}

Toda a comunicação entre os componentes da arquitetura é realizada via mensagens SOAP encapsuladas dentro do protocolo HTTP, exceto a atualização de informação de desempenho dos provedores para o $U D D I$, que é realizada por meio de uma conexão TCP em uma porta prédefinida. Para elucidar o processo de comunicação entre cliente, Broker, UDDI, provedores e o LogServer, são apresentadas a seguir as etapas principais:

- Cliente x Broker: Cliente envia mensagem SOAP para o Broker solicitando determinado serviço. O Broker recebe essa solicitação e faz uma chamada SOAP ao UDDI;

- Broker x UDDI: Após receber a solicitação do cliente o Broker procura no UDDI o serviço que melhor atenda ao pedido do cliente. A mensagem SOAP é processada e uma resposta contendo a $U R L$ do provedor de serviços é retornada ao Broker.

- Broker x Provedor: Ao receber a resposta do UDDI contendo a URL do provedor o Broker realiza uma requisição ao Web Service hospedado no provedor. Após a requisição ser processada pelo Web Service uma resposta é retornada ao Broker que posteriormente a reencaminha à aplicação cliente.

- Atualização de Informações de $Q o S$ no $U D D I$ : As informações de $Q o S$ provenientes dos provedores de serviços no formato de um índice de desempenho baseado no trabalho de (Branco, 2004) são propagadas dos provedores de serviços para o registro UDDI por meio de uma conexão em uma porta pré-definida na aplicação. As informações de carga são obtidas pela ferramenta Ganglia por meio do daemon gmond escravo em cada um dos provedores e enviadas por meio de uma conexão TCP para o UDDI que possui um gmond mestre concentrando as informações dos gmonds escravos. Todas as informações são armazenadas na base de dados do UDDI e atualizadas a cada período de 2 segundos. Essa informação na forma do índice de desempenho é utilizada pelos algoritmos implementados no Broker para selecionar o melhor provedor de serviços de acordo com a solicitação da aplicação cliente.

\subsubsection{Broker}

As informações de qualidade de serviço são de fundamental importância para que os componentes participantes da WSARCH possam se comunicar. Em geral, as informações propagadas 
são dos provedores de serviços para o Broker, do UDDI para o Broker e do cliente para o Broker de serviços. A Figura 4.5 descreve as três interfaces presentes no Broker, cada uma das quais armazenando informações de $Q o S$ vindas de outros componentes da arquitetura.

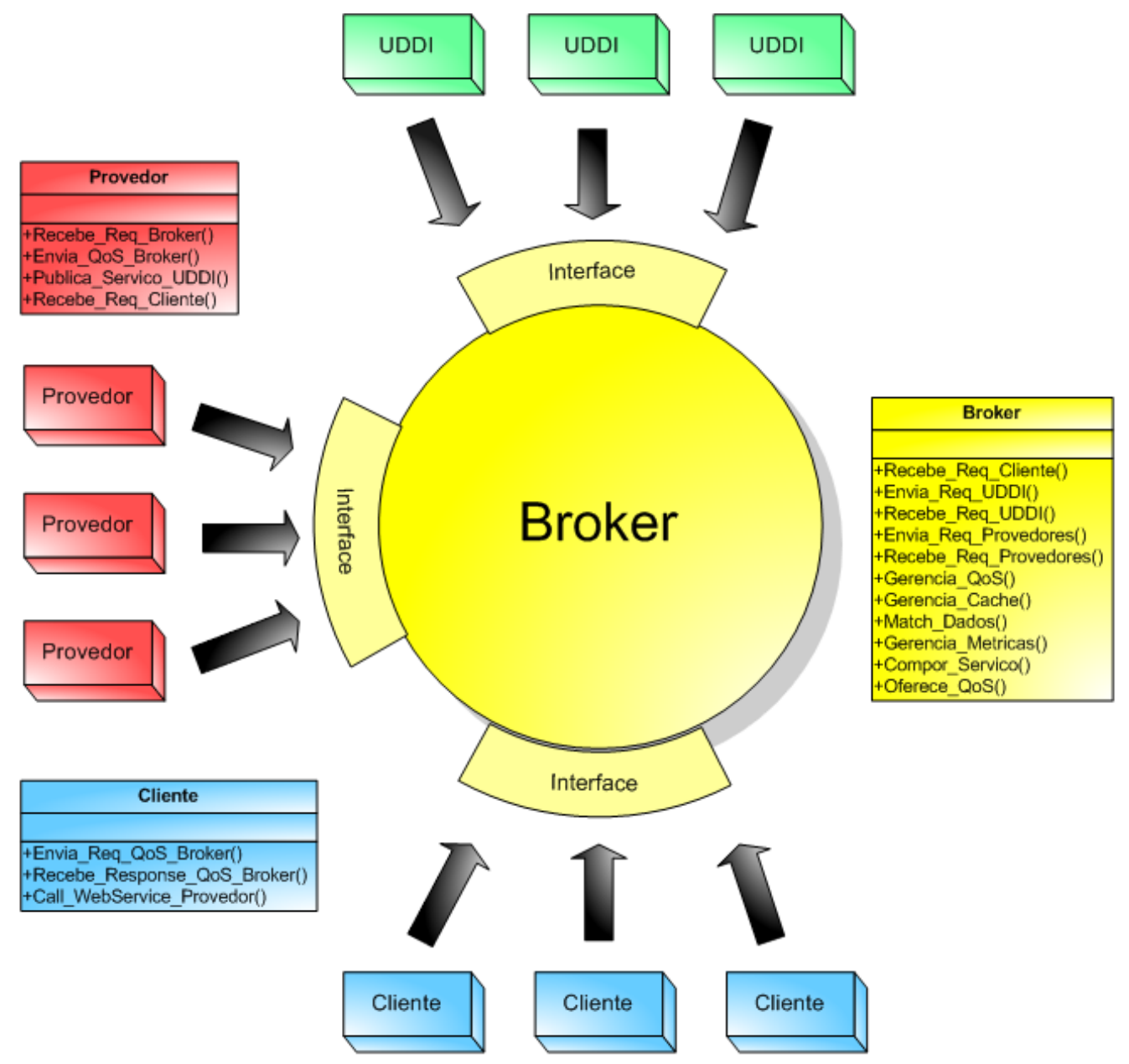

Figura 4.5: Broker e Interfaces

Os provedores de serviços propagam as informações a partir dos dados coletados pelo sistema de gerenciamento que utiliza o Ganglia, como mostra a Figura 4.6.

Essas informações são atualizadas periodicamente a medida que o estado do provedor de serviços sofre modificações ( $C P U$, memória, disco, etc). A cada nova medida programada no protótipo implementado para 2 segundos no provedor de serviços, uma requisição contendo as informações é enviada ao UDDI Server que as armazena numa estrutura de dados em que constam a $U R L$ do provedor, se ele está ativo/inativo, e quais as métricas, ou associação de métricas que foram coletadas. Essas informações são utilizadas pelo Broker da WSARCH para a escolha dos serviços candidatos ao atendimento da solicitação do cliente do serviço. A Figura 4.6 mostra ainda a interação do UDDI Server, Broker e clientes com o LogServer. O LogServer armazena métricas referentes ao tempo de resposta, variação do índice de carga do provedor de serviços, tempo de sobrecarga da arquitetura, dentre outros. 


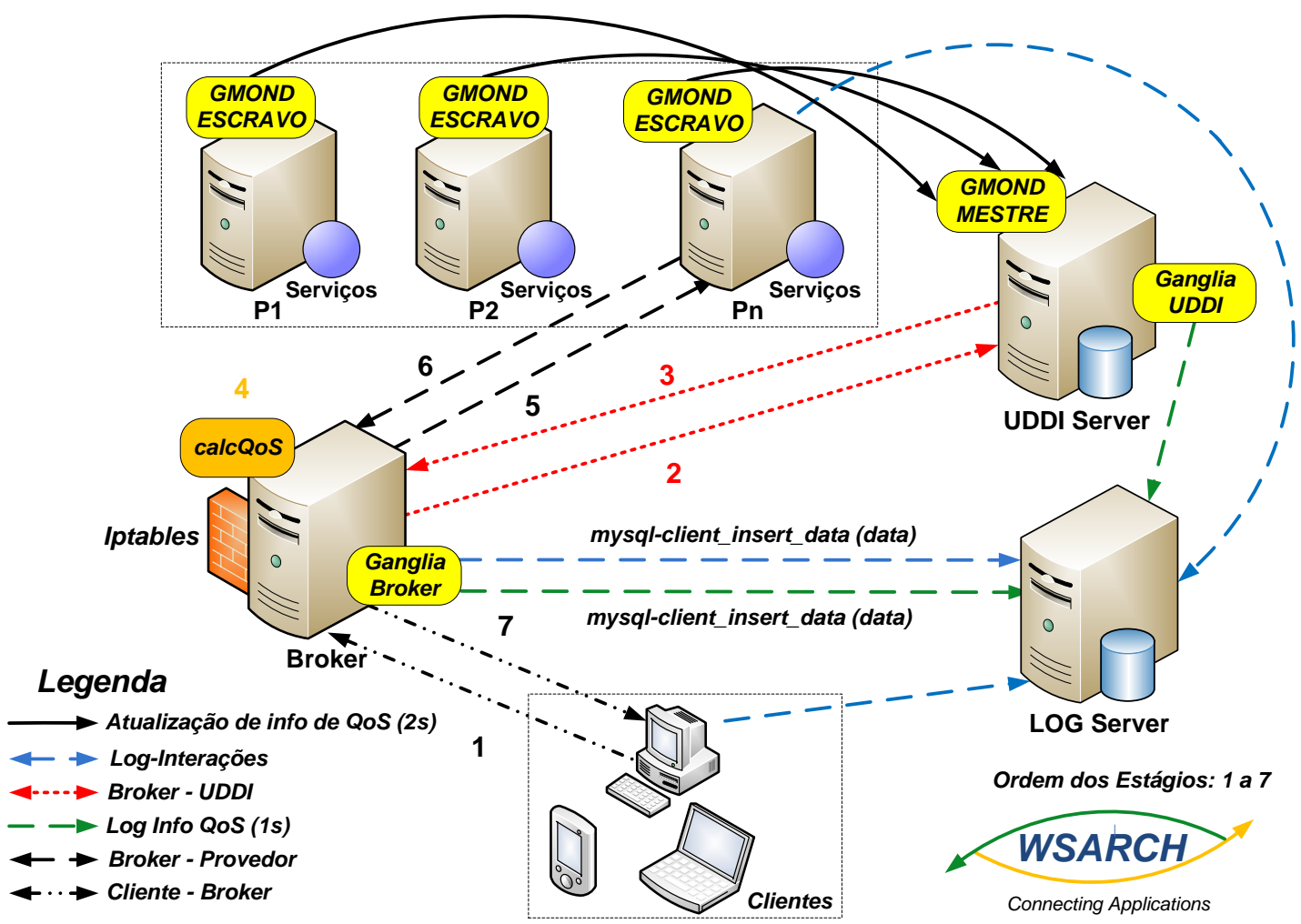

Figura 4.6: WSARCH - Informações de QoS

\section{Algoritmos Implementados}

O Broker da arquitetura WSARCH funciona como um agente roteador/escalonador de mensagens SOAP recebidas de Web Services clientes. Todas as requisições são analisadas antes de serem encaminhadas para os respectivos provedores de serviços que podem atender tais requisições. Os critérios de roteamento/escalonamento de mensagens são baseados em algoritmos implementados no Broker, os quais possuem características distintas tais como: selecionar com base no conteúdo da mensagem SOAP, com base em alguma informação do cabeçalho, com base em classes de aplicações, etc. No protótipo inicial do Broker, dois algoritmos são implementados: o primeiro é o Algoritmo de Classificação que apenas seleciona os provedores de serviços com base em um índice de desempenho (este é composto de um índice de $C P U$ juntamente com um índice de memória do provedor de serviços). O cálculo deste índice de desempenho é feito por meio de uma adaptação do algoritmo proposto por (Branco, 2004). A técnica proposta por (Branco, 2004) utiliza Distância Euclidiana para calcular o índice desempenho que varia de 0 a 1 . No caso da arquitetura WSARCH, o cálculo do índice é utilizado para classificar os clientes nas classes Gold, Silver e Bronze. Os clientes da classe Gold serão atendidos quando o índice de desempenho estiver mais próximo de 0 (zero). Para os clientes da classe Bronze o índice de desempenho deve ficar próximo de 1 (um) sinalizando para o pior recurso a ser escolhido. O índice de desempenho mais próximo da média é escolhido para a classificação dos clientes da classe Silver. Um problema do algoritmo de classificação é que mantidas as mesmas pro- 
porções de chegada de requisições para clientes Gold e Bronze, o processamento das requisições dos clientes da classe Gold pode sofrer interferências como será discutido no capítulo de validação da arquitetura WSARCH. O segundo algoritmo, denominado Algoritmo de Reserva de Recursos é uma variante do primeiro, cujo objetivo é reservar uma quantidade de recursos para as classes de clientes. Entende-se como classe cliente: Gold, Silver, Bronze e para a classe de serviço destaca-se: $C P U$-Bound, Memory-Bound, etc. Assim, os clientes terão suas requisições processadas de acordo com a quantidade de provedores disponíveis para cada classe de cliente. Ou seja, os clientes da classe Gold terão mais provedores disponíveis que os clientes da classe Silver e estes por sua vez mais provedores disponíveis que os clientes da classe Bronze. Dentre os provedores alocados para tal classe, escolhe-se o melhor provedor de acordo com o índide de desempenho. Vale ressaltar que os dois algoritmos propostos neste trabalho visam a validação e o funcionamento da arquitetura WSARCH. No entanto, a estrutura de software do Broker viabiliza a construção de novos algoritmos de roteamento/escalonamento de mensagens mais eficazes, os quais serão abordados em trabalhos futuros.

\subsubsection{Registro UDDI}

O registro UDDI possui a finalidade de armazenar informações funcionais sobre os Web Services implantados em um provedor de serviços. Além dessa finalidade, para os propósitos deste trabalho de doutorado, o registro UDDI foi alterado para também contemplar informações de $Q o S$ dos provedores de serviços. Nesse sentido, no momento em que o Broker recebe uma requisição do cliente, deve consultar o registro UDDI e verificar os provedores de serviços disponíveis (identificado por suas $U R L s$ ) e também a qualidade de serviço por eles oferecidas. O atributo de $Q o S$ utilizado para a validação foi o índice de desempenho, porém outros atributos tais como: taxa de ocupação de $C P U$, tempo de resposta, satisfação do cliente, etc., possam ser utilizados. Em resumo, o UDDI deve possuir uma tabela em que constam as informações apresentadas na Tabela 4.2 .

Tabela 4.2: Informações de QoS armazenadas no registro UDDI

\begin{tabular}{|c|c|}
\hline URL do Provedor & Métrica \\
\hline http://192.168.2.20:8080/services/ & Índice de Desempenho \\
\hline http://192.168.2.21:8080/services/ & Índice de Desempenho \\
\hline$\cdot$ & $\cdot$ \\
\hline$\cdot$ & $\cdot$ \\
\hline$\cdot$ & $\cdot$ \\
\hline \hline
\end{tabular}

A métrica listada na Tabela 4.2 é apenas uma métrica específica, o que não impede de se utilizar uma combinação entre outras métricas para a construção de um novo índice. Isso é possível, uma vez que o Ganglia fornece diversas informações sobre o estado do provedor de Web Services, facilitando assim a escolha da utilização da métrica. É importante mencionar que a extensão do 
UDDI para armazenar informações não-funcionais não foi uma tarefa trivial. Foi necessário alterar parte da estrutura de dados e de armazenamento do UDDI para que as informações dinâmicas provenientes dos provedores pudessem ser utilizadas pelo Broker da WSARCH. Para os propósitos da arquitetura foi utilizada a primeira versão considerando a especificação 2.0 do UDDI. A versão mais recente da especificação do UDDI diferente daquela utilizada na WSARCH (JUDDI da Apache Software Foundation), permite que o acesso aos dados seja feito de forma menos dispendiosa uma vez que ela utiliza Hibernate para garantir persistência de dados. A nova versão do jUDDI deve ser implantada nas próximas fases de desenvolvimento da arquitetura WSARCH, o que deve incluir ajustes e otimizações no código.

\subsubsection{Implementação dos Provedores de Serviços}

Os provedores de serviços foram implementados utilizando-se de um motor de processamento de mensagens SOAP denominado Axis2, este acoplado ao servidor de aplicações denominado Tomcat. As aplicações desenvolvidas para o teste de validação da arquitetura são implantadas no provedor de serviços em um repositório do Axis2. Toda requisição SOAP proveniente do Broker de serviços é capturada pelos receptores de mensagens do Axis2, processadas, e a resposta encapsulada na mensagem de retorno ao Broker e posteriormente à aplicação cliente. Assim que a aplicação é desenvolvida e implantada no provedor ela pode receber requisições provenientes dos clientes do Web Service. Vale ressaltar que nesta etapa de implementação das aplicações provedoras foi necessário realizar uma alteração no código fonte do Axis2 para que este coletasse informações do tempo de processamento de cada serviço implantado nos provedores. Essa alteração foi realizada nos receptores de mensagens que são parte integrantes do Axis2. A natureza das aplicações que foram desenvolvidas para a WSARCH será detalhada na próxima seção. Embora qualquer tipo de aplicação possa ser utilizada na arquitetura, os testes de validação contemplaram somente a utilização de aplicações $C P U$-Bound.

\subsubsection{Categorias das Aplicações}

No contexto do desenvolvimento da arquitetura WSARCH e de qualquer outra arquitetura orientada a serviços, as aplicações podem ser de naturezas distintas, cada uma delas com suas particularidades, as quais podem degradar o desempenho de um sistema caso não sejam consideradas na política de roteamento/escalonamento de mensagens. As requisições enviadas por diferentes categorias de aplicações e a resposta advinda dos provedores dos serviços possuem forte relação com a característica das aplicações. Por exemplo, o resultado de uma simples requisição SOAP para uma aplicação que acessa uma base de dados, pode retornar uma mensagem SOAP de resposta muito grande, dependendo do que foi solicitado na requisição, e degradar o tempo de resposta do ponto de vista do cliente, uma vez que a interação cliente e provedor envolve não somente a execução de um dado, mas também o encapsulamento/desencapsulamento das mensagens SOAP. As aplicações 
podem utilizar com mais frequência determinados recursos e se comportar de modos diferentes quando estão em processo de execução. Devido a tais diferenças, as tarefas são agrupadas em classes, e isso deve ser levado em consideração pelos algoritimos de roteamento/escalonamento de mensagens presente em um Broker de serviços. O objetivo é sempre melhorar o desempenho do sistema, uma vez que alguns recursos podem sofrer sobrecarga enquanto outros permanecem ociosos. A Figura 4.7 apresenta uma visão geral para a classificação de aplicações.

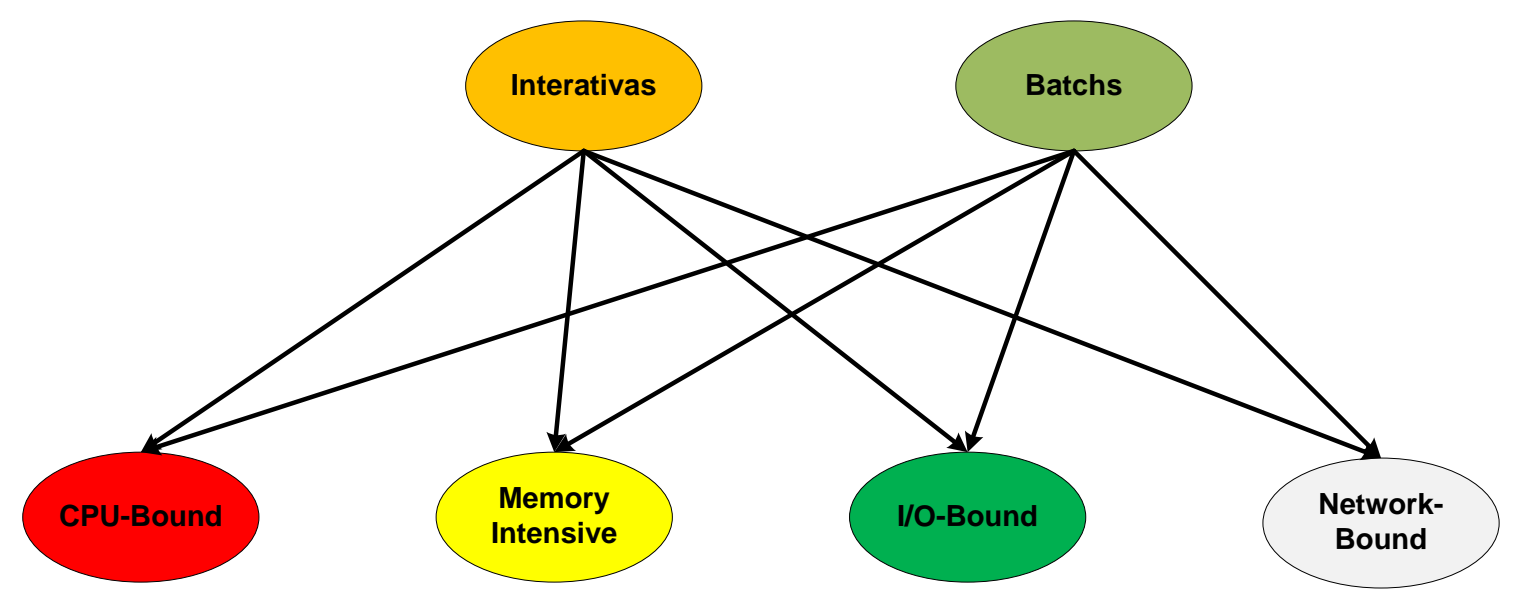

Figura 4.7: Classificação das Aplicações (Branco, 2004)

De acordo com (Saphir et al., 1995) as aplicações podem ser classificadas em função do método de execução em:

- Interativas: Possui como característica principal a interação da aplicação com o usuário. A interatividade (mais ou menos interativa) vai depender da frequência com que essa interação ocorre. Nessa categoria de aplicações um dos fatores mais importantes é o tempo de resposta, o qual deve ser priorizado no momento do roteamento/escalonamento das mensagens SOAP;

- Batchs: Aplicações que são submetidas em lote, em que não há interação com o usuário. O fator primordial é o tempo de execução para essa classe. As políticas de roteamento de mensagens direcionadas a essa classe podem ser mais flexíveis e considerar mais fatores para realizar o roteamento, uma vez que não possuem usuários on-line.

Ao considerar a intensidade de utilização dos recursos, as aplicações podem ser classificadas em (Voorsluys, 2006):

- CPU-bound: As aplicações desta categoria realizam processamento a maior parte do tempo, mantendo o processador ocupado desde o momento em que elas são escalonadas para execução. Exemplos típicos são: aplicações baseadas em métodos matemáticos. Para este tipo de aplicação costuma se utilizar o termo computation-intensive. 
- Memory-Intensive: Esta categoria de aplicações caracteriza-se pela necessidade de grande quantidade de memória principal. As tarefas que passam um tempo considerável escrevendo e lendo na memória, ou que armazena grande quantidade de dados, podem ser categorizadas como memory-intensive. Frequentemente, as aplicações memory-intensive também são consideradas CPU-bound, já que juntamente com o armazenamento de grandes quantidades de dados, deve haver o processamento dos mesmos. Estas aplicações também são conhecidas como memory-bound, porém esta denominação é menos utilizada. Como exemplos destacam-se: programas de data mining, modelos climáticos, reconhecimento de voz buscas em grandes bases de dados, processamento de vídeo, entre outros.

- I/O-bound: Aplicações que necessitam armazenar, ou ler, muitas informações de dispositivos de armazenamento secundário (por exemplo, rede ou disco), passando a maior parte do tempo realizando operações de $I / O$. Elas também podem ser denominadas $I / O$-intensive.

- Network-bound: Aplicações que realizam a comunicação em rede de maneira intensa. Podem também ser denominadas communication-intensive ou ainda communication-bound. Destaque para aplicações que executam na Internet e em plataformas paralelas distribuídas.

O que é interessante destacar é que as aplicações podem pertencer a uma ou mais classes, uma vez que elas não são mutuamente exclusivas. Portanto, é possível que uma aplicação seja CPU-bound e memory-intensive ao mesmo tempo. Outra possibilidade é que as tarefas alterem sua classificação durante a execução. Deste modo, uma aplicação pode ser classificada como network-bound no momento de sua submissão e mudar seu comportamento durante a execução, sendo classificada como I/O-bound, por exemplo (Voorsluys, 2006).

\section{Implementação das Aplicações}

Para o propósito do teste inicial da WSARCH foi considerada uma aplicação inteiramente $C P U$-Bound, incluindo operações matemáticas simples dentro de alguns laços aninhados na ordem de $O\left(n^{4}\right)$. Aplicações mais robustas considerando várias categorias foram implementadas e testadas em um trabalho de mestrado associado a este projeto de doutorado. Uma das aplicações implementadas no projeto de mestrado citado anteriormente refere-se à transferência de dados anexados em mensagens SOAP na WSARCH, utilizando as técnicas MTOM e SwA já previamente explicadas. Para permitir que anexo de dados fosse utilizado na WSARCH, foi necessária implantar uma nova funcionalidade na arquitetura que contemplasse a correta transferência das informações entre provedor, Broker e aplicação cliente. Com base nesta aplicação de transferência de dados anexados, uma aplicação mais completa foi implementada, considerando também $C P U$-Bound e IO-Bound, nos quais representam, respectivamente, a funcionalidade da aplicação $C P U$-Bound definida anteriormente e escrita de arquivos de texto no disco do provedor. Tais operações são executadas de forma sequencial, ou seja, a operação de $C P U$-Bound é executada inicial- 
mente, seguida da operação de IO-Bound. Por fim um arquivo binário é transferido do provedor selecionado para o cliente efetuando uma operação de download.

\subsubsection{LogServer}

O LogServer é um componente que foi adicionado à arquitetura com o propósito de armazenar todas as informações referentes aos dados dos experimentos realizados para o teste da WSARCH. O LogServer recebe informações de todos os componentes, tais como tempo de processamento dos provedores de serviço, tempo de busca no registro UDDI, tempo de seleção do melhor serviço pelo Broker, tempo de parser da WSDL depois que o Broker escolher o melhor serviço candidato para atender a requisição do cliente, tempo de resposta total e tempo de invocação para o provedor escolhido. Outras informações também são armazenadas: horário de cada requisição, identificação dos clientes, identificação dos provedores e índice de desempenho escolhido para determinado cliente e também o histórico de índice do Broker, do provedor e também do UDDI.

Para implementar o LogServer foi utilizada uma versão servidora da distribuição Linux Ubuntu versão 9.10 de 64 bits. Além disso também foi configurada uma versão do servidor de banco de dados relacional denominado $M y S q l$. Para que todas as informações de desempenho fossem inseridas no banco de dados, cada um dos componentes da WSARCH se utiliza de um cliente que aguarda pelo dado resultante (por exemplo, assim que o tempo de processamento do serviço no provedor é obtido) e realiza uma conexão TCP entre o cliente $M y S Q L$ e o LogServer que contem o servidor de banco de dados. Todas os dados dos experimentos são armazenados nesta base de dados, o que permitiu maior flexibilidade para que os dados coletados fossem analisados posteriormente. Esta análise será discutida detalhadamente no capítulo de resultados deste projeto de doutorado. É importante mencionar que a cada experimento realizado o LogServer e todos os componentes da arquitetura eram reinicializados para que não houvesse interferência de mecanismos de cache dos provedores, Broker, UDDI e da base de dados relacional.

\subsubsection{Controle de Erros}

A arquitetura WSARCH possui uma natureza bastante distribuída e certamente pode estar suscetível a problemas de instabilidade diante da ocorrência de diversos eventos, os quais são listados a seguir:

- Falha na propagação de informações de QoS (UDDI, Broker, Cliente): Falhas na propagação de informações de $Q o S$ podem prejudicar a escolha do provedor de serviços pelo Broker e influenciar no tempo de resposta final percebido pela aplicação cliente.

- Indisponibilidade do provedor de serviços: A indisponibilidade do provedor pode ser causada por sobrecarga no atendimento de requisições quando por exemplo, a capacidade de processamento dos provedores são limitadas e também causada por falha de hardware ou mal funcionamento das aplicações. 
- Indisponibilidade do registro UDDI: Pode se causada por falha na busca por um serviço não mais existente, por falha na inserção de informações dos Web Services, por falha na atualização de informações dos Web Services e por falha na remoção de informações dos Web Services.

- Indisponibilidade do Broker: O Broker é o elemento central da arquitetura e também pode sofrer de problemas de disponibilidade quando houver uma sobrecarga de $C P U$ e memória em razão de uma grande rajada de requisições proveniente dos clientes. Num futuro próximo é possível construir uma federação de Brokers de modo a permitir que na ausência de um Broker outros possam assumir a responsabilidade no roteamento/escalonamento de requisições. Assim como os outros componentes da arquitetura (UDDI e provedores), o Broker também pode apresentar falhas de hardware.

Embora a especificação inicial da arquitetura WSARCH ainda não contemple todos os mecanismos tolerante a falhas (isso deve ser abordado na próxima etapa de desenvolvimento que envolve a otimização da arquitetura), vale ressaltar que todas essas falhas são registradas durante a execução das aplicações por meio de registros dos Logs capturados para análise posterior.

\subsection{Composição de Serviços}

Os mecanismos de composição de serviços associados à arquitetura WSARCH podem ser utilizados por meio de um módulo complementar denominado DWSC-M (Dynamic Web Services Composition Middleware) (Kuehne, 2009) o qual foi implementado testado e validado em outro projeto de mestrado associado à WSARCH. Apesar deste módulo ainda não estar integrado à arquitetura é importante destacar como aplicações compostas podem ser integradas e testadas na WSARCH. Um serviço composto envolve a interação entre diversos Web Services, de modo que o resultado de um funcione como parâmetro de entrada para o próximo Web Service do fluxo, até que uma resposta seja retornada ao cliente que fez a requisição. Por exemplo: Para efetuar a compra de uma passagem aérea para determinado destino, é natural que haja disponibilidade de vôo para o destino desejado, a disponibilidade de reserva em um Hotel e também a disponibilidade de locação em uma locadora de veículos. Nesse sentido, algumas regras de negócios precisam ser discutidas, considerando o fluxo exemplo, descrito na Figura 4.8.

De acordo com o fluxo da Figura 4.7 na arquitetura WSARCH, o cliente deve inicialmente consultar o Broker de serviços sobre a disponibilidade de vôos em uma data especificada, um Hotel no destino escolhido e também a possibilidade de haver uma opção de aluguel de veículo na data estipulada. Sendo assim, o Broker da WSARCH deve receber quatro parâmetros na requisição SOAP enviada pelo cliente: a identificação do cliente (CPF), a data do vôo, o nome ou código do Hotel e o nome ou código da locadora de veículos. Ao receber a requisição SOAP do cliente, o Broker extrai esses parâmetros e inicia uma busca ao repositório UDDI para pesquisar sobre a 


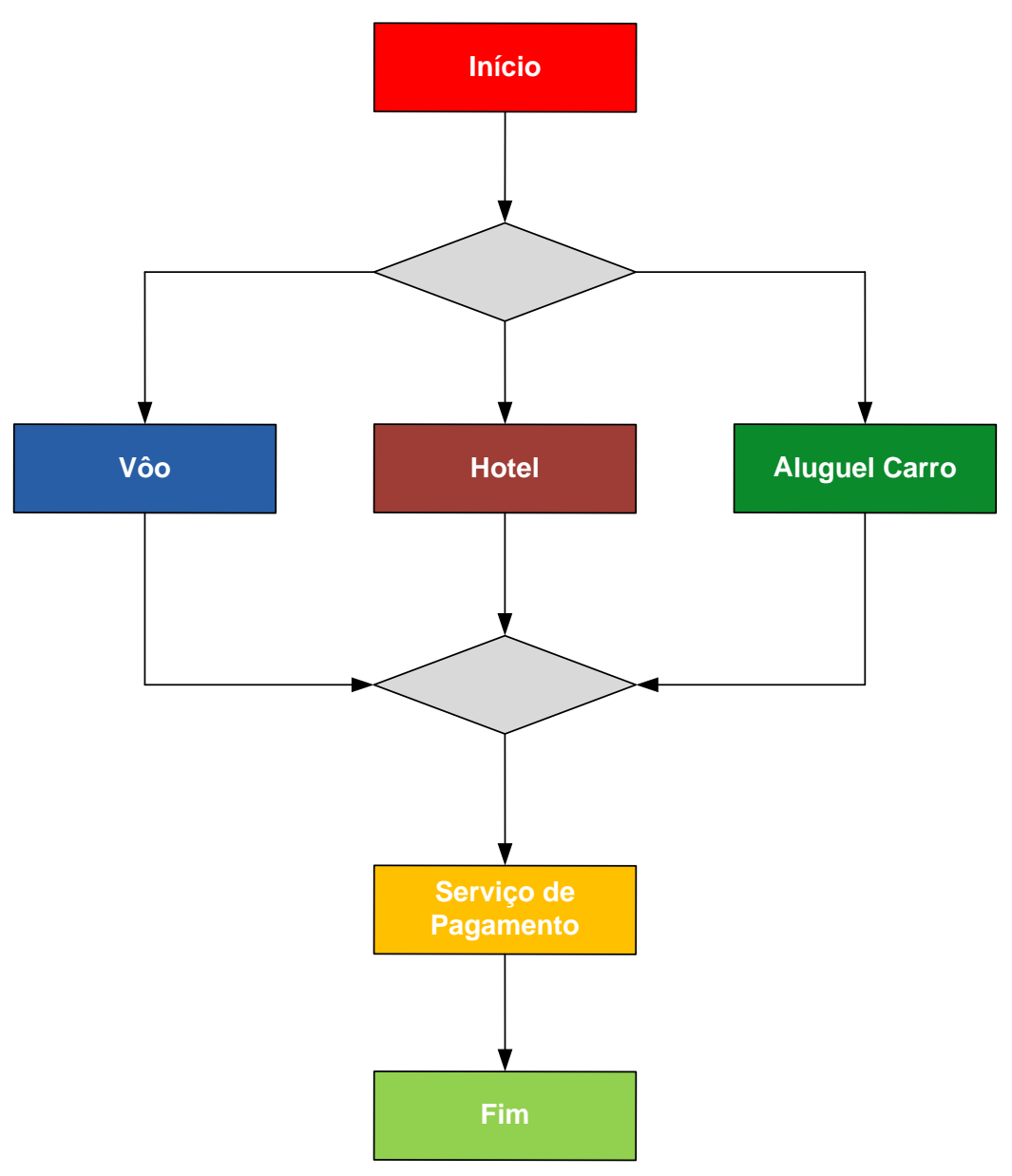

Figura 4.8: Fluxo de composição de uma reserva de viagens

existência de serviços candidatos ao atendimento da solicitação do cliente. Como na prática pode haver vários provedores que funcionalmente realizam as mesmas tarefas, a escolha do melhor Web Service para o atendimento da requisição do cliente deve levar em consideração também a carga de trabalho imposta a um provedor em particular. As informações da carga de trabalho ( $C P U$, memória, disco, paginação, etc), ou a combinação delas por meio de um índice de desempenho serão utilizadas pelo Broker (por meio de um algoritmo de seleção) para uma tomada de decisão. A resposta retornada ao cliente deve obedecer a um acordo de nível de serviço previamente estipulado, isto é, os provedores precisam oferecer exatamente aquilo que o cliente deseja ou algo bem próximo ao desejado, desde que isso esteja previsto no acordo. O cumprimento do acordo não é trivial e para que ele seja cumprido, é preciso considerar algumas situações em relação a este fluxo:

- Mensagens de sucesso ou falha devem ser enviadas ao cliente do Web Service quando do término do fluxo.

- O Broker da WSARCH deve registrar a ocorrência das requisições efetuadas pelos clientes e armazenar em uma base de dados auxiliar se a busca por determinado serviço no fluxo foi positiva ou negativa. 
- Cada serviço participante do fluxo deve gerar um ID. Cada ID de um serviço será parte de um ID_FINAL que corresponde ao fluxo composto.

- O Broker deve realizar o tratamento de erros caso algum serviço no fluxo apresente problemas e o contrato de serviço não possa ser cumprido. Ou seja, se por alguma exceção, o pagamento no Web Service de pagamento não puder ser efetivado, uma operação de rollback (desfazer uma transação corrente fazendo com que todas as modificações realizadas pela transação sejam rejeitadas) deve ser realizada para cancelar a reserva de vôo, reserva de hotel e locação de veículo. Como as informações de cada serviço são identificadas por um ID, o processo de rollback na base de dados será realizado com base neste ID.

- As informações da carga de trabalho de cada provedor serão propagadas periodicamente para o Broker da WSARCH, que as utilizará em conjunto com os algoritmos de roteamento/escalonamento de mensagens

O exemplo de composição de serviços apresentado nesta seção é apenas uma das possibilidades de implementação de fluxos de composição na arquitetura WSARCH. A integração do DWSC-M à WSARCH permitirá que novas aplicações possam ser desenvolvidas e seus comportamentos analisados.

\subsection{Considerações Finais}

Este capítulo descreveu a proposição de uma arquitetura para a provisão de Web Services com qualidade de serviço. Foram apresentados a estrutura inicial da arquitetura, seus módulos, submódulos e um levantamento de alguns parâmetros de qualidade de serviços que foram explorados durante o desenvolvimento do projeto de doutorado. Também foram descritas as possíveis interações que podem ocorrer entre os módulos da arquitetura (cliente, Broker e provedores de serviço). Neste capítulo também foi discutido todo o processo de implementação dos componentes da arquitetura e as dificuldades encontradas durante essa fase do desenvolvimento. Muitos foram os desafios técnicos desde o planejamento da arquitetura, o que vai desde a escolha da linguagem de programação, motor de processamento de mensagens, configuração e implantação da infra-estrutura física, configuração de um firewall para integrar duas redes distintas (clientes e provedores pertencem a redes separadas), ferramentas de monitoração, até a coleta e análise de dados. No âmbito técnico um dos desafios mais complicados foi determinar qual parte do motor de processamento de mensagens Axis 2 deveria ser alterada para a correta obtenção do tempo de processamento de uma mensagem SOAP no provedor de serviços. Essa tarefa não foi trivial pois o Axis2 possui milhares de linhas de código.

Como objetivo principal, este trabalho explora mais detalhadamente uma forma de provisão de QoS para os Web Services, utilizando técnicas já existentes, além da proposição de novas metodologias de utilização de parâmetros de $Q o S$ aplicados à implementação da arquitetura descrita nesse 
projeto de doutorado. Uma forma de análise de desempenho dessa arquitetura é necessária, uma vez que há uma carência deste tópico na literatura da área. Nesse sentido, o próximo capítulo descreve todos os procedimentos utilizados para avaliar o desempenho da arquitetura WSARCH. Espera-se que essa avaliação de desempenho sirva como estudo de caso para empresas, provedores de serviços e de conteúdo, indústria e órgãos governamentais que queiram se beneficiar da computação orientada a serviço como forma de integrar aplicações, equipamentos e processos de negócios. 


\section{Validação da Arquitetura WSARCH}

\subsection{Considerações Iniciais}

Neste capítulo são descritos os projetos experimentais utilizados para validar a arquitetura WSARCH. Na Seção 5.2 é apresentado como a WSARCH foi configurada para a realização dos experimentos, incluindo as etapas de configuração do ambiente computacional (software e hardware) e o planejamento dos experimentos, ambos necessários para a fase de validação da arquitetura. A validação apresenta dois enfoques. O primeiro visa demonstrar que a arquitetura está funcionando da forma projetada. Nessa fase é realizada uma análise comportamental da WSARCH (Seção 5.3.1), e é verificado como dois componentes da arquitetura (Broker e LogServer) influenciam nos resultados da execução dos serviços (Seções 5.3.2 e 5.3.3). O segundo enfoque visa demonstrar como a arquitetura proposta atinge seu objetivo de ser uma ferramenta que possibilita avaliar o desempenho de Web Services com qualidade de serviço (Seções 5.3.4, 5.3.5 e 5.3.6). Para a realização dos testes da arquitetura foi necessário a configuração de um ambiente computacional envolvendo elementos de software e hardware. Para os elementos de software foram utilizados máquinas virtuais Java, motores de processamento de mensagens SOAP, aplicações clientes e servidoras, Broker para o roteamento de mensagens $S O A P$, além de aplicações auxiliares utilizadas para a coleta e análise dos dados proveniente dos estudos dos fatores envolvidos no planejamento de experimentos. Para os elementos de hardware foram consideradas unidades de processamento multi-core (todas homogêneas), utilizadas para o processamento de mensagens tanto no cliente quanto nos provedores de serviços. Um número considerável de experimentos podem ser analisados, no entanto, em função da natureza dinâmica da arquitetura WSARCH, alguns deles foram escolhidos para serem avaliados. 


\subsection{Avaliação de Desempenho da WSARCH}

\subsubsection{Configuração do Ambiente}

Para uma correta avaliação de desempenho de um sistema computacional, é imprescindível detalhar todos os elementos de hardware e software utilizados e verificar como tais elementos podem influenciar de forma positiva ou negativa o desempenho da arquitetura. A Tabela 5.1 apresenta a infra-estrutura computacional utilizada composta de um ambiente de testes contendo sete unidades de processamento que funcionam como provedores de serviços, uma unidade de processamento que atua como um registro de informações de serviços, oito unidades atuando como clientes e uma unidade funcionando como o Broker da arquitetura. Há também uma unidade de processamento que corresponde ao servidor de Log (LogServer) que armazena informações dos experimentos (em tempo de execução) dos componentes da arquitetura.

Tabela 5.1: Elementos de Hardware

\begin{tabular}{|c|c|c|c|}
\hline Componente & Quantidade & Tipo & Descrição \\
\hline $\begin{array}{l}\text { Service } \\
\text { Provider }\end{array}$ & 7 unidades & $\begin{array}{l}\text { Intel QuadCore Q6600 2GB de } \\
\text { RAM, HD 120GB, } 7200 \text { RPM }\end{array}$ & $\begin{array}{l}\text { Hospedar os serviços imple- } \\
\text { mentados }\end{array}$ \\
\hline UDDI & 1 unidade & $\begin{array}{l}\text { Intel QuadCore Q6600 2GB de } \\
\text { RAM, HD 120GB, } 7200 \text { RPM }\end{array}$ & $\begin{array}{l}\text { Repositório de informações de } \\
\text { serviços }\end{array}$ \\
\hline Broker & 1 unidade & $\begin{array}{l}\text { Intel QuadCore Q9400 8GB de } \\
\text { RAM, HD 500GB, } 7200 \text { RPM }\end{array}$ & $\begin{array}{l}\text { Roteamento/Escalonamento } \\
\text { de mensagens com base em } \\
\text { algoritmos de seleção de } \\
\text { serviços e índice de carga dos } \\
\text { provedores de serviços }\end{array}$ \\
\hline Clients & 8 unidades & $\begin{array}{l}4 \text { unidades (Intel QuadCore } \\
\text { Q9400 4GB de RAM, HD } \\
\text { 750GB, } 7200 \text { RPM) e } 4 \\
\text { unidades (Intel QuadCore } \\
\text { Q6600 4GB de RAM, HD } \\
\text { 320GB, 7200 RPM) }\end{array}$ & $\begin{array}{l}\text { Clientes que acessam os } \\
\text { serviços hospedados nos } \\
\text { provedores de serviços. São } \\
\text { três tipos (classes de clientes) } \\
\text { cada uma das quais contendo } \\
\text { X requisições. }\end{array}$ \\
\hline LogServer & 1 unidade & $\begin{array}{l}\text { Intel QuadCore Q9400 4GB de } \\
\text { RAM, HD 500GB, } 7200 \text { RPM }\end{array}$ & $\begin{array}{l}\text { Armazenar informações } \\
\text { em tempo de execução dos } \\
\text { componentes da arquitetura } \\
\text { (clientes, provedores, Broker, } \\
\text { Uddi) }\end{array}$ \\
\hline
\end{tabular}

Além dos elementos de hardware descritos na Tabela 5.1, a Tabela 5.2 descreve os elementos de software contemplados no desenvolvimento da arquitetura. Ainda na Tabela 5.2 há um destaque para os elementos de software utilizados como ferramentas de suporte e das ferramentas e aplicações desenvolvidas para que a arquitetura fosse concebida em sua totalidade. Os elementos assinalados com um (*) foram desenvolvidos para a WSARCH enquanto os assinalados com um (\#) foram adaptados. 
Tabela 5.2: Elementos de Software

\begin{tabular}{|c|c|c|}
\hline Nome & Descrição & Utilização \\
\hline Apache Axis2 \# & $\begin{array}{l}\text { Motor de processamento de men- } \\
\text { sagens SOAP }\end{array}$ & $\begin{array}{l}\text { Clientes, Provedores, Broker, } \\
\text { UDDI }\end{array}$ \\
\hline Apache Tomcat \# & Container de Servlets & Provedores \\
\hline JUDDI \# & $\begin{array}{l}\text { Implementação Java da especifi- } \\
\text { cação UDDI da OASIS }\end{array}$ & UDDI \\
\hline $\begin{array}{l}\text { Java Virtual Ma- } \\
\text { chine }\end{array}$ & Máquina Virtual Java & $\begin{array}{l}\text { Clientes, Provedores, Broker, } \\
\text { UDDI }\end{array}$ \\
\hline Ganglia & $\begin{array}{l}\text { Sistema de monitoração dis- } \\
\text { tribuído e escalável }\end{array}$ & Provedor, UDDI, Broker \\
\hline MySQL Server & $\begin{array}{l}\text { Sistema Gerenciador de Bancos } \\
\text { de Dados (SGBD), utilizado pelo } \\
\text { jUDDI e também pelo Broker da } \\
\text { WSARCH }\end{array}$ & UDDI, LogServer \\
\hline $\begin{array}{l}\text { WSARCH-Broker } \\
*\end{array}$ & Broker da arquitetura WSARCH & Broker \\
\hline $\begin{array}{l}\text { WSARCH- } \\
\text { LoadInfoColector } \\
*\end{array}$ & $\begin{array}{l}\text { Aplicação desenvolvida para } \\
\text { padronizar as informações obti- } \\
\text { das do daemon Gmetad do } \\
\text { Ganglia }\end{array}$ & Provedores, UDDI, Broker \\
\hline $\begin{array}{l}\text { WSARCH- } \\
\text { GeneralLoadIndex } \\
*\end{array}$ & $\begin{array}{l}\text { Aplicação desenvolvida para } \\
\text { compor um índice de carga para } \\
\text { ser utilizado pelo Broker na } \\
\text { seleção de serviços }\end{array}$ & UDDI, Broker \\
\hline WSARCH-Client * & $\begin{array}{l}\text { Aplicações clientes desenvolvidas } \\
\text { para testes da arquitetura }\end{array}$ & Clientes \\
\hline CPU-BoundApp * & $\begin{array}{l}\text { Aplicação servidora orientada ao } \\
\text { consumo de CPU }\end{array}$ & Provedores \\
\hline
\end{tabular}

\subsubsection{Planejamento dos Experimentos}

O planejamento de experimentos é uma etapa fundamental da avaliação de desempenho de sistemas computacionais e não é considerada trivial, já que é preciso definir quais dados, em que quantidade, e em que condição os dados devem ser coletados durante um determinado experimento.

Para que o planejamento de um experimento reflita nos resultados apresentados, é importante obter o máximo de informações com mínima quantidade de experimentos. Deste modo, é possível reduzir consideravelmente o esforço que seria aplicado para a realização dos experimentos. Uma análise de experimentos apropriada também auxilia na separação dos efeitos de vários fatores que podem afetar o desempenho. Além disso é possível determinar se um fator tem efeitos significativos sobre o desempenho, ou se a diferença observada é simplesmente devido os parâmetros que não são controlados ou às variações aleatórias causadas por erros de aferição (Jain, 1991). Vários são os termos utilizados durante a etapa de projeto e análise de experimentos (Jain, 1991). Dentre esses termos, vale ressaltar a variável de resposta, fatores, níveis e interação. A variável de resposta 
representa o comportamento do sistema avaliado. Os fatores são as características do sistema que afetam as variáveis de resposta e que se pretende avaliar. Os valores que um determinado fator pode assumir são denominados níveis. A interação mostra a dependência entre os fatores.

Em complemento aos termos presentes em uma avaliação de desempenho há vários tipos de técnicas utilizadas para determinar a etapa de planejamento de experimentos (Jain, 1991). As mais utilizadas são o planejamento simples, planejamento fatorial completo e o planejamento fatorial parcial. No planejamento simples, etapas básicas dessa abordagem consistem em: considerar uma configuração inicial, fixar todos os valores e variar um fator por vez, e verificar se esse fator afeta o desempenho. É fácil de ser implementado, além de ser muito utilizado. No entanto, não permite verificar a interação entre os fatores. No planejamento fatorial completo são utilizadas todas as combinações considerando todos os fatores e níveis. Com isso, todos os fatores são avaliados, o efeito de cada fator é determinado, e as interações entre fatores podem ser verificadas. O principal problema dessa abordagem é o custo da avaliação de desempenho, no qual é gerada uma grande quantidade de experimentos. Para reduzir a quantidade de experimentos gerados, pode-se reduzir o número de níveis para cada fator, reduzir o número de fatores, ou então utilizar a abordagem de fatorial parcial. A abordagem de fatorial parcial consiste em utilizar apenas uma fração do planejamento fatorial completo. Nessa abordagem considera-se apenas parte de todos os experimentos.

Para a validação da WSARCH foram considerados diversos projetos experimentais. A maioria desses projetos segue o planejamento fatorial simples, uma vez que o objetivo da avaliação de desempenho do protótipo da WSARCH é verificar o funcionamento dos componentes e a influência de fatores de forma isolada na variável de resposta escolhida e apresentada nos experimentos. Não houve preocupação nesta etapa de avaliação de desempenho em determinar a interação entre todos os fatores identificados nos experimentos. Como a WSARCH é uma arquitetura distribuída e envolve diversos componentes, muitos fatores podem e deverão ser considerados e relacionados na próximas etapas de avaliação de desempenho em trabalhos futuros.

Os experimentos apresentados neste projeto de doutorado foram conduzidos com o objetivo de considerar seis aspectos relacionados ao protótipo da WSARCH, ou seja, validação da arquitetura, sobrecarga gerada pela utilização do LogServer, sobrecarga do Broker, carga de trabalho, o tempo de processamento nos provedores de serviços e os algoritmos de diferenciação de serviços. Para atingir os objetivos especificados, definiu-se no início deste capítulo o planejamento de experimentos da WSARCH considerando os fatores e níveis descritos na Tabela 5.3.

Para todos os experimentos foram realizadas 5 execuções utilizadas para determinar a média, o desvio padrão e o intervalo de confiança de $95 \%$ de acordo com a tabela $T$-Student. O número de execuções foi definido considerando-se a necessidade de obter diferença significativa dentre os intervalos de confiança dos experimentos que implica em comparação dos resultados. A Tabela 5.4 sumariza todos os experimentos realizados.

O experimento Exp001 refere-se a um experimento inicial para destacar o funcionamento da arquitetura WSARCH. Os experimentos Exp002 e Exp003 foram realizados para determinar como 
Tabela 5.3: Fatores e níveis realativos aos experimentos

\begin{tabular}{|c|c|}
\hline Fatores & Níveis \\
\hline \hline Log & ON/OFF \\
\hline Carga de Trabalho - Tempo entre Requisições & $0-3 \mathrm{~s}$ \\
\hline Carga de Trabalho - Número de Processos & $1-6$ \\
\hline \multirow{3}{*}{ Algoritmo de Diferenciação de Serviços } & Classificação \\
\cline { 2 - 2 } & RSV (4 Gold, 3 Bronze) \\
\cline { 2 - 2 } & RSV (5 Gold, 2 Bronze) \\
\hline
\end{tabular}

Tabela 5.4: Experimentos realizados

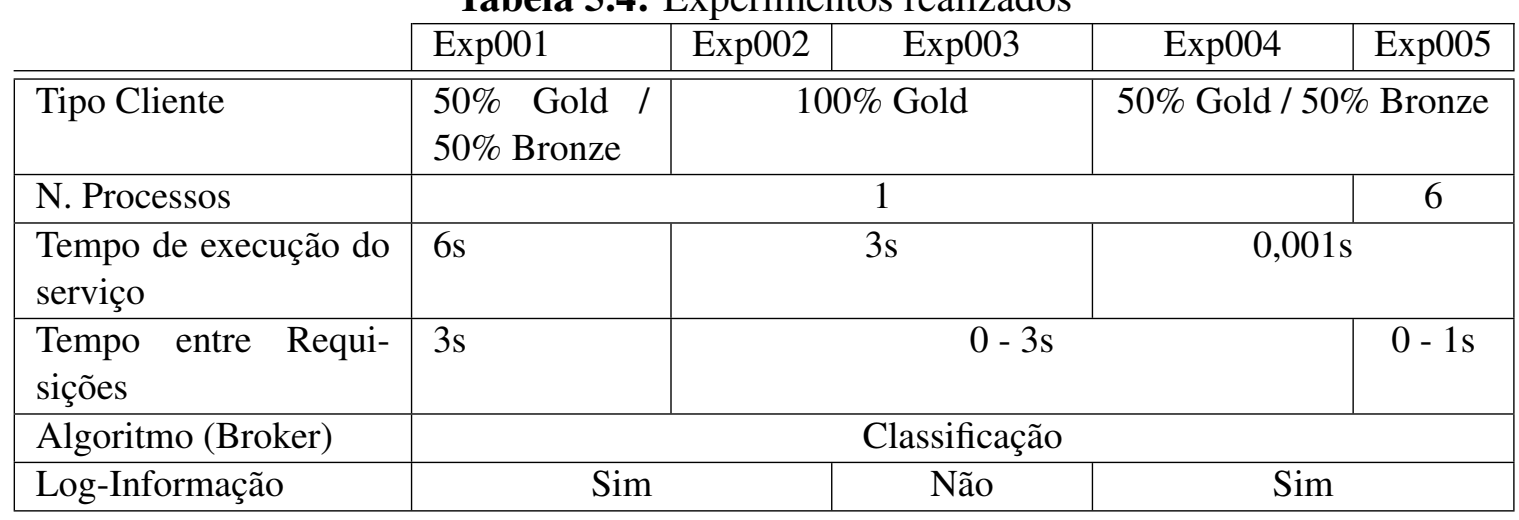

\begin{tabular}{|l|l|c|c|c|}
\cline { 2 - 5 } \multicolumn{1}{c|}{} & Exp006 & Exp007 & Exp008 & Exp009 \\
\hline Tipo Cliente & $100 \%$ Gold & \multicolumn{3}{c|}{$50 \%$ Gold / 50\% Bronze } \\
\hline N. Processos & 1 & \multicolumn{3}{|c|}{6} \\
\hline $\begin{array}{l}\text { Tempo de execução do } \\
\text { serviço }\end{array}$ & $0,001 \mathrm{~s}$ & \multicolumn{3}{|c|}{$3 \mathrm{~s}$} \\
\hline $\begin{array}{l}\text { Tempo entre Requi- } \\
\text { sições }\end{array}$ & $0-3 \mathrm{~s}$ & \multicolumn{3}{c|}{0 - 1s } \\
\hline Algoritmo (Broker) & \multicolumn{2}{|c|}{ Classificação } & RSV (4G, 3B) & RSV (5G, 2B) \\
\hline Log-Informação & \multicolumn{3}{|c|}{ Sim } \\
\hline
\end{tabular}

o LogServer pode influenciar nos resultados obtidos com a execução dos experimentos. Os experimentos Exp004 e Exp005 se destacam por apresentar o comportamento da arquitetura WSARCH mediante a variação do tempo entre as requisições. O experimento Exp006 verifica como o tempo de processamento nos provedores pode influenciar no tempo de resposta médio percebido pela aplicação cliente. Os experimentos Exp007, Exp008 e Exp009 avaliam os diferentes algoritmos de roteamento/escalonamento de mensagens implementados no Broker da arquitetura. Para todos os experimentos foram considerados 8 clientes e 7 provedores de serviços. Cada processo considera a execução de 200 requisições de serviço. Todos os serviços considerados são $C P U$-Bound. A natureza do Cluster é do tipo Livre, ou seja, somente executavam as aplicações necessárias para o funcionamento da WSARCH. 


\subsection{Análise dos Resultados}

Nesta seção são apresentados alguns resultados obtidos com o protótipo da WSARCH. Os experimentos apresentados foram conduzidos com o objetivo de considerar seis aspectos relacionados ao protótipo da WSARCH. O primeiro aspecto a ser considerado é a validação da arquitetura e a demonstração de que o protótipo desenvolvido atinge os objetivos apresentados na especificação da WSARCH. Essa validação é realizada por meio de testes que seguem as diretrizes sugeridas por (Sargent, 1999) para validação de modelos de simulação. No segundo aspecto verificou-se se o Broker, que centraliza quase toda a execução da WSARCH pode se tornar um gargalo no sistema durante a troca de informações entre os componentes da arquitetura. Essa avaliação é apresentada na Seção 5.3.2. O terceiro aspecto considerado é a quantificação da sobrecarga gerada pela utilização do LogServer. Como a WSARCH visa a avaliação de desempenho de arquiteturas orientadas a serviço, torna-se necessário coletar informações sobre os tempos envolvidos na execução de cada fase do atendimento de um serviço. Essa avaliação, descrita na Seção 5.3.3, quantifica a sobrecarga gerada nessa coleta. As Seções 5.3.4 a 5.3.6 são referentes aos testes de validação da arquitetura WSARCH em relação a variação dos fatores apresentados na Tabela 5.3. O quarto aspecto considera a carga de trabalho imposta à arquitetura a qual é discutida na Seção 5.3.4. O quinto aspecto aborda o tempo de processamento no provedor de serviços sendo este aspecto caracterizado na Seção 5.3.5. E por fim, o sexto aspecto analisado considera a utilização dos algoritmos de diferenciação de serviços implementados para efetuar o escalonamento/roteamento de mensagens na arquitetura WSARCH.

\subsubsection{Análise Comportamental}

Os resultados provenientes dos primeiros testes de funcionamento da arquitetura WSARCH não possuem propósitos comparativos e também não há nenhuma preocupação em relação ao desempenho do sistema. O principal objetivo é verificar se as informações estão sendo propagadas de forma correta e se os componentes da arquitetura estão integrados de modo a permitir que as mensagens SOAP sejam enviadas e recebidas corretamente. Diversos experimentos foram realizados com o objetivo de avaliar o comportamento da WSARCH. Nesses experimentos foram considerados diferentes níveis para os fatores definidos. Em todos os casos, consegue-se demonstrar o comportamento adequado da WSARCH. Para mostrar o funcionamento nesta tese, escolheu-se um experimento que apresenta um comportamento típico.

O primeiro caso de análise é referente ao experimento Exp001, em que pode ser verificado o funcionamento do Algoritmo de Classificação descrito na Seção 4.5.3, situação na qual é testada uma aplicação do tipo CPU-Bound, com metade dos clientes do tipo Bronze como mostra a Figura 5.1 e metade do tipo Gold, de acordo com a Figura 5.2 onde cada cliente executa um processo que envia 200 requisições. 


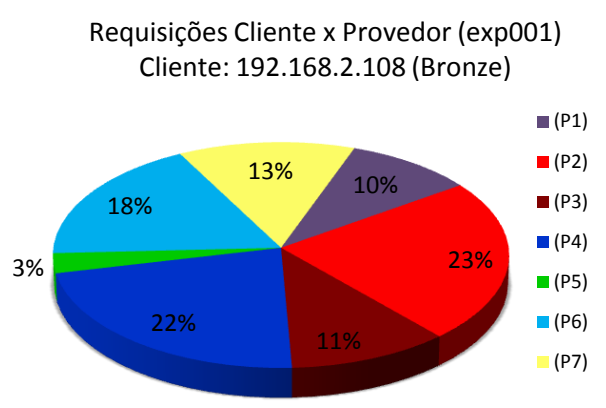

Requisições Cliente x Provedor (exp001) Cliente: 192.168.2.114 (Bronze)

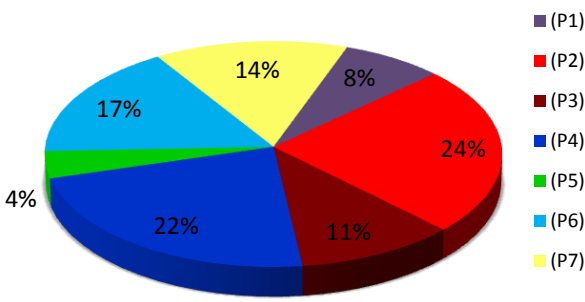

Requisições Cliente x Provedor (exp001) Cliente: 192.168.2.112 (Bronze)

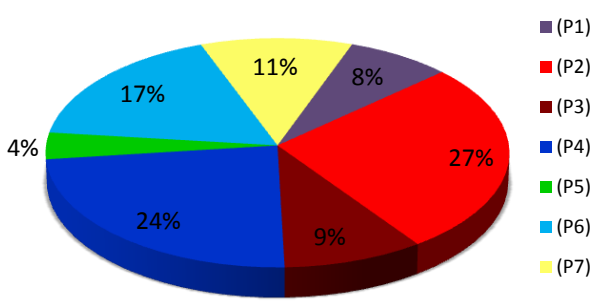

Requisições Cliente x Provedor (exp001) Cliente: 192.168.2.115 (Bronze)

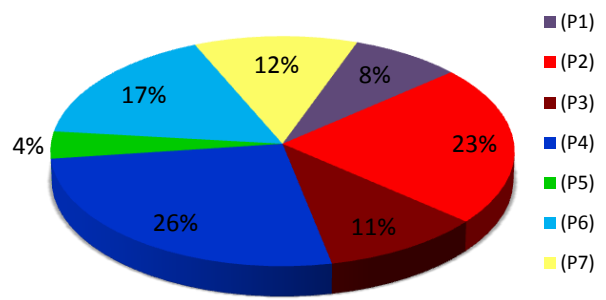

Figura 5.1: Distribuição das requisições - Cliente (Bronze) X Provedor

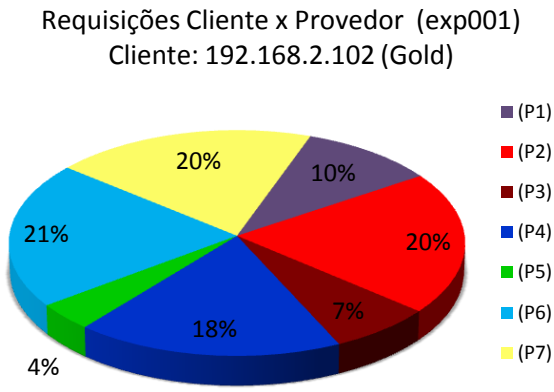

Requisições Cliente x Provedor (exp001) Cliente: 192.168.2.104 (Gold)

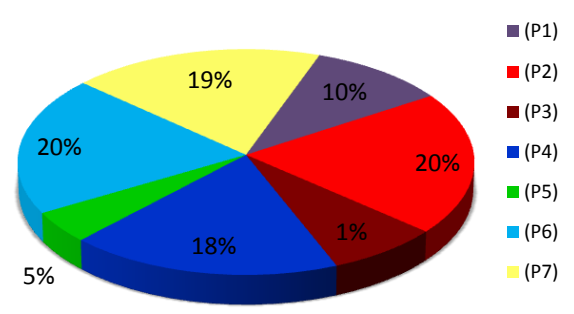

Requisições Cliente x Provedor (exp001) Cliente: 192.168.2.103 (Gold)

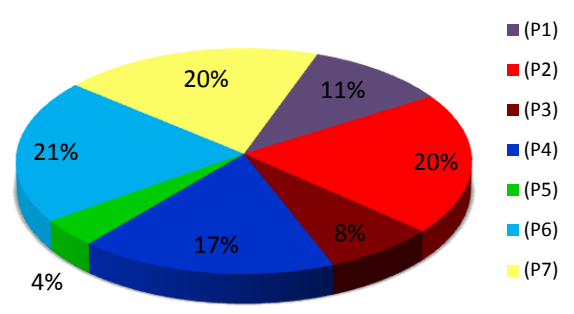

Requisições Cliente x Provedor (exp001) Cliente: 192.168.2.105 (Gold)

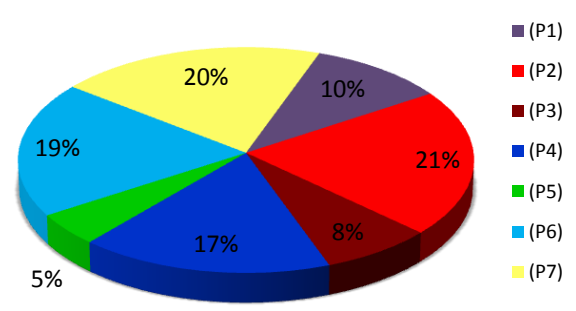

Figura 5.2: Distribuição das requisições - Cliente (Gold) X Provedor

O tempo entre requisições considerado neste experimentos é constante e igual a 3 segundos. A aplicação executada leva por volta de 6 segundos. Como são considerados 7 provedores de serviços tem-se uma situação de pouca carga para os provedores, levando a uma distribuição adequada dos clientes nos provedores de serviços. Além disso, essa parametrização facilita a avaliação dos re- 
sultados visando a validação do funcionamento da arquitetura. Os gráfico das Figuras 5.1 e 5.2 apresentam a distribuição das requisições segundo o Algoritmo de Classificação para cada um dos provedores presentes no experimento. Tanto para o cliente Gold quanto para o cliente Bronze a média de atendimento manteve-se equilibrada para todos os provedores, como é esperado devido a parametrização considerada. O Algoritmo de Classificação não considera nenhuma reserva de recursos e apenas distribui as requisições de acordo com o índice de desempenho. Isso significa que considerando todos os provedores, aquele que apresentar o melhor índice, ou seja, mais próximo de 0 (zero) será o escolhido para processar as requisições dos clientes da classe Gold. Em contrapartida, o provedor que apresentar o índice de desempenho mais próximo de 1 (um) será o escolhido para processar as requisições dos clientes da classe Bronze.

Diversos outros experimentos foram realizados e também contribuem para mostrar que a WSARCH apresenta o comportamento esperado. Esses experimentos além de validar o comportamento da arquitetura, também possibilitam outras conclusões e são apresentados nas seções específicas.

\subsubsection{Sobrecarga no Broker}

Ainda com relação ao experimento Exp001 é possível observar que a carga de trabalho imposta ao Broker da arquitetura não causou degradação no desempenho geral da arquitetura, como pode ser visualizado no gráfico da Figura 5.3. Nela são mostrados o índice de carga de $C P U\left(I C_{c p u}\right)$, índice de carga de memória $\left(I C_{\text {memory }}\right.$ ) e o índice de desempenho $(I D)$. Vale ressaltar que quanto mais próximo de zero estiver o índice melhor. Inicialmente, durante o warmup do sistema, é natural que ocorra variações nos índices até que eles se estabilizem.

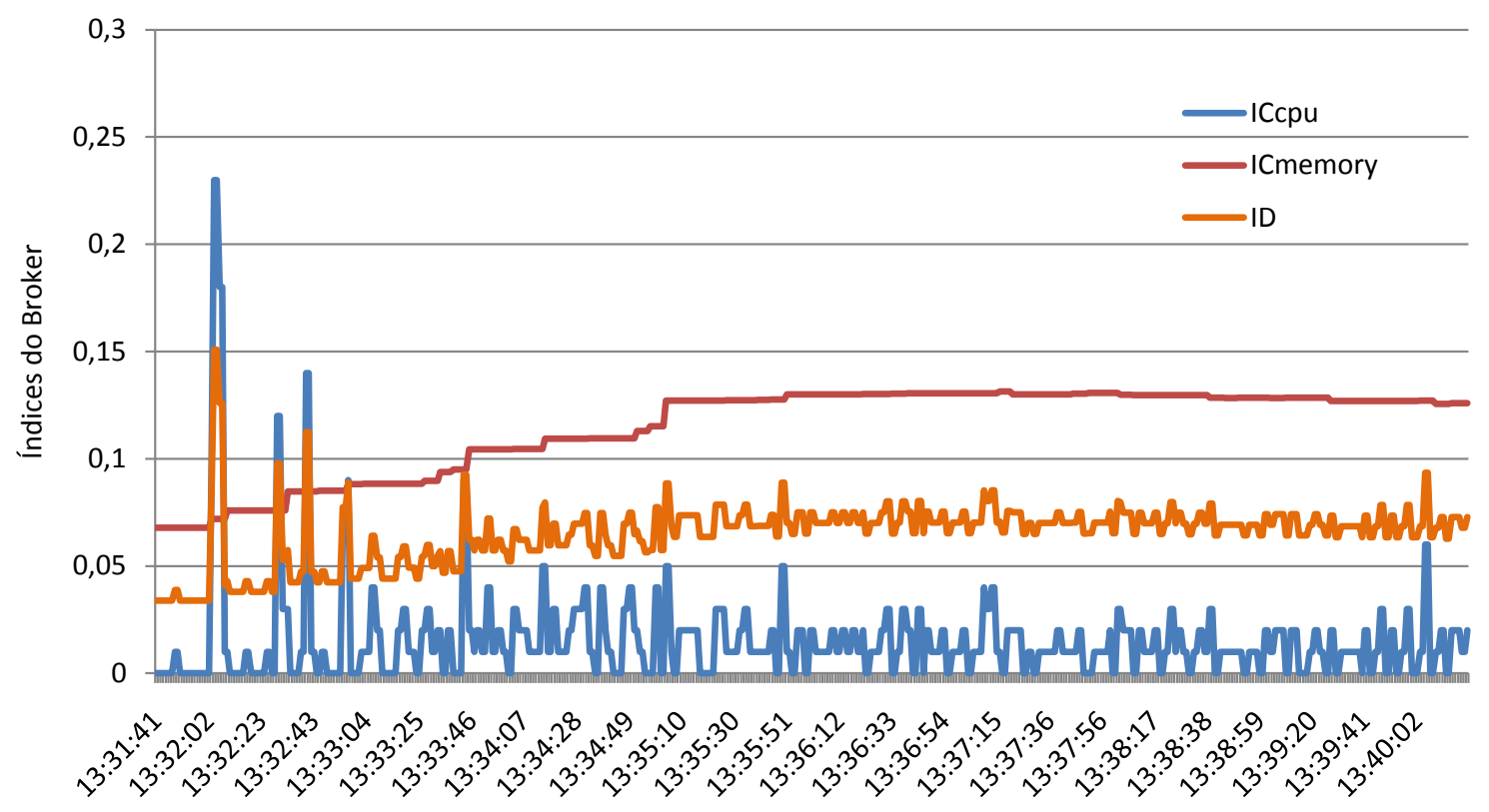

Figura 5.3: Comportamento típico do Broker da WSARCH 
O gráfico da Figura 5.3 mostra que no início do experimento tem-se algumas variações nos índices de $C P U$ e memória. Com algum tempo, os índices se estabilizam em valores bem baixo (menores que 0,15). Mesmo durante o warmup os índices não ultrapassam o índice de 0,24. A Tabela 5.5 complementa as informações do gráfico da Figura 5.3 em que é mostrado o comportamento do Broker da arquitetura em três experimentos distintos. Os dados da média e desvio padrão (DP) demonstram que mesmo ocorrendo variação da entrada de dados para os Web Services (Exp002 e Exp004), variação no tempo entre as requisições (Exp004 para Exp005) e variação na quantidade de processos por clientes, o Broker da arquitetura não sofre sobrecarga em termos de $C P U$ e memória, o que sinaliza um índice de desempenho próximo de zero.

Tabela 5.5: Média e Desvio Padrão do comportamento do Broker

\begin{tabular}{|c|c|c|c|c|c|c|}
\multicolumn{1}{c|}{} & \multicolumn{2}{c|}{ Exp002 } & \multicolumn{2}{c|}{ Exp004 } & \multicolumn{2}{c|}{ Exp005 } \\
\hline \hline & Média & D. Padrão & Média & D. Padrão & Média & D. Padrão \\
\hline Índice CPU & 0,0185 & 0,0111 & 0,02531 & 0,01229 & 0,03490 & 0,02962 \\
\hline Índice Memória & 0,0885 & 0,0021 & 0,14740 & 0,01980 & 0,16572 & 0,02610 \\
\hline Índice Desempenho & 0,0535 & 0,0057 & 0,08635 & 0,01249 & 0,10031 & 0,02246 \\
\hline
\end{tabular}

Em geral, descontada a faixa inicial (warmup inicial do experimento) o índice de desempenho do Broker da WSARCH ficou abaixo de 0,1. Nota-se também que a principal contribuição para o aumento/diminuição do índice de desempenho é o fator memória, visto que este recurso é massivamente utilizado pelos processadores de mensagens $X M L$ para extrair as informações das mensagens SOAP enviadas/recebidas por clientes e provedores de serviços. O comportamento mostrado nesta seção confirma que o Broker não representa um gargalo para a WSARCH.

\subsubsection{Sobrecarga devido ao LogServer}

Todas as atividades dos componentes da arquitetura WSARCH, incluindo tempo de processamento nos provedores, tempo de resposta das requisições dos clientes, tempo de busca, tempo de seleção de serviços, tempo de parser, dentre outros, são armazenadas em um servidor de Log. É importante ressaltar que a inclusão/exclusão do LogServer não compromete o funcionamento da arquitetura. Ou seja, se o LogServer for excluído, as interações entre os componentes continuam as mesmas. No entanto, para que fosse possível avaliar o desempenho geral da arquitetura e seus componentes foi primordial a inclusão do LogServer para que este armazenasse informações sobre tempo, processamento, vazão, etc. A inclusão do LogServer gera uma sobrecarga adicional (S) nas atividades da WSARCH, como pode ser verificado na heurística apresentada nas equações 5.1, $5.2,5.3$ e 5.4 .

$$
\begin{gathered}
S_{B R O K E R}=S_{A C E S S O_{\text {Broker }}}+S_{Q O S_{C} a l c} \\
S_{W S A R C H}=S_{B R O K E R}+S_{L O G}
\end{gathered}
$$




$$
S_{S O A}=S_{U D D I}+S_{P A R S E R}+S_{A C E S S O_{\text {Provedor }}}
$$

$$
S_{T O T A L}=S_{S O A}+S_{W S A R C H}
$$

De acordo com as equações 5.1 à 5.4 é possível observar que a sobrecarga adicional gerada pelo LogServer pode ser obtida a partir da diferença entre $S_{W S A R C H}-S_{B R O K E R}$ e evidenciada nos resultados apresentados no gráfico da Figura 5.4, referentes aos experimentos Exp002 e Exp003.

\section{Tempo médio de sobrecarga da arquitetura}

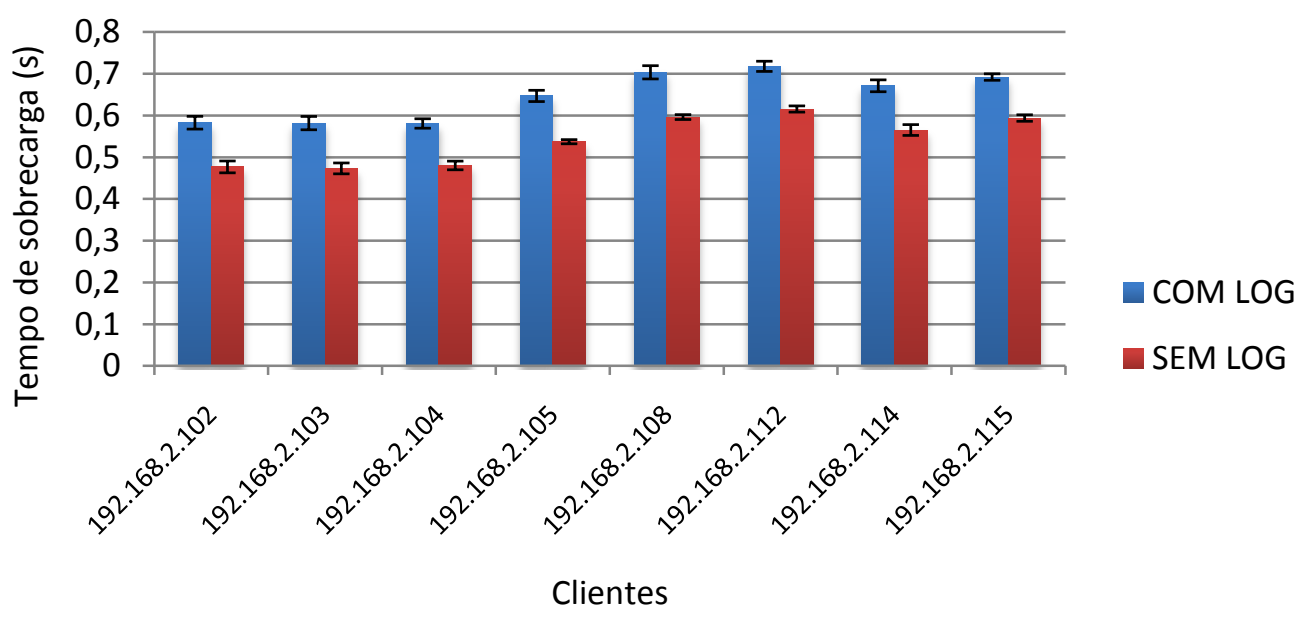

Figura 5.4: Arquitetura WSARCH com LogServer ativado/desativada

A sobrecarga do LogServer é gerada em função dos vários acessos para escrita de informações em uma base de dados relacional que armazena todos os dados dos experimentos. A Tabela 5.6 sumariza a porcentagem de aumento na sobrecarga da WSARCH, e destaca que a influência máxima do LogServer no tempo de sobrecarga na arquitetura não ultrapassa os $23 \%$.

Tabela 5.6: Média e Desvio Padrão do comportamento da WSARCH em relação ao LogServer

\begin{tabular}{|l|c|c|c|c|c|}
\cline { 2 - 5 } \multicolumn{1}{c|}{} & \multicolumn{2}{c|}{ LogServer Ativado } & \multicolumn{2}{c|}{ LogServer Desativado } & \multirow{2}{*}{ \% de aumento } \\
\cline { 2 - 5 } \multicolumn{1}{c|}{} & Média & Desvio Padrão & Média & Desvio Padrão & \\
\hline $\mathbf{1 9 2 . 1 6 8 . 2 . 1 0 2}$ (Gold) & 0,5827 & 0,0152 & 0,4769 & 0,00142 & 22,19 \\
\hline $\mathbf{1 9 2 . 1 6 8 . 2 . 1 0 3}$ (Gold) & 0,5818 & 0,159 & 0,4733 & 0,0130 & 22,92 \\
\hline $\mathbf{1 9 2 . 1 6 8 . 2 . 1 0 4}$ (Gold) & 0,5809 & 0,0112 & 0,4803 & 0,0104 & 20,93 \\
\hline $\mathbf{1 9 2 . 1 6 8 . 2 . 1 0 5}$ (Gold) & 0,6470 & 0,0135 & 0,5373 & 0,0050 & 20,41 \\
\hline $\mathbf{1 9 2 . 1 6 8 . 2 . 1 0 8}$ (Bronze) & 0,7035 & 0,0158 & 0,5963 & 0,0058 & 17,98 \\
\hline $\mathbf{1 9 2 . 1 6 8 . 2 . 1 1 2}$ (Bronze) & 0,7179 & 0,0012 & 0,6156 & 0,0074 & 16,60 \\
\hline $\mathbf{1 9 2 . 1 6 8 . 2 . 1 1 4}$ (Bronze) & 0,6712 & 0,0142 & 0,5652 & 0,0129 & 18,74 \\
\hline $\mathbf{1 9 2 . 1 6 8 . 2 . 1 1 5}$ (Bronze) & 0,6922 & 0,0077 & 0,5940 & 0,0077 & 16,53 \\
\hline
\end{tabular}

Em geral, essa sobrecarga não influi no tempo de processamento das mensagens SOAP nos provedores de serviços conforme observado no gráfico da Figura 5.5, mas sim no tempo de resposta 
final obtido pelos clientes da arquitetura WSARCH. Analisando-se o gráfico da Figura 5.5, podese concluir que não existe diferença estatística entre os tempos do experimento com o LogServer ativado e com o LogServer desativado.

\section{Tempo médio de processamento nos provedores}

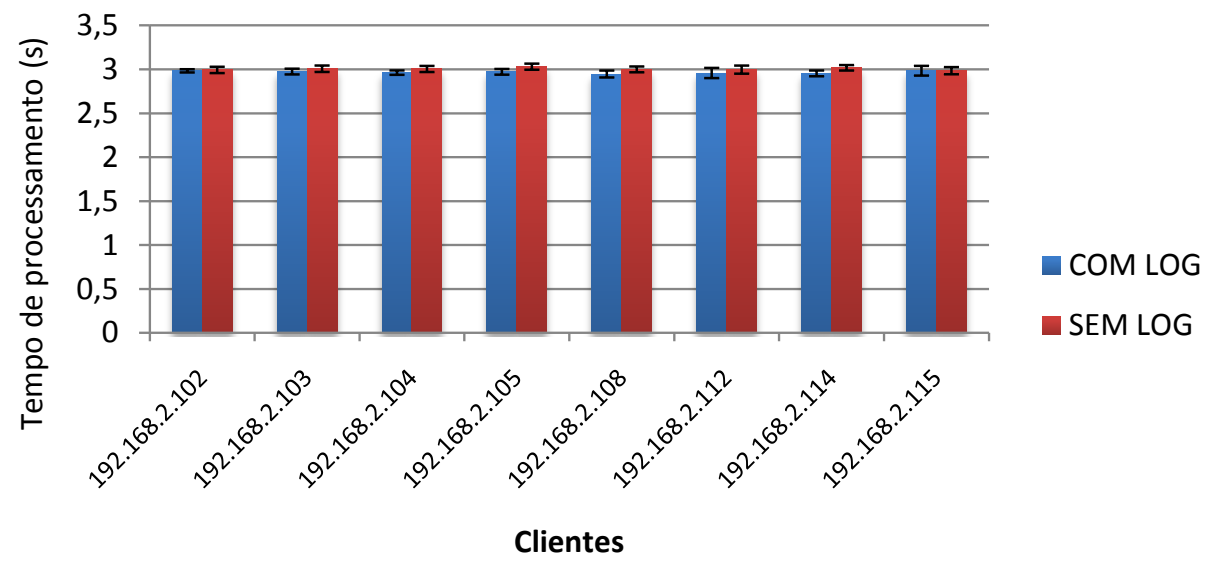

Figura 5.5: Comportamento da WSARCH quanto ao tempo de processamento nos provedores

\subsubsection{Influência da Carga de Trabalho}

Para apresentar o comportamento da arquitetura WSARCH mediante à variação da carga de trabalho foram realizados dois experimentos. No primeiro experimento Exp004 o tempo entre as requisições segue uma distribuição uniforme entre 0 e $3 \mathrm{~s}$ com um único processo ativo por cliente enviando requisições ao Broker. O experimento Exp005 apresenta um tempo entre requisições seguindo uma distribuição uniforme entre 0 e $1 \mathrm{~s}$ e com 6 processos ativos por clientes enviando requisições ao Broker da WSARCH.

\section{Tempo médio de sobrecarga da arquitetura}

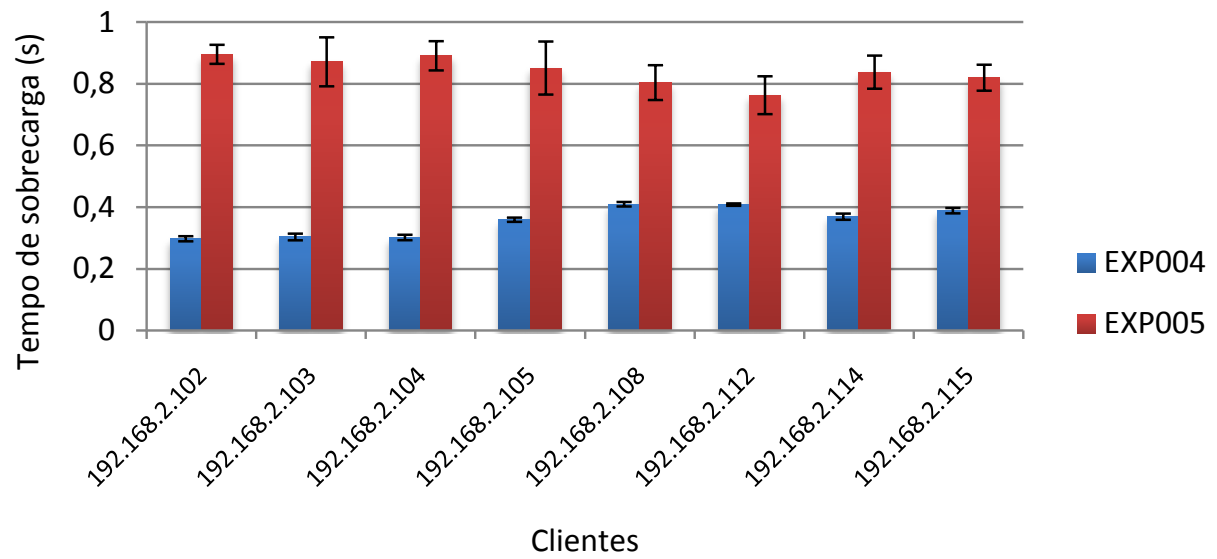

Figura 5.6: Sobrecarga da arquitetura mediante variação do tempo entre requisições 
Para avaliar a influência da carga de trabalho nos resultados da WSARCH, analisou-se a sobrecarga imposta à arquitetura e o tempo médio de resposta na WSARCH. O gráfico da Figura 5.6 evidencia o quanto a arquitetura WSARCH apresenta uma sobrecarga maior quando há uma carga de trabalho maior. Por sua vez, o gráfico da Figura 5.7 destaca como a variação do tempo entre as requisições causou impacto negativo no tempo médio de resposta para cada cliente participante do experimento.

Tempo médio de resposta

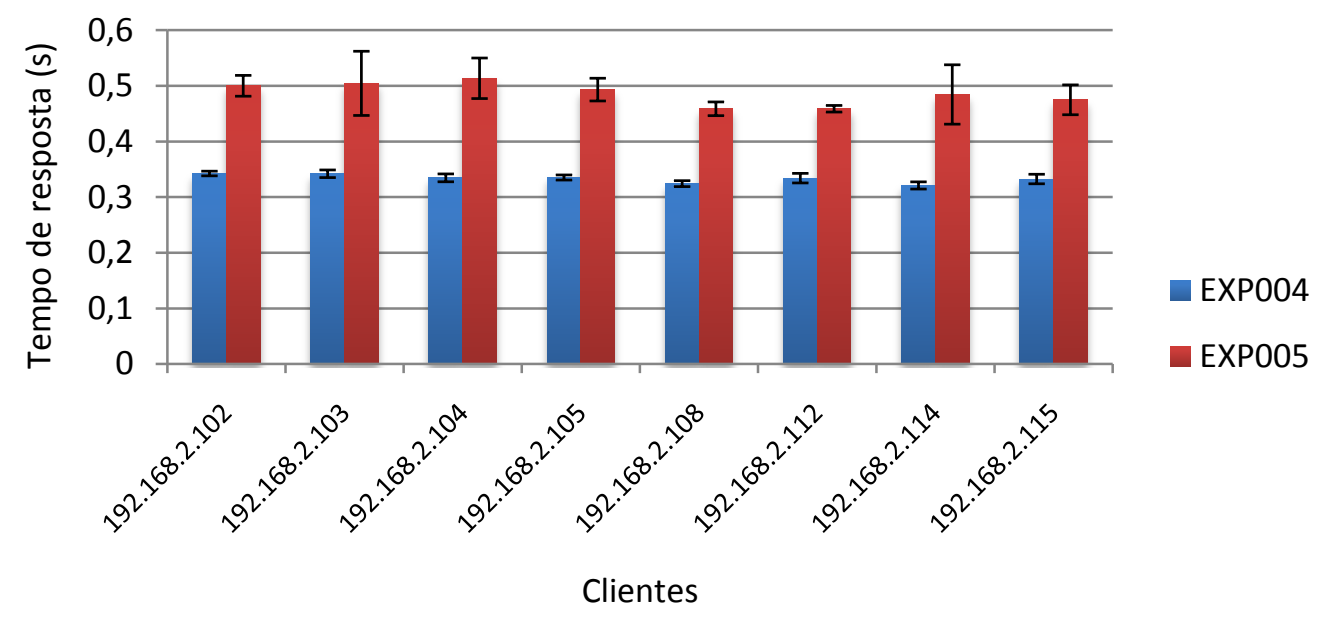

Figura 5.7: Tempo médio de resposta para os experimentos Exp004 e Exp005

Na Tabela 5.7 são apresentados o comportamento da média e o desvio padrão para 5 execuções para cada um dos clientes participantes dos experimentos. Além disso, também é mostrada a percentagem de aumento em relação à sobrecarga causada pela variação do parâmetro tempo entre as requisições e também em função do número de processos ativos.

Tabela 5.7: Média e Desvio Padrão do comportamento da WSARCH para variação do tempo entre requisições

\begin{tabular}{|c|c|c|c|c|c|}
\cline { 2 - 5 } \multicolumn{1}{c|}{} & \multicolumn{2}{c|}{ Exp004 } & \multicolumn{2}{c|}{ Exp005 } & \multirow{2}{*}{ \% de aumento } \\
\cline { 2 - 5 } \multicolumn{1}{c|}{} & Média & Desvio Padrão & Média & Desvio Padrão & \\
\hline $\mathbf{1 9 2 . 1 6 8 . 2 . 1 0 2}$ (Gold) & 0,2975 & 0,0083 & 0,8952 & 0,0308 & 200,90 \\
\hline 192.168.2.103 (Gold) & 0,3033 & 0,0107 & 0,8708 & 0,0793 & 187,10 \\
\hline 192.168.2.104 (Gold) & 0,3016 & 0,0088 & 0,8904 & 0,0473 & 195,17 \\
\hline 192.168.2.105 (Gold) & 0,3591 & 0,0068 & 0,8507 & 0,0860 & 136,85 \\
\hline $\mathbf{1 9 2 . 1 6 8 . 2 . 1 0 8}$ (Bronze) & 0,4094 & 0,0072 & 0,8035 & 0,0564 & 96,26 \\
\hline $\mathbf{1 9 2 . 1 6 8 . 2 . 1 1 2}$ (Bronze) & 0,4081 & 0,0038 & 0,7627 & 0,0613 & 86,86 \\
\hline 192.168.2.114 (Bronze) & 0,3690 & 0,0100 & 0,8373 & 0,0536 & 126,93 \\
\hline 192.168.2.115 (Bronze) & 0,3885 & 0,0087 & 0,8194 & 0,0421 & 110,89 \\
\hline
\end{tabular}

Para o resultado apresentado foram considerada uma média de 5 execuções com um intervalo de confiança de $95 \%$ de acordo com a tabela T-Student. Na próxima subseção serão discutidos os resultados referentes ao aumento no tempo de processamento nos provedores de serviços. 


\subsubsection{Tempo de Processamento nos Provedores}

Os resultados discutidos nesta seção são referentes a dois experimentos cujo o processamento nos provedores de serviços sofre variação. O experimento Exp002 corresponde a uma aplicação que executa em média 3 segundos, enquanto o experimento Exp006, corresponde a um tempo de execução de 0,001 s no provedor de serviços. Os valores de tempo de execução são determinados em função de um parâmetro de entrada enviado pela aplicação cliente, de modo que quando a mensagem SOAP é desencapsulada no provedor, o parâmetro enviado pelo cliente é utilizado pelo serviço que será executado. O serviço recebe o parâmetro e faz um cáculo que sinaliza para a utilização de $C P U$.

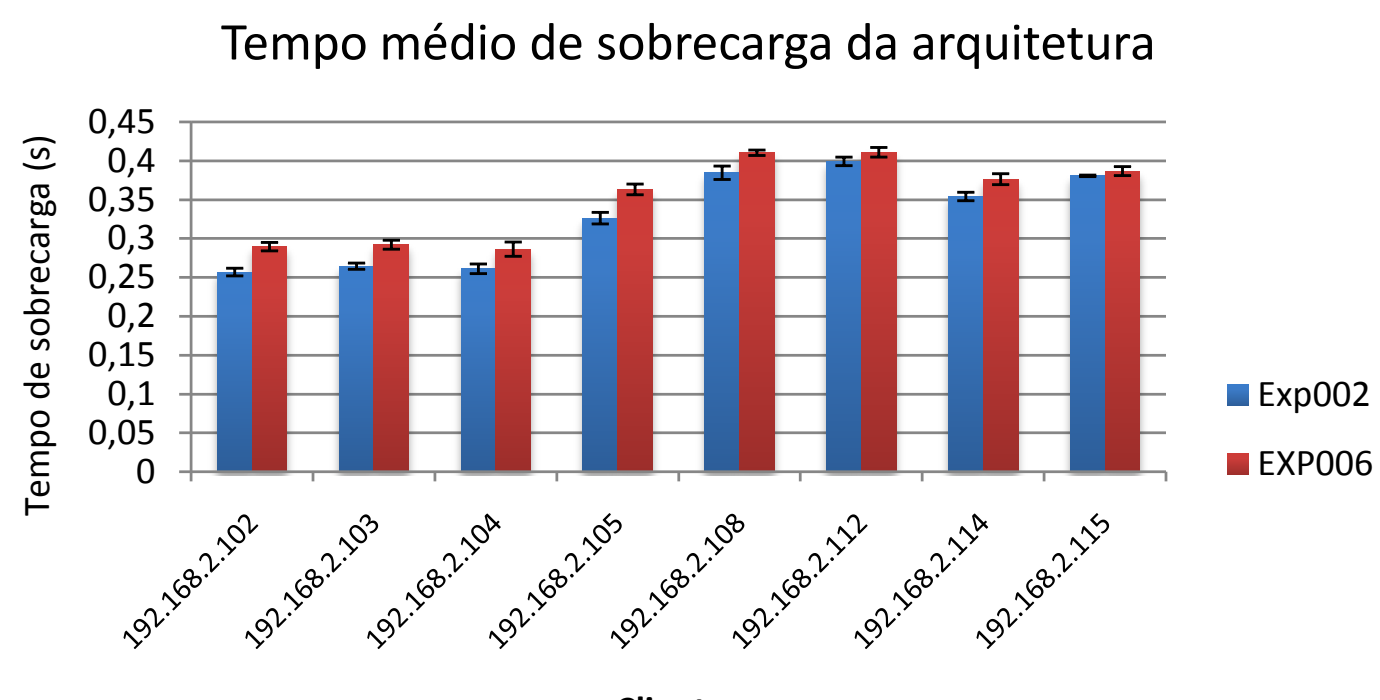

Clientes

Figura 5.8: Sobrecarga da arquitetura com variação do tempo de processamento nos provedores de serviços

A conclusão obtida com os experimentos realizados nessa fase, mantendo o mesmo fluxo de requisições para os dois experimentos, é que o tempo de processamento nos provedores apresenta pouca influência na sobrecarga imposta pela arquitetura como mostra a Figura 5.8. Os dados referentes ao experimento Exp006 mostram que nessa situação, a sobrecarga é maior em relação aos dados resultantes do experimento Exp002. Isso ocorre por que a capacidade de atendimento do Broker da arquitetura é alta em função dos recursos computacionais nele presentes (CPU e memória) conforme discutidos na Seção 5.2.2.

A influência do tempo de processamento na sobrecarga do sistema fica mais evidente na Tabela 5.8 em que são apresentados os dados referentes à média e o desvio padrão dos experimentos citados. Conforme pode ser observado, quando o tempo de processamento aumentou em 3000 mil vezes, a sobrecarga do sistema aumentou em menos de $12,7 \%$. Isso ocorre devido à sobrecarga para execução dos serviços ter pouca influência no tempo de processamento da requisição. 
Tabela 5.8: Média e Desvio Padrão do comportamento da WSARCH para variação do tempo entre requisições

\begin{tabular}{|c|c|c|c|c|c|}
\cline { 2 - 5 } \multicolumn{1}{c|}{} & \multicolumn{2}{c|}{ Exp002 } & \multicolumn{2}{c|}{ Exp006 } & \multirow{2}{*}{$\%$ de aumento } \\
\cline { 2 - 5 } \multicolumn{1}{c|}{} & Média & Desvio Padrão & Média & Desvio Padrão & \\
\hline 192.168.2.102 (Gold) & 0,2569 & 0,0049 & 0,2895 & 0,0054 & 12,70 \\
\hline 192.168.2.103 (Gold) & 0,2644 & 0,0040 & 0,2921 & 0,0057 & 10,44 \\
\hline 192.168.2.104 (Gold) & 0,2611 & 0,0061 & 0,2863 & 0,0091 & 9,68 \\
\hline 192.168.2.105 (Gold) & 0,3262 & 0,0074 & 0,3631 & 0,0068 & 11,32 \\
\hline 192.168.2.108 (Bronze) & 0,3846 & 0,0086 & 0,4103 & 0,0034 & 6,68 \\
\hline 192.168.2.112 (Bronze) & 0,3992 & 0,0054 & 0,4109 & 0,0062 & 2,93 \\
\hline 192.168.2.114 (Bronze) & 0,3541 & 0,0054 & 0,3763 & 0,0070 & 6,29 \\
\hline 192.168.2.115 (Bronze) & 0,3806 & 0,0009 & 0,3867 & 0,0057 & 1,61 \\
\hline
\end{tabular}

O tempo médio de resposta sofre modificações proporcionais ao tempo de processamento, uma vez que esse é um componente do tempo de resposta final. Ou seja, quando o tempo de processamento aumenta, a lógica é que o tempo de resposta final percebido pelo cliente também aumente, como mostra o gráfico da Figura 5.9.

\section{Tempo médio de resposta}

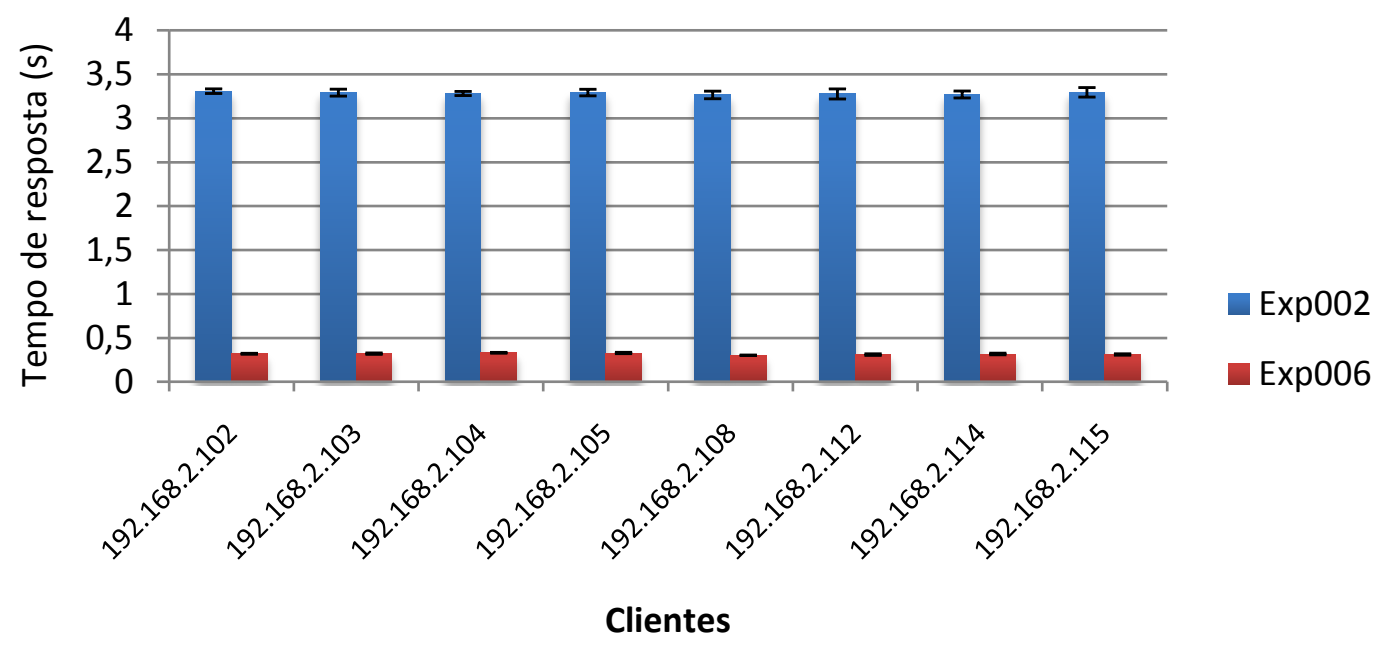

Figura 5.9: Tempo médio de resposta da arquitetura para diferentes clientes

\subsubsection{Algoritmo de Escalonamento de Mensagens}

Um teste importante também realizado para validar a arquitetura WSARCH foi considerar diferentes algoritmos de roteamento/escalonamento de mensagens. Os dois algoritmos implementados apresentam características simples quanto à diferenciação de serviços, mas cumprem com o propósito de escalonar/rotear mensagens de acordo com critérios pré-determinados. Devido a característica modular da arquitetura WSARCH é possível implementar novos algoritmos de escalonamento no Broker da arquitetura considerando técnicas de inteligência artificial, ontologias, dentre 
outros. No contexto da validação da arquitetura, dois algoritmos são utilizados: Algoritmo de Classificação e o Algoritmo de Reserva de Recursos, ambos discutidos na seção 4.5.3 desta tese.

\section{Algoritmo de Classificação}

Considerando os algoritmos implementados, os primeiros resultados correspondem ao experimento Exp007, situação em que são mostradas a classificação das requisições para os clientes da classe Bronze de acordo com a Figura 5.10 e para os clientes da classe Gold segundo a Figura 5.11.
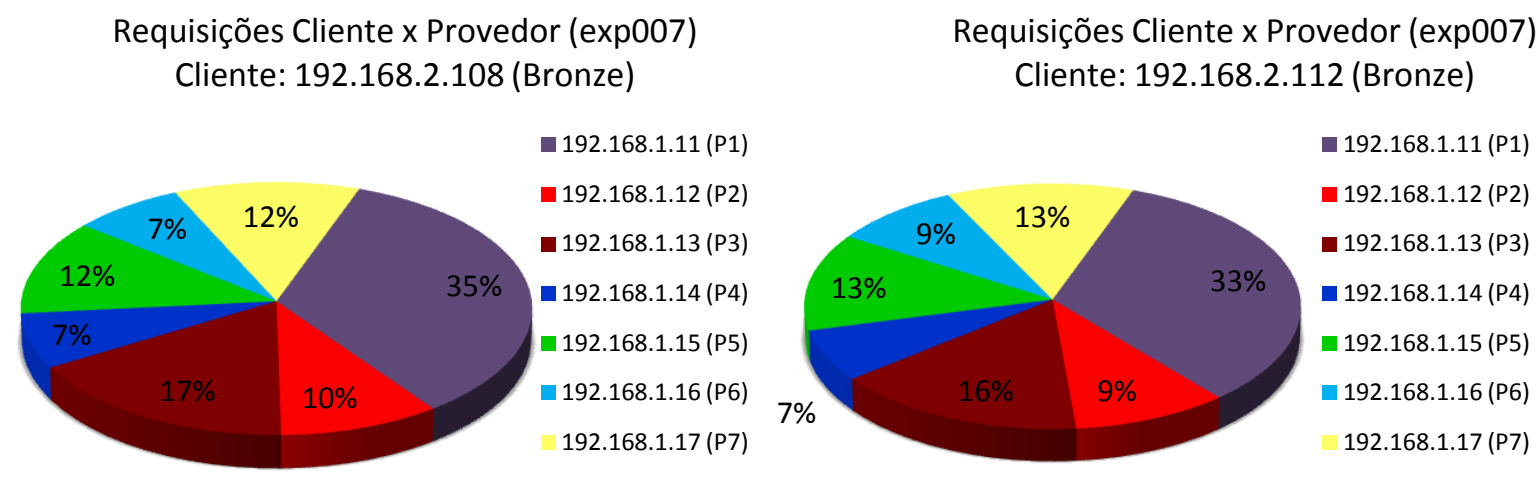

Requisições Cliente x Provedor (exp007) Cliente: 192.168.2.114 (Bronze)

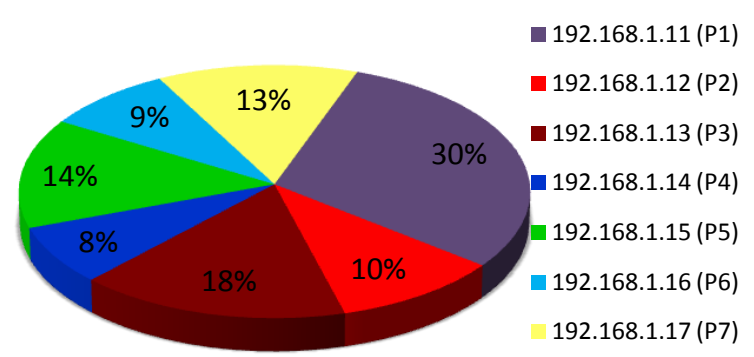

Requisições Cliente x Provedor (exp007) Cliente: 192.168.2.115 (Bronze)

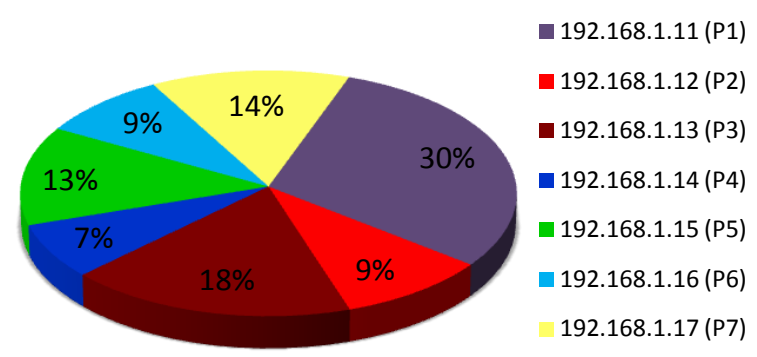

Figura 5.10: Algoritmo de Classificação - 50\% Bronze

Uma ocorrência importante de se notar é uma maior concentração de requições para um determinado provedor da classe Bronze ( $\mathrm{P} 1->30 \%$ em média). Isso se deve ao fato do provedor ser o pior da lista de provedores que o Broker obteve no momento de escolha para realizar a requisição solicitada pelo cliente ao provedor de serviços. Esse provedor acabou sendo o mais penalizado e por esse motivo o mais escolhido para a classe de serviço, uma vez que seu índice de desempenho não apresentou melhorias.

Outra constatação é que o tempo médio de resposta também é maior para os clientes da classe Bronze em relação aos clientes da classe Gold como mostra o gráfico da Figura 5.12. Para os provedores da classe Gold as requisições foram distribuídas mais uniformemente.

Em relação ao tempo médio dos elementos de $S O A$ (elementos que fazem parte de uma arquitetura SOA original, sem a presença do Broker de serviços e do LogServer), ocorre um comporta- 
Requisições Cliente x Provedor (exp007) Cliente: 192.168.2.102 (Gold)

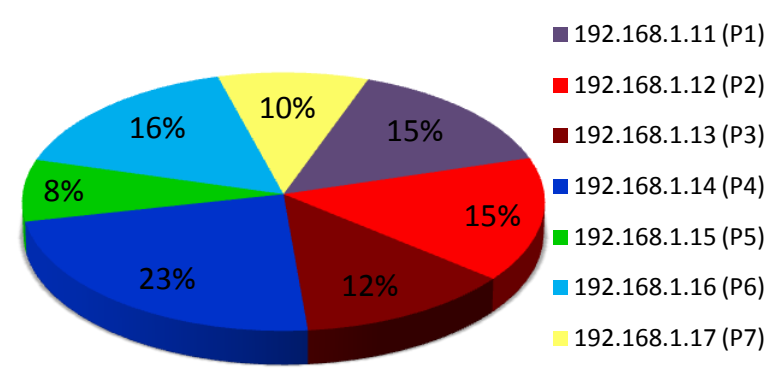

Requisições Cliente x Provedor (exp007) Cliente: 192.168.2.104 (Gold)

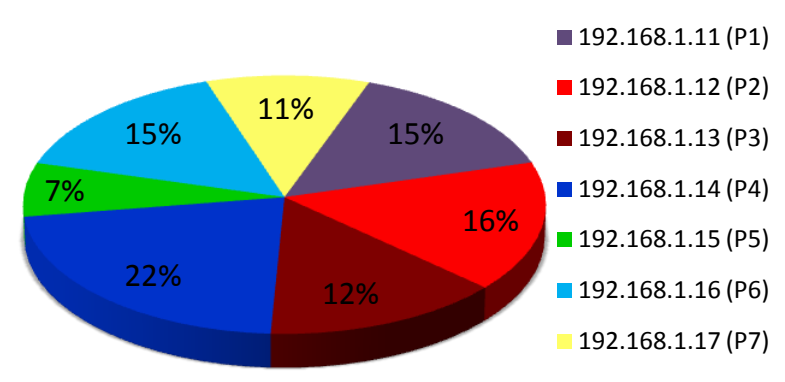

Requisições Cliente x Provedor (exp007) Cliente: 192.168.2.103 (Gold)

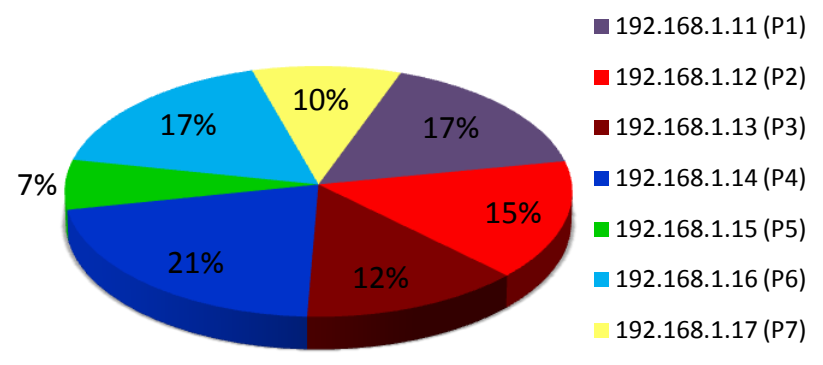

Requisições Cliente x Provedor (exp007) Cliente: 192.168.2.105 (Gold)

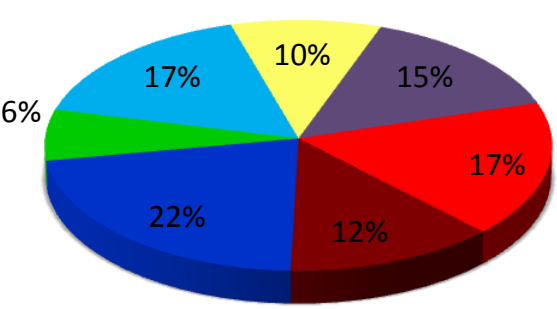

— 192.168.1.11 (P1)

- 192.168.1.12 (P2)

— 192.168.1.13 (P3)

— 192.168.1.14 (P4)

- 192.168.1.15 (P5)

— 192.168.1.16 (P6)

192.168.1.17 (P7)

Figura 5.11: Algoritmo de Classificação - 50\% Gold

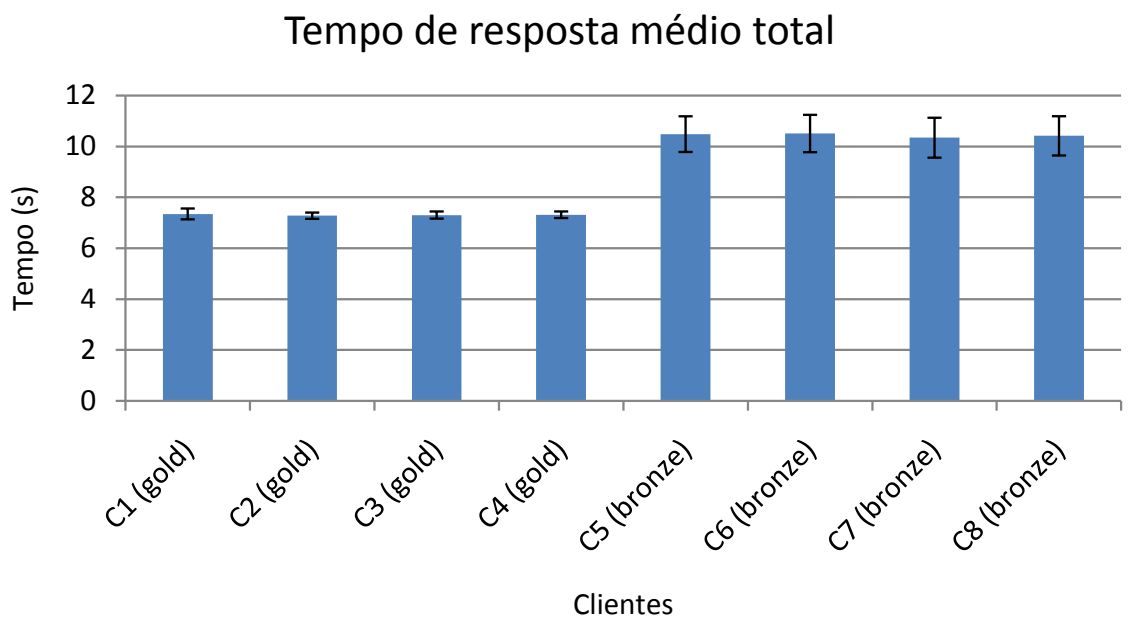

Figura 5.12: Tempo médio de resposta para clientes Gold e Bronze

mento parecido com o parâmetro tempo de resposta médio para os clientes da classe Bronze, como destaca o gráfico da Figura 5.13. 


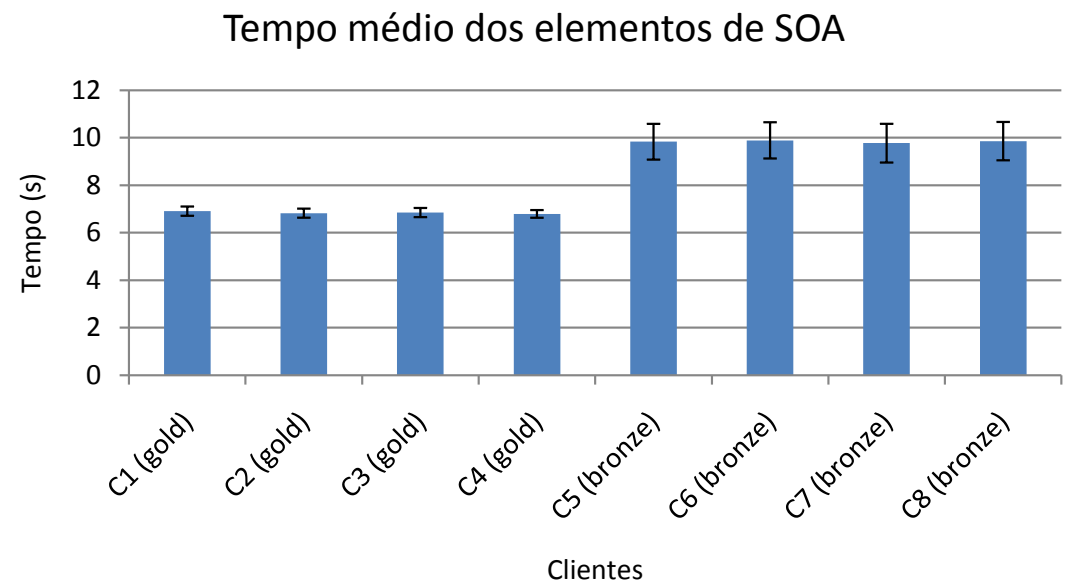

Figura 5.13: Clientes da classe Gold e Bronze x Tempo médio de SOA

Em relação ao tempo médio de sobrecarga da arquitetura WSARCH observa-se que este é maior para os clientes da classe Bronze em relação aos clientes da classe Gold, como mostra o gráfico da Figura 5.14. Isso ocorreu devido ao fato dos clientes da classe Gold executarem nas máquinas com maior potência computacional, conforme apresentado na Tabela 5.1.

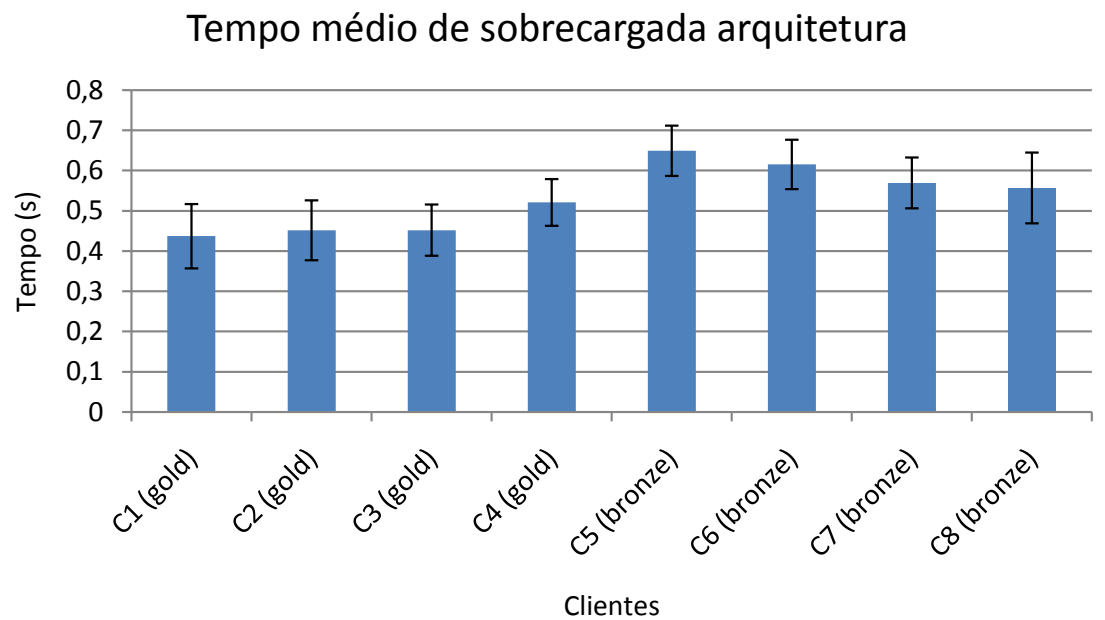

Figura 5.14: Sobrecarga da arquitetura para Clientes Gold e Bronze

Outro ponto importante a ser discutido é destacado no gráfico da Figura 5.15. O tempo de processamento médio por provedor de serviços para clientes da classe Bronze é maior em relação aos clientes da classe Gold, visto que há uma penalização intríseca para os clientes da classe Bronze que sempre tem suas requisições atendidas nos provedores que apresentam o pior índice de desempenho no instante de seleção dos provedores pelo Broker da arquitetura WSARCH. 


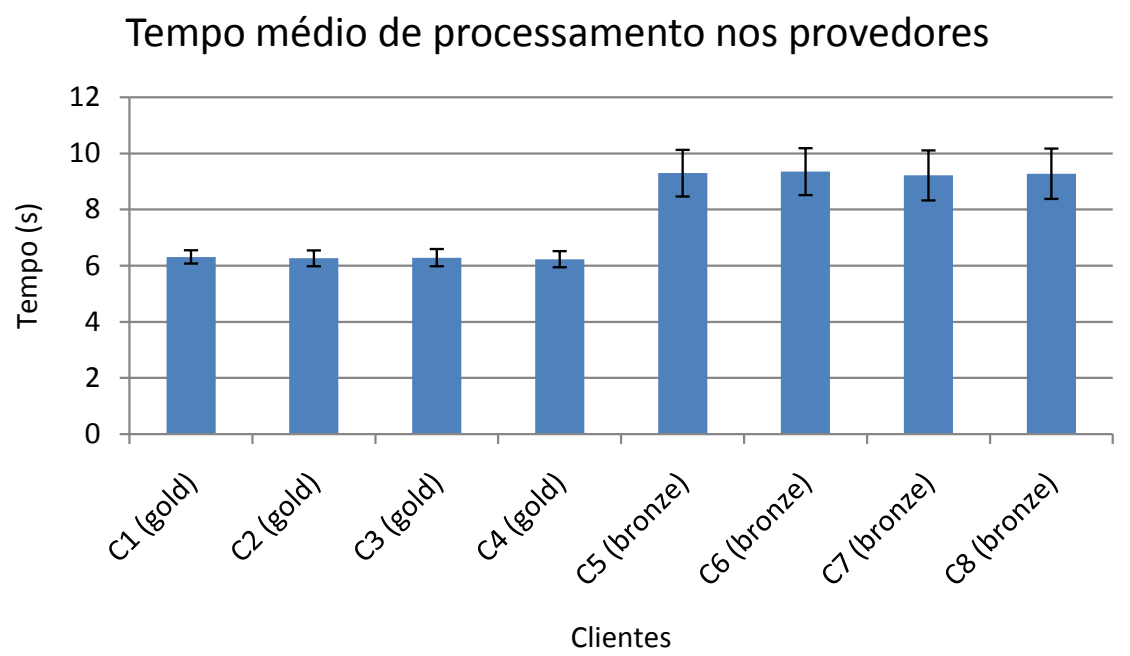

Figura 5.15: Tempo de processamento médio: Clientes Gold x Clientes Bronze

\section{Algoritmo de Reserva de Recursos}

Ainda em relação a implementação dos algoritmos de roteamento/escalonamento, dois experimentos foram realizados baseado na utilização do Algoritmo de Reserva de Recursos.

- Exp008: 4 provedores para clientes da classe Gold e 3 provedores para clientes da classe Bronze

- Exp009: 5 provedores para clientes da classe Gold e 2 provedores para clientes da classe Bronze

A análise do experimento Exp008 apresenta resultados que comprovam a diferenciação de serviços se comparados com os resultados provenientes do experimento em que foi utilizado o Algoritmo de Classificação. Naquela ocasião, nenhuma reserva de recursos foi feita e assim as requisições não eram distribuídas de forma equitativa. A reserva de recursos para as classes de serviços associadas com o índice de desempenho faz com que requisições de cliente da classe Gold somente sejam processadas pelos recursos alocados a essa classe. O mesmo ocorre com requisições de clientes da classe Bronze os quais têm suas requisições atentidas somente pelos recursos previamente alocados.

Os algoritmos implementados funcionam como prova de conceito para verificar a ocorrência de diferenciação de serviços, porém, a arquitetura WSARCH possui suporte para que novos algoritmos possam ser implementados e comparados com os já existentes. Como observado, os gráficos das Figuras 5.16 e 5.17 detalham como ocorreu a distribuição das requisições obedecendo os recursos disponibilizados para as classes de serviços, Bronze e Gold respectivamente.

Quando a configuração do experimento Exp008 é considerada, não pode-se afirmar estatisticamente que houve diferenciação de serviços em relação ao tempo de resposta médio total, como 
Requisições Cliente x Provedor (exp008) Cliente: 192.168.2.108 (Bronze)

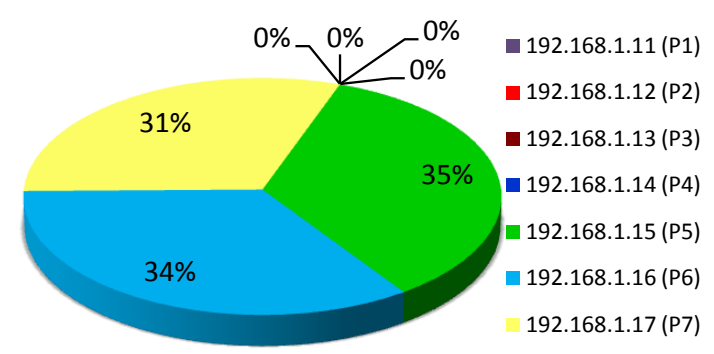

Requisições Cliente x Provedor (exp008) Cliente: 192.168.2.114 (Bronze)

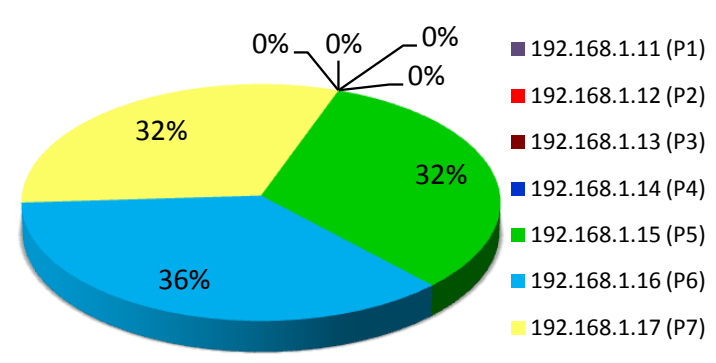

Requisições Cliente x Provedor (exp008) Cliente: 192.168.2.112 (Bronze)

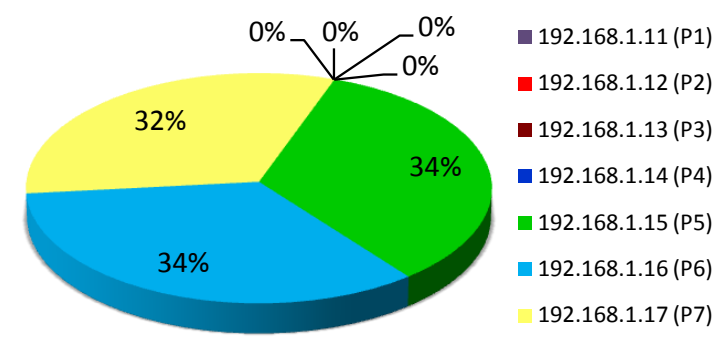

Requisições Cliente x Provedor (exp008) Cliente: 192.168.2.115 (Bronze)

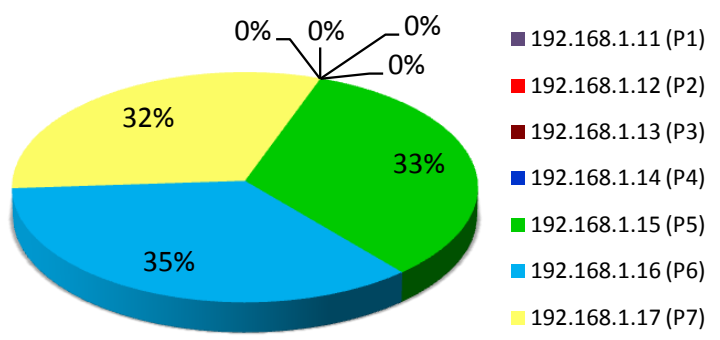

Figura 5.16: Algoritmo de Reserva de Recursos com 3 provedores para a classe Bronze

Requisições Cliente x Provedor (exp008) Cliente: 192.168.2.102 (Gold)

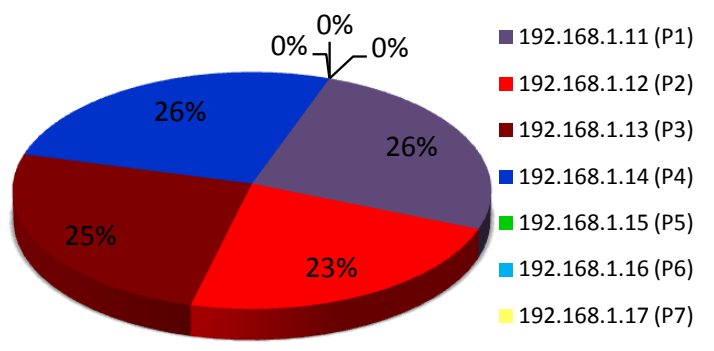

Requisições Cliente x Provedor (exp008) Cliente: 192.168.2.104 (Gold)

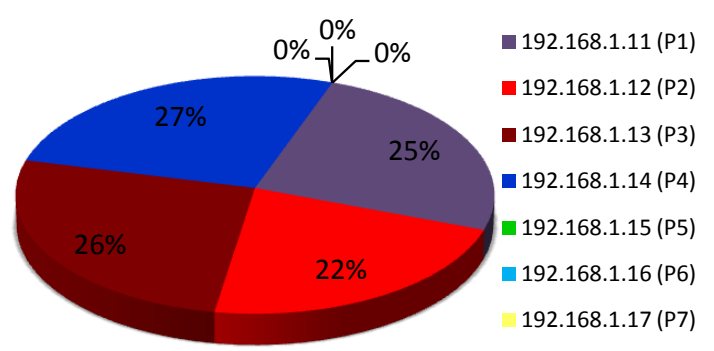

Requisições Cliente x Provedor (exp008) Cliente: 192.168.2.103 (Gold)

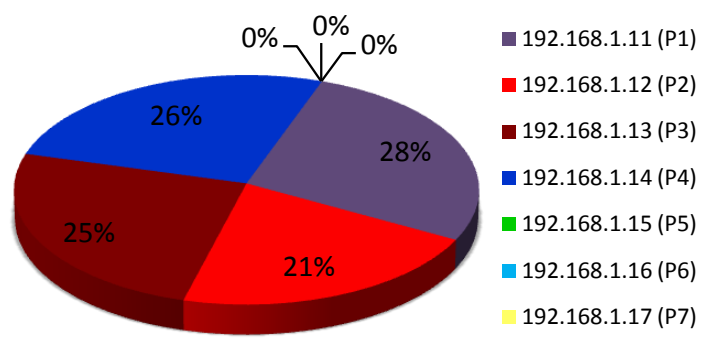

Requisições Cliente x Provedor (exp008) Cliente: 192.168.2.105 (Gold)

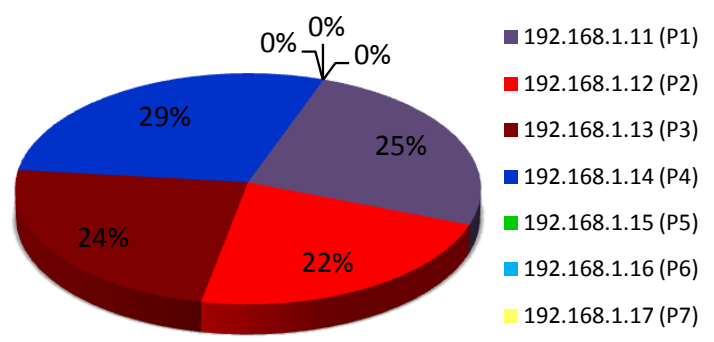

Figura 5.17: Algoritmo de Reserva de Recursos com 4 provedores para a classe Gold 
fica evidente no gráfico da Figura 5.18. A pequena diferença dos recursos alocados para as duas classes não foi suficiente para permitir uma diferenciação no tempo.

\section{Tempo de resposta médio total}

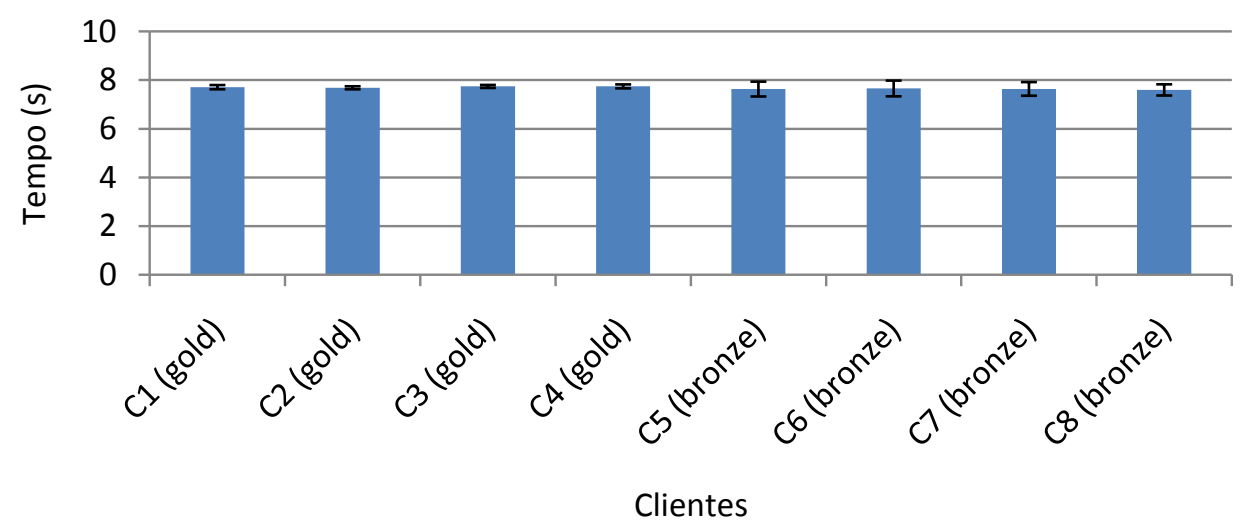

Figura 5.18: Não ocorrência da diferenciação de serviços em relação ao tempo médio de resposta

A mesma situação em relação a não ocorrência da diferenciação aparece também no tempo médio dos elementos de $S O A$, de acordo com o gráfico da Figura 5.19, uma vez que a diferença na quantidade de recursos disponíveis é pequena, e não reflete positivamente nos resultados.

Tempo médio dos elementos de SOA

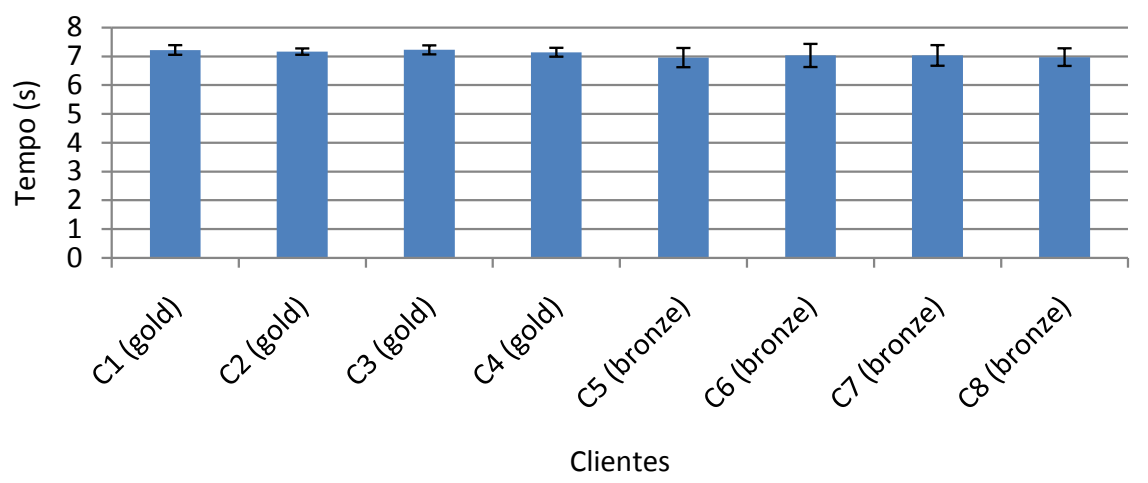

Figura 5.19: Não ocorrência da diferenciação em relação ao elementos de SOA

No entanto, quando consideramos a sobrecarga da WSARCH foi observado que esta é menor para os clientes da classe Gold em relação aos clientes da classe Bronze, como mostra o gráfico da Figura 5.20. Os clientes da classe Bronze executarem nas máquinas com menor poder computacional, as quais são descritas na Tabela 5.1.

A situação em relação à diferenciação de serviços permanece parecida quando são comparados os tempos de processamento médios para as classes Gold e Bronze respectivamente como é destacado no gráfico da Figura 5.21. 


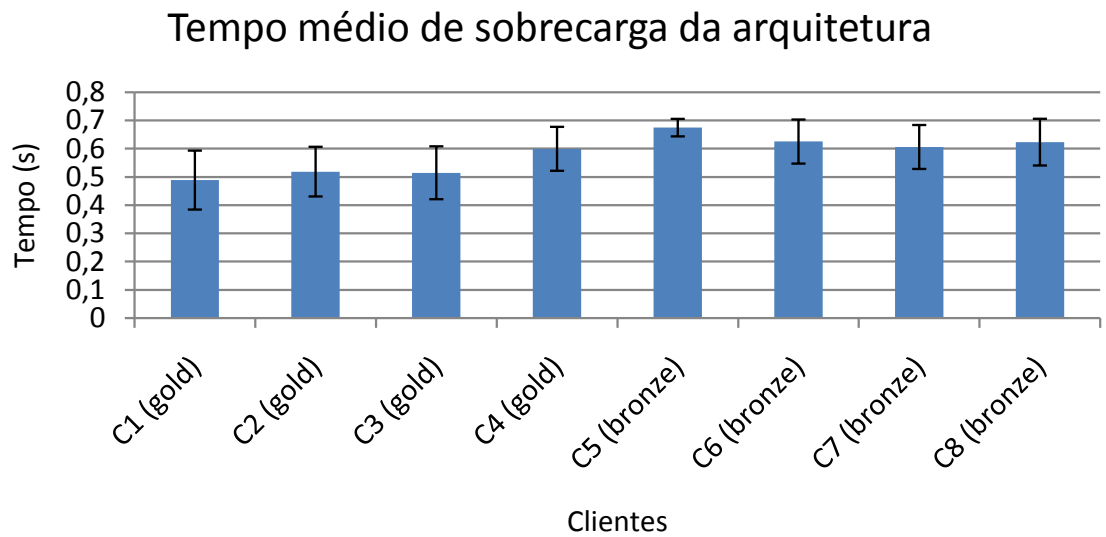

Figura 5.20: Diferenciação de serviços considerando a sobrecarga da WSARCH Tempo médio de processamento nos provedores

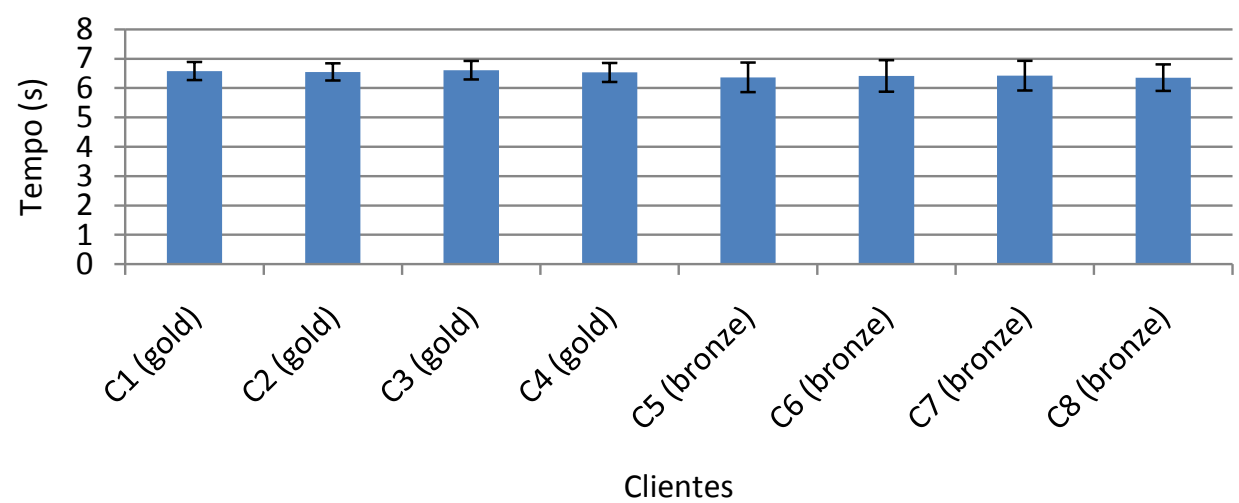

Figura 5.21: Não ocorrência da diferenciação de serviços para o tempo médio de processamento

Os resultados que ilustram efetivamente a diferenciação de serviços com o algoritmo de reserva de recursos aparece no experimento Exp009, quando é aumentada a quantidade de recursos para a classe Gold e diminuído os recursos para a classe Bronze, como mostram os gráficos das Figuras 5.22 e 5.23. Diferentemente do experimento Exp008, a nova redistribuição dos recursos deve colaborar para uma melhor qualidade de serviço para os clientes da classe Gold, através da melhoria do tempo de resposta médio total, do tempo de sobrecarga de SOA e do tempo de processamento nos provedores de serviços em relação aos clientes da classe Bronze.

No gráfico da Figura 5.24 é visível a diferenciação de serviços para os clientes da classe Gold em relação aos clientes da classe Bronze.

A diferenciação também aparece quando é analisado o tempo de médio dos elementos de $S O A$, de acordo com o gráfico da Figura 5.25.

Para a sobrecarga da arquitetura WSARCH, como mostra o gráfico da Figura 5.26, observa-se que o tempo médio é maior para os clientes da classe Bronze em relação àqueles da classe Gold. Os clientes da classe Gold executaram nas máquinas com melhor hardware, de acordo com os 
Requisições Cliente x Provedor (exp009) Cliente: 192.168.2.108 (Bronze)

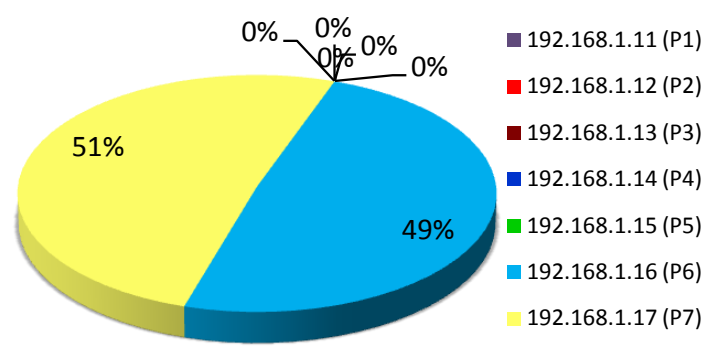

Requisições Cliente x Provedor (exp009) Cliente: 192.168.2.114 (Bronze)

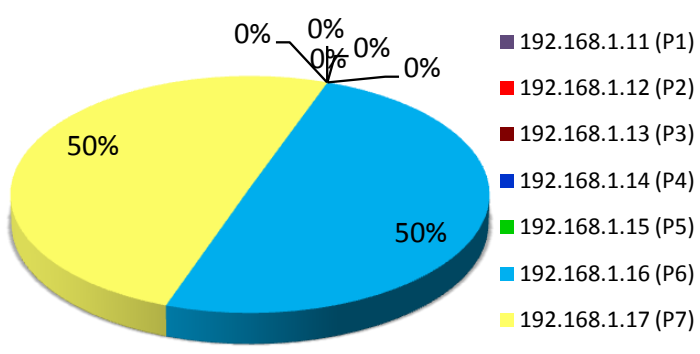

Requisições Cliente x Provedor (exp009) Cliente: 192.168.2.112 (Bronze)

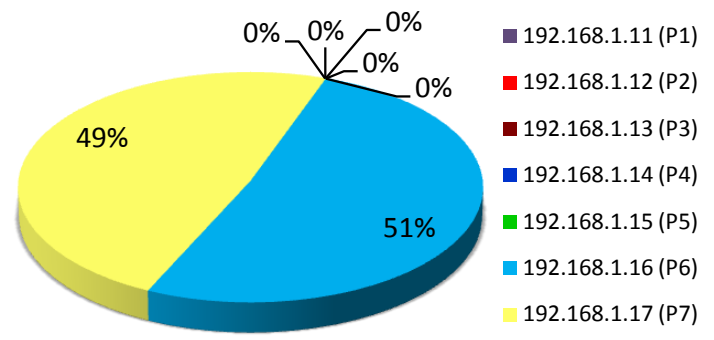

Requisições Cliente x Provedor (exp009) Cliente: 192.168.2.115 (Bronze)

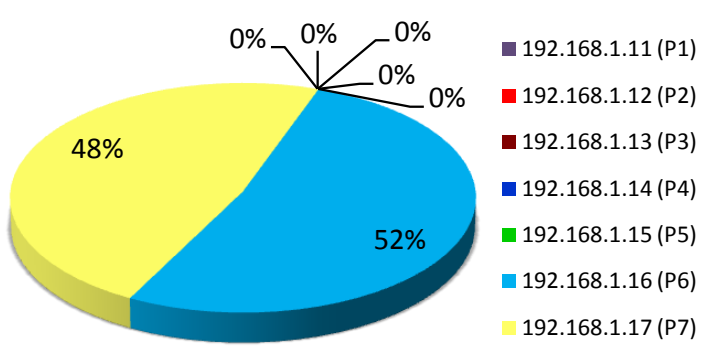

Figura 5.22: Algoritmo de Reserva de Recursos com 2 provedores para a classe Bronze

Requisições Cliente x Provedor (exp009) Cliente: 192.168.2.102 (Gold)

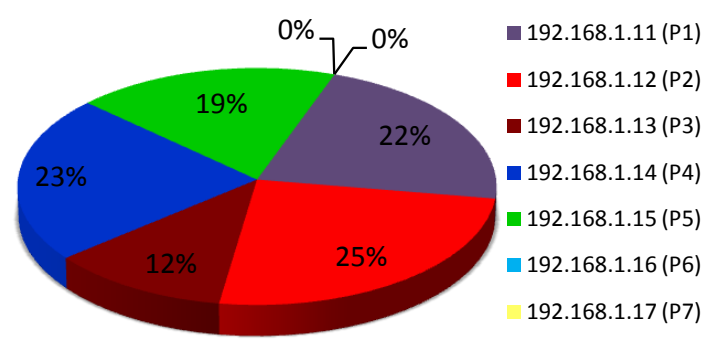

Requisições Cliente x Provedor (exp009) Cliente: 192.168.2.104 (Gold)

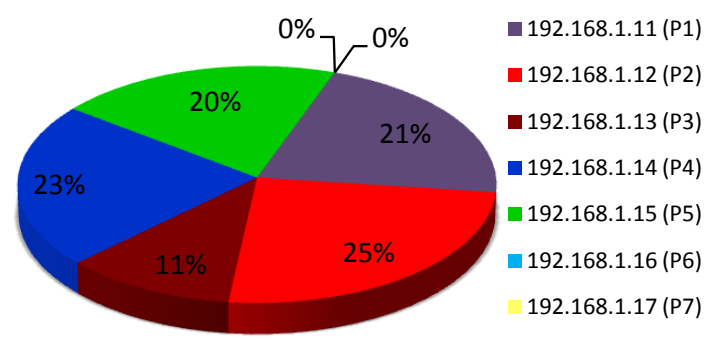

Requisições Cliente x Provedor (exp009) Cliente: 192.168.2.103 (Gold)

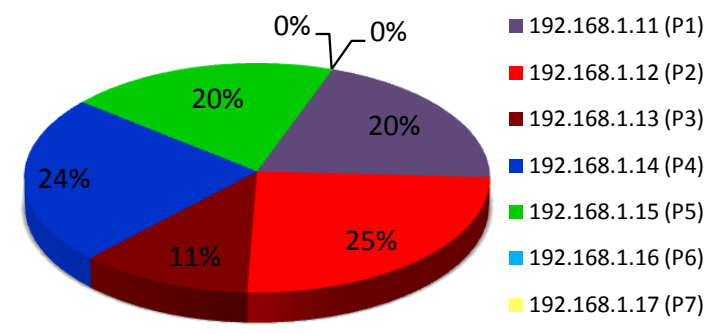

Requisições Cliente x Provedor (exp009) Cliente: 192.168.2.105 (Gold)

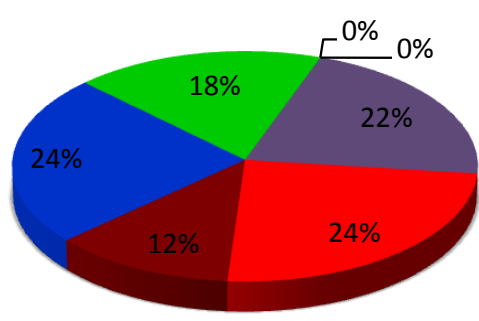

— 192.168.1.11 (P1) — 192.168.1.12 (P2) — 192.168.1.13 (P3) - 192.168.1.14 (P4) — 192.168.1.15 (P5) — 192.168.1.16 (P6) 192.168.1.17 (P7)

Figura 5.23: Algoritmo de Reserva de Recursos com 5 provedores para a classe Gold 
Tempo de resposta médio total

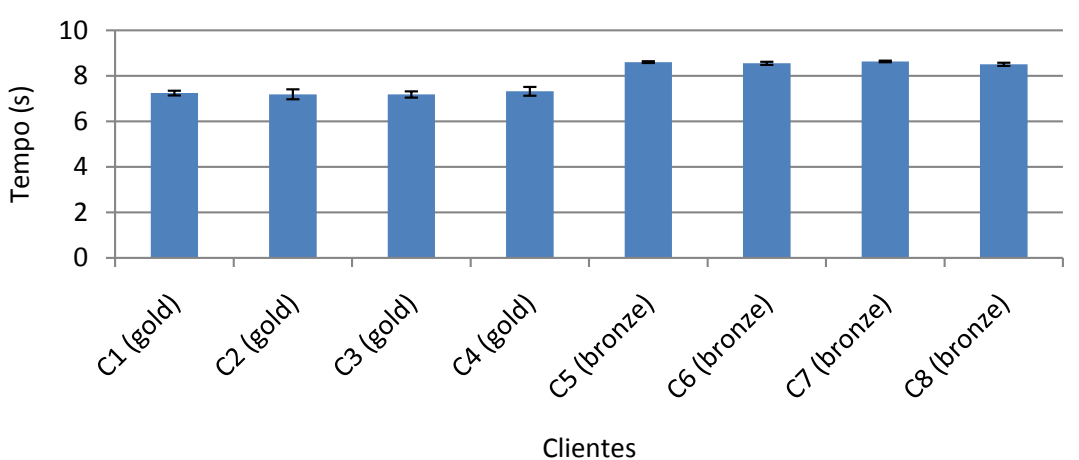

Figura 5.24: Diferenciação de serviços para diferentes clientes

Tempo médio dos elementos de SOA

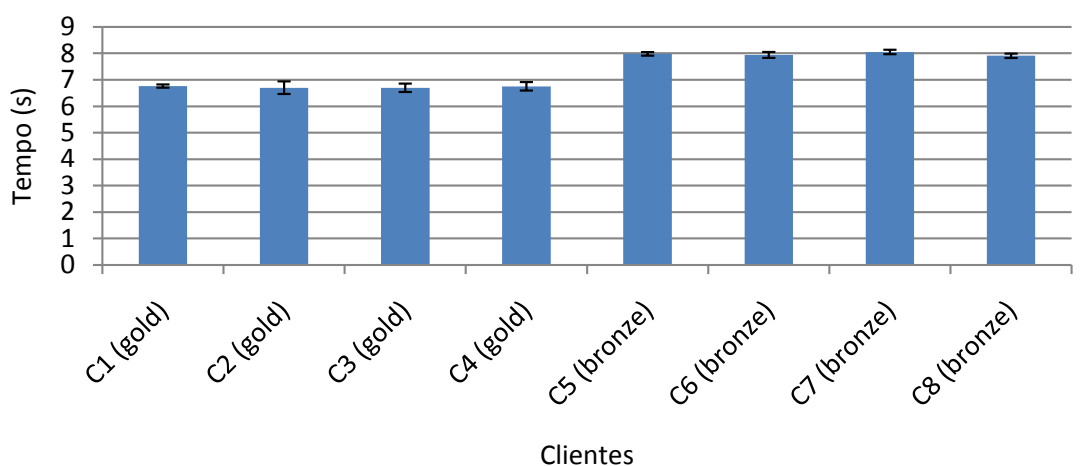

Figura 5.25: Diferenciação de serviços considerando os elementos de SOA

dados da Tabela 5.1, contribuindo para o aumento da sobrecarga quando considera-se os clientes da classe Bronze e para a diminuição da sobrecarga quando considera-se os clientes da classe Gold.

Tempo médio de sobrecarga da arquitetura

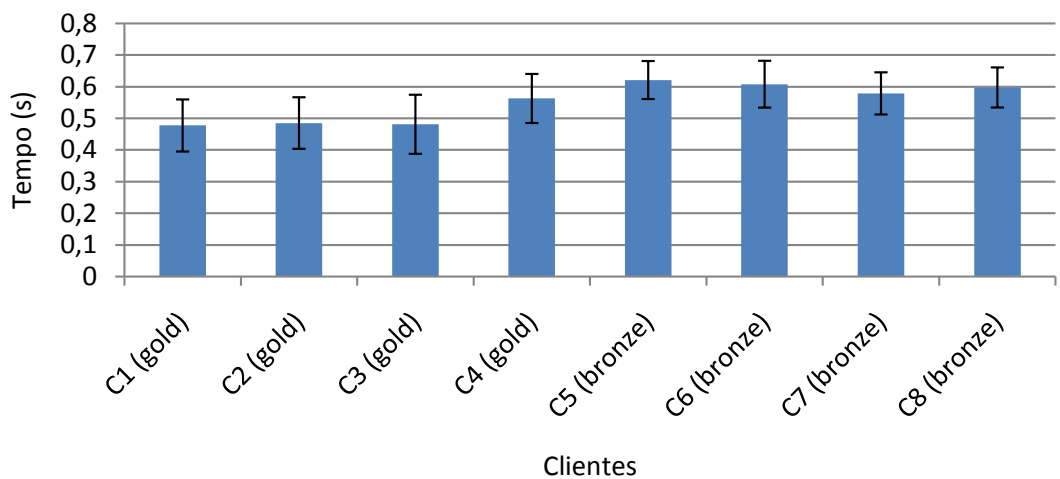

Figura 5.26: Diferenciação de serviços considerando a sobrecarga da WSARCH 
Para complementar os resultados referentes à diferenciação de serviços, os resultados do gráfico da Figura 5.27 mostram como a distribuição de recursos realizados pelo algoritmo de recursos penaliza uma classe de serviços em detrimento da outra, ao considerar que $\mathrm{N}$ recursos estarão disponíveis para determinada classe de serviços de acordo com o índice de desempenho utilizado para a seleção dos provedores de serviços.

Tempo médio de processamento nos provedores

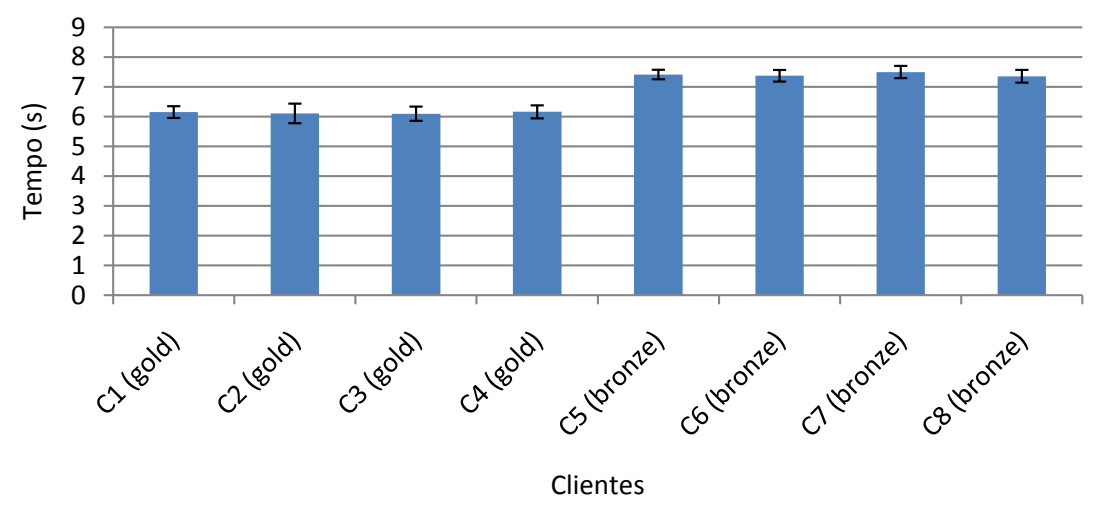

Figura 5.27: Diferenciação de serviços para o tempo médio de processamento

\subsection{Considerações Finais}

Este capítulo apresentou os resultados de validação e demonstração de como avaliar o desempenho de uma arquitetura para provisão de Web Services com qualidade de serviços denominada WSARCH. Foram discutidos inicialmente a configuração do ambiente de validação e testes envolvendo configurações de software e hardware, um planejamento de experimentos segundo a validação da arquitetura, a sobrecarga gerada pelos novos componentes adicionadas em uma arquitetura $S O A$ original e os algoritmos de diferenciação de serviços. É importante frisar que os resultados apresentados nesta tese servirão de base para comparações com novos algoritmos que podem ser implementados no Broker da arquitetura, outras técnicas de propagação de informações de QoS entre os componentes da arquitetura, dentre outros. O próximo capítulo tem como objetivo apresentar de forma detalhada as conclusões obtidas com o desenvolvimento deste projeto de doutorado, no que diz respeito aos resultados alcançados, participação de projetos correlacionados que nasceram em função da proposta da arquitetura WSARCH e de novos projetos futuros que já estão em andamento no grupo de pesquisa, bem como novos projetos que ainda estão por vir, de modo a contribuir para o estado da arte em arquiteturas orientadas a serviços com foco em desempenho. 


\subsection{Considerações iniciais}

A proposta de uma arquitetura para provisão de Web Services com qualidade de serviços surge da necessidade de permitir que aplicações sejam consideradas de forma diferente em determinadas condições tanto de hardware quanto de software em um ambiente complexo e dinâmico como a Web. Uma arquitetura SOA para Web Services original não contempla um elemento direcionador de mensagens $S O A P$, o que inviabiliza na prática que as aplicações tenham um mínimo de qualidade diante da percepção de um cliente de um determinado serviço. Não obstante, a inclusão de um Broker e de técnicas de escalonamento de mensagens baseados em atributos de $Q o S$ provenientes dos provedores de serviços podem ajudar na diminuição do tempo de processamento das mensagens SOAP e conseqüentemente na diminuição do tempo de resposta final. Nesse contexto, este capítulo descreve as principais conclusões e trabalhos futuros provenientes da modelagem e prototipação de uma arquitetura orientada a serviços com suporte à $Q o S$ denominada WSARCH - Web Services Architecture. Na Seção 6.2 são discutidas as conclusões obtidas com o desenvolvimento do projeto de doutorado. Na Seção 6.3 são caracacterizadas as dificuldades relacionados ao desenvolvimento da WSARCH. Na Seção 6.4 é retratada as principais contribuições provenientes da prototipação da arquitetura. Na Seção 6.5 é apresentada a produção científica oriunda do trabalho proposto, incluindo relatórios técnicos, notas didáticas, artigos aceitos em conferências nacionais e internacionais, artigos submetidos para revistas especializadas, a editoração de um livro sobre problemas de desempenho relacionados a arquiteturas orientadas a serviços e a colaboração direta em projetos de pesquisas originados a partir do desenvolvimento da arquitetura WSARCH. Na Seção 6.6 destaca-se a participação em conferências nacionais e internacionais e uma visita técnica à Uni- 
versidade de Roma Tor Vergata em Setembro de 2008. Para finalizar, na Seção 6.7 são detalhados alguns trabalhos futuros relacionados com o tema desta tese.

\subsection{Conclusões}

A idéia da arquitetura WSARCH surgiu em um contexto em meados do ano de 2006 em que a literatura apresentava proposições de diversas outras arquiteturas orientadas a serviços com os mesmos propósitos da WSARCH. Muitos trabalhos relacionados na época e ainda atualmente apenas propõem situações em que determinada arquitetura possa ser implementada na prática. O diferencial da proposta da arquitetura WSARCH em detrimento de inúmeros modelos arquiteturais da literatura é que ela nasceu inicialmente como uma proposta para ser efetivamente implementada, mesmo diante dos desafios inerentes que poderiam surgir durante o desenvolvimento do projeto de uma arquitetura de software. A arquitetura WSARCH em seu estado atual apresenta-se implementada na forma de um protótipo funcional e operacional utilizando um ambiente de clusters de servidores de aplicações, diferentes tipos de aplicações, elemento de armazenamento de informações funcionais dos provedores de serviços, elementos de monitoração de informações não funcionais em tempo real dos provedores de serviços e elemento de armazenamento de informações de desempenho de todos os elementos participantes da arquitetura.

Os resultados iniciais obtidos com o desenvolvimento da proposta da WSARCH foram possíveis porque a proposta inicial contemplava a divisão da arquitetura em módulos funcionais, os quais foram sendo desenvolvidos em paralelo através de projetos de mestrados e iniciações científicas orientados por alguns docentes do Grupo de Sistemas Distribuídos e Programação Concorrente (GSDPC) do ICMC-USP com a colaboração do autor desta tese, durante os quatro anos de desenvolvimento do trabalho.

Inúmeras melhorias podem ser realizadas no protótipo atual da arquitetura WSARCH, porém, todos os resultados obtidos coincidiram com aqueles planejados na proposta deste trabalho de doutorado. A arquitetura WSARCH é composta de módulos os quais foram devidamente discutidos e implementados durante o desenvolvimento do projeto de doutorado.

O desenvolvimento dos projetos de mestrados e iniciações científicas é um ponto importante a ser considerado, uma vez que contribuiu para a experiência do autor em relação ao gerenciamento dos projetos e do trabalho em equipe, este de fundamental importância para a construção de um protótipo.

\subsection{Dificuldades relacionadas ao Projeto}

A dificuldade da construção de um protótipo esbarra tanto em questões do âmbito técnico quanto gerencial e também em relação ao tempo para ser possível obter um protótipo com funcionalidades adequadas. A tarefa árdua está relacionada à montagem e configuração do cluster 
utilizado para os experimentos, a escolha e aprendizando dos softwares considerados durante os experimentos, em especial o motor de processamento de mensagens SOAP conhecido como Axis2 e à implementação dos componentes da arquitetura. Muitas foram as dificuldades durante o desenvolvimento da arquitetura. No entanto, serão listadas as consideradas mais importantes. A primeira dificuldade encontrada para iniciar esse projeto de doutorado foi a ausência de material didático que oferecesse condições adequadas que pudessem acelerar a prototipação da WSARCH. Assim, uma das atividades dentre as inúmeras desenvolvidas durante o doutorado, foi a escrita de um material didático sobre Web Services, o qual é mostrado o funcionamento básico do Axis2, seus módulos e sub-módulos. Ainda em relação ao Axis2, foi necessário realizar modificações no código fonte desse framework para que funcionalidades da WSARCH estivessem operacionais ao término do protótipo. Nessa fase também é importante destacar a dificuldade em codificar o Broker da arquitetura uma vez que ele é o elemento fundamental da WSARCH e o qual todos os outros componentes fazem algum tipo de interação.

A segunda dificuldade está relacionada à construção de um ambiente computacional para o teste de desempenho, o que não é tarefa trivial. Para a prototipação da WSARCH foi preciso instalar e configurar o sistema operacional utilizado nos provedores, Broker, clientes e UDDI, interligar redes diferentes (clientes pertenciam a uma rede, enquanto o restante dos componentes da arquitetura à outra rede) através de regras de firewall utilizando o Iptables. Além disso foi necessário implantar o LogServer para coletar informações de todos os componentes. Em particular a configuração do LogServer também foi uma tarefa dispendiosa, principalmente pelo fato de todos os componentes enviarem informações à base de dados desenhada exclusivamente para o armazenamento das informações dos experimentos. Em complemento a essas dificuldades, também foi preciso estudar a ferramenta de monitoração Ganglia para utilizá-la na coleta de informações que seriam disponibilizadas para a construção de um índice de desempenho. Ainda nesta etapa, foi preciso desenvolver uma aplicação que realizava a coleta de todas as informações disponibilizadas pelos daemons escravos da ferramenta Ganglia presente nos provedores de serviços e as enviassem ao daemon mestre dessa mesma ferramenta configurada no registro UDDI.

A terceira dificuldade está relacionada à fase de validação da arquitetura WSARCH. Para a validação é preciso estabelecer um projeto de experimento e isso envolve a checagem de todos os componentes da arquitetura, tanto de hardware quanto de software. Foi preciso gerar uma bateria inicial de testes durante uma semana para verificar se todos os componentes atendiam aos requisitos iniciais de validação. Feito isso, foram realizados diversos experimentos e alguns deles escolhidos para serem apresentados como resultados desse projeto de pesquisa.

\subsection{Contribuições}

A contribuição mais evidente desta tese de doutorado é a implementação de um protótipo da arquitetura WSARCH que possibilita acesso aos serviços em um conjunto de provedores, con- 
siderando diferenciação e qualidade de serviço. Esse protótipo permite que diversos experimentos considerando um número significante de algoritmos, tecnologias, protocolos, etc., sejam avaliados.

Apesar da contribuição mais evidente desta tese ser o protótipo, seu desenvolvimento possibilitou outras contribuições não menos importantes. Nesse sentido, cabe ressaltar a contribuição em relação a como avaliar o desempenho de arquiteturas orientadas a serviços. Foram amplamente estudados os fatores que influenciam o desempenho desses sistemas e como pode-se atingir $Q o S$ em arquiteturas orientadas a serviços, que utilizam Web Services. Os seguintes resultados devem ser destacados em relação a avaliação de desempenho e $Q o S$ :

- A criação de um guia geral em que são discutidas as diretrizes básicas para avaliação de desempenho em Web Services. Isso deve auxiliar a construção de novos serviços com foco em $Q o S$

- Projeto e desenvolvimento da arquitetura WSARCH que permitirá oferecer melhor QoS para os Web Services e ainda servirá como base para analisar diferentes características de Web Services;

Outras contribuições que complementam a prototipação da arquitetura WSARCH são listadas a seguir:

- A criação de um Broker de serviços, responsável pelo roteamento de mensagens entre clientes, provedores e registros de serviços.

- Desenvolvimento de algoritmos para permitir que serviços sejam selecionados levando-se em consideração aspectos de qualidade de serviço. Para decidir se um serviço é ou não adequado é preciso considerar tantos seus atributos funcionais quanto os não funcionais (tempo de resposta, disponibilidade, etc.)

- Avaliação de desempenho de três técnicas de attachments de dados em Web Services (Estrella et al., 2009).

- A criação de um middleware para composição dinâmica de Web Services com qualidade de serviço, em que foram implementados algoritmos de seleção de Web Services, os quais devem servir de prova de conceito para mostrar o funcionamento do middleware acoplado à WSARCH em um futuro próximo. Este middleware é um módulo da WSARCH e foi desenvolvido como um dos projetos de mestrados associados à arquitetura.

- Avaliação de desempenho das operações de busca e inserção de informações funcionais sobre os Web Services, essas presentes no registro UDDI. Neste estudo foram consideradas WSDLs de diferentes tamanhos, no qual foram avaliados o impacto em relação ao tamanho da $W S D L$ no tempo de reposta final, uma vez que uma operação de inserção de dados no $U D D I$ envolve: recepção da mensagem, parser dos dados da WSDL, inserção dos dados em uma base de dados relacional e mensagem de resposta retornada ao cliente. 
- A criação de uma métrica cujo objetivo é decidir pela compressão de mensagens SOAP em relação ao tipo de dado, tamanho e capacidade da rede de comunicação. A compressão de mensagens tem como objetivo principal a redução do tempo de resposta na troca de informações entre duas entidades de uma arquitetura orientada a serviços.

\subsection{Produção Científica}

Esta Seção apresenta a produção científica proveniente do trabalho de doutorado (artigos aceitos e publicados) bem como os trabalhos em fase de submissão referente à arquitetura WSARCH e trabalhos correlacionados. Além disso são apresentados os projetos de pesquisa em que o autor participou como colaborador direto e também uma visita técnica em universidade do exterior.

\subsubsection{Relatórios Técnicos e Notas Didáticas}

- Avaliação de Desempenho de Web Services Attachments. http://www.usp.br/sibi/

- Consistência na Publicação e Recuperação de Web Services no Registro UDDI http://www.usp.br/sibi/

- Web Services Tutorial http://www.usp.br/sibi/

- Instalação e Configuração de Clusters Bewoulf http://www.usp.br/sibi/

\subsubsection{Artigos}

- A Performance Evaluation Study for Web Services Attachments. In: 7th IEEE International Conference on Web Services. July 2009, Los Angeles - USA. http://doi.ieeecomputersociety.org/10.1109/ICWS.2009.48

- Real Time Compression of SOAP Messages in a SOA Environment. In: 26th ACM International Conference on Design of Communication, September 2008, Lisbon - Portugal. http://doi.acm.org/10.1145/1456536.1456568

- Diretrizes para Avaliação de Desempenho de Web Services. In: XXVIII Brazilian Computer Society Congress - Wperformance (Workshop em Desempenho de Sistemas Computacionais e de Comunicação), July 2008, Belém - Pará - Brazil 
- Caracterização dos Dados Trocados Entre Serviços Web e Provedores de Serviços. In: XIV Simpósio Brasileiro de Sistemas Multimídia e Web (WebMedia 2008), October 2008, Vila Velha - ES - Brazil

- WSARCH: An Architecture for Web Services Provisioning with Quality of Service Support. Submetido à revista IEEE Transactions on Services Computing. http: //www2 . computer.org/portal/web/tsc - Abril de 2010.

- Performance Issues on Service Oriented Architectures. Submetido à revista Performance Evaluation (Elsevier)

http:www.elsevier.com/locate/peva - Abril de 2010

- DWSC-M: A Dynamic Web Services Composition Middleware. Submetido à revista IEEE Transactions on Services Computing.

http: //www2 . computer.org/portal/web/tsc - Abril de 2010.

\subsubsection{Livros e Capítulos}

Além da divulgação dos resultados em conferências nacionais e internacionais durante o doutorado, no final do período de desenvolvimento do projeto da arquitetura WSARCH a proposta de edição de um livro sobre desempenho em arquiteturas orientadas a serviços foi aprovada, de modo que o livro será publicado em meados de 2011. O livro em questão tem o título de: Performance and Dependability in Service Computing: Concepts, Techniques and Research Directions. Todas as informações sobre o processo de edição do livro pode ser encontrado no seguinte endereço eletrônico: http://www.icmc.usp.br/ pdsc. Em relação a este livro a seguinte proposta de capítulo foi aceita:

- Engineering Secure Web Services. To be published by: IGI Global Disseminator of Knowledge - To appear in 2011.

\subsubsection{Colaboração em projetos de pesquisa}

- Avaliação de Desempenho do UDDI em uma Arquitetura Orientada a Serviços (Iniciação Científica)

- Construindo Web Services para avaliação de desempenho de uma arquitetura orientada a serviços com suporte à QoS (Mestrado)

- Estudo e Caracterização de Cargas de Trabalho para Avaliação de Desempenho de Web Services (Mestrado)

- Modelos e Algoritmos para Composição de Web Services com QoS (Mestrado) 
- Um Estudo Comparativo das Especificações de Segurança para Web Services aplicado a uma Arquitetura Orientada a Serviços (Mestrado)

- Utilização de Web Semântica para Seleção de Informações de Web Services no Registro UDDI. Uma Abordagem com Qualidade de Serviço (Mestrado)

\subsubsection{Participação em projetos de pesquisa relacionados ao doutorado}

- Implementação e Avaliação de Desempenho de uma Arquitetura Orientada a Serviços com suporte à QoS (Edital Universal CNPq, 2007 - 2009)

- Políticas de escalonamento e controle de admissão para servidores Web com diferenciação de serviço - modelagem, avaliação e protótipo (Projeto FAPESP, 2007 - 2010)

- Instituto Nacional de Sistemas Embarcados Críticos (FAPESP, CAPES, CNPq, MCT, 2009 - 2012)

\subsection{Participação em Conferências}

Para complementar as atividades do projeto de doutorado, o autor participou das seguintes conferências:

- 26th ACM International Conference on Design of Communication, September 2008, Lisbon - Portugal

- XXVIII Brazilian Computer Society Congress - Wperformance (Workshop em Desempenho de Sistemas Computacionais e de Comunicação), July 2008, Belém - Pará - Brazil

- 7th IEEE International Conference on Web Services. July 2009, Los Angeles - USA

- Conferência Internacional de Segurança de Aplicações (AppSec Brasil 2009), October 2009 - Câmara dos Deputados em Brasília, DF, Brasil.

A viagem para o congresso em Lisboa possibilitou uma visita técnica à Universidade de Roma Tor Vergata. A visita técnica ocorreu em 25 de Setembro de 2008 nas dependência no Dipartimento Di Informática, Sistemi e Produzione em Roma - Itália. Na ocasião, o bolsista foi recebido pela professora doutora Valéria Cardellini, pesquisadora da área de Sistemas Disitribuídos e Web Services. Em Janeiro de 2009, a Prof. Dra. Valéria Cardellini foi recebida no ICMC-USP/São Carlos para a participação do II Programa de Verão e III Workshop de Matemática Computacional, Estatística e Computação com a apresentação de uma palestra envolvendo suas linhas de pesquisa. Neste mesmo período se iniciaram as discussões para a possibilidade de uma acordo de cooperação internacional entre a Universidade de São Paulo e a Universidade de Roma Tor Vergata, acordo este que foi assinado no dia 03 de Setembro de 2009. 


\subsection{Trabalhos futuros}

A concepção da arquitetura WSARCH envolveu inicialmente o aprendizado de diversas tecnologias e metodologias científicas para que a criação de um protótipo funcional fosse possível. As dificuldades para se codificar uma arquitetura de testes com o objetivo de avaliação de desempenho são inúmeras e não é uma tarefa trivial, uma vez que envolve particularidades como: a montagem de uma infra-estrutura computacional (clientes, provedores, registros de serviços), escolha de um motor de processamento de mensagens (a literatura dispõe de diversas delas), linguagens de programação, etc. O gerenciamento do projeto, é também uma atividade essencial, uma vez que outros trabalhos relacionados e já identificados neste documento são módulos integrantes da WSARCH. A evolução da arquitetura WSARCH é essencial para a obtenção de novos resultados. Muitas características presentes na especificação inicial da arquitetura, que por motivos relacionados ao tempo e em função das inúmeras outras atividades que fizeram parte do processo de doutoramento e não puderam ser efetivadas, devem ser consideradas. Dentre as principais melhorias propostas para trabalhos futuros (as quais fazem parte de uma proposta de um projeto de pós-doutorado) destacam-se:

- Implementar técnicas de negociação de requisições para os provedores de serviços e clientes, o que envolve a criação de algoritmos para o atendimento de requisições em classes de serviços

- Implementar novos algoritmos de roteamento de mensagens no Broker de serviços, e integrálos no projeto Apache Synapse, o qual somente implementa um algoritmo de roteamento do tipo Round Robin. Algoritmos de roteamento específicos para determinadas categorias de aplicações podem melhorar o desempenho geral do sistema.

- Implementar algoritmos de composição de serviços mais robustos e que considerem acordos de níveis de serviços (SLA). Os algoritmos atuais de composição de Web Services, implementados na WSARCH por meio do middleware de composição (DWSC-M) (Kuehne, 2009), foram importantes como prova de conceito, porém não são as melhores alternativas, uma vez que ainda não consideram $S L A$ s. Diretamente relacionado com $S L A$ s apresenta-se a evoluçao de serviços e a dificuldade em lidar com as mudanças (infra-estrutura, protocolos de negócios, comportamento, política operacional) o que dificulta o estabelecimento de um SLA.

- Estudar a viabilidade de incorporação de aspectos de segurança nas interações entre os componentes da arquitetura WSARCH. A segurança é um tópico que não foi concebido na proposta inicial da arquitetura, e considera-se importante este aspecto na próxima etapa da evolução da arquitetura, visto que este é de fundamental importância para que a troca de mensagens entre Web Services de diferentes organizações seja realizada de forma segura. Os padrões atuais de segurança para Web Services ainda estão em fase de maturação e se 
utilizados incorretamente podem ocosionar diversos problemas, como os apresentados na Tabela 3.1 deste documento. Estes problemas podem ser estudados e possivelmente pode ser utilizada a infra-estrutura atual da WSARCH para criação de um ambiente de testes para analisar os problemas de segurança em Web Services e as contra-medidas necessárias para garantir um equilíbrio entre segurança e desempenho.

A lista de trabalhos futuros ainda deve-se estender a medida que novas funcionalidades vão sendo incorporadas ao protótipo da arquitetura WSARCH. Para divulgar os próximos resultados referentes a nova fase de implementação das atividades da arquitetura WSARCH, considera-se importante que os resultados sejam difundidos em conferências de qualidade internacional assim como em journals específicos da área. 

Aalst, W. M. P.; Hofstede, A. H. M. Yawl: yet another workflow language. Information Systems, v. 30, n. 4, p. $245-275,2005$.

Disponível em: http://www.sciencedirect.com/science/article/ B6V0G-4C039R5-1/2/66c659c2c37a2ef89a76a7e929a36db 9

Aiello, M.; el Khoury, E.; Lazovik, A.; Ratelband, P. Optimal qos-aware web service composition. IEEE International Conference on E-Commerce Technology, v. 0, p. 491-494, 2009.

Alodib, M.; BordBar, B. A model-based approach to fault diagnosis in service oriented architectures. European Conference on Web Services, v. 0, p. 129-138, 2009.

Alrouh, B.; Ghinea, G. A performance evaluation of security mechanisms for web services. International Symposium on Information Assurance and Security, v. 2, p. 715-718, 2009.

Andreolini, M.; Casalicchio, E.; Colajanni, M.; Mambelli, M. A cluster-based web system providing differentiated and guaranteed services. Cluster Computing, v. 7, n. 1, p. 7-19, 2004.

Andresen, D.; Sexton, D.; Devaram, K.; Ranganath, V. Lye: a high-performance caching soap implementation. 2004, p. 143 - 150 vol.1.

A.Plastino; C.C.RIbeiro; N.Rodriguez Uma ferramenta para desenvolvimento de aplicações spmd com suporte para balanceamento de carga. Relatório Técnico, Rio de Janeiro, Brasil, 1999.

APPARAO, V. Xml protocol requirements. 2001.

Disponível em: http://www.w3.org/TR/2001/wD-xmlp-reqs-20010319 (Acessado em 05/04/2010) 
ARdgna, D.; PERnicI, B. Global and local qos contraints guarantee in web services selection. In: Proceedings of the IEEE International Conference on Web Services, 2005.

Atkinson, C.; Bostan, P.; Hummel, O.; Stoll, D. A practical approach to web service discovery and retrieval. In: ICWS '07: IEEE International Conference on Web Services, 2007, p. $241-248$.

AxIS2, A. Apache axis2/java. 2010.

Disponível em: http: //ws . apache.org/axis2/ (Acessado em 05/04/2010)

Badidi, E.; Esmahi, L.; Serhani, M. A.; Elkoutbi, M. Ws-qosm: A broker-based architecture for web services qos management. In: Innovations in Information Technology, 2006, p. $1-5$.

BanerJee, S.; Basu, S.; Garg, S.; Garg, S.; Lee, S.-J.; Mullan, P.; Sharma, P. Scalable grid service discovery based on uddi. In: MGC '05: Proceedings of the 3rd international workshop on Middleware for grid computing, New York, NY, USA: ACM, 2005, p. 1-6.

Banks, A.; Challenger, J.; Clarke, P.; Davis, D.; King, R. P.; Witting, K.; Donoho, A.; Holloway, T.; IbBotson, J.; TodD, S. Httpr specification. 2002.

Disponível em: http://www.ibm.com/developerworks/library/ ws-httprspec/ (Acessado em 05/04/2010)

Benkner, S.; Engelbrecht, G. A generic qos infrastructure for grid web services. In: Telecommunications, 2006. AICT-ICIW'06. International Conference on Internet and Web Applications and International Conference on Services/Advanced, 2006, p. 141 - 141.

Berners-Lee, T.; Fischetti, M. Weaving the web: The original design and ultimate destiny of the world wide web by its inventor. San Francisco: Harper, xi, 226 p., 1999.

Bhinder, R.; Maheswaran, M.; Diamond, J. Evaluation of request distribution schemes for web-server clusters. In: Canadian Conference on Electrical and Computer Engineering, 2004, p. 1609 - 1612 Vol.3.

Blake, M. B.; Sliva, A. L.; Muehlen, M.; Nickerson, J. V. Binding now or binding later: The performance of uddi registries. 2007, p. 171c-171c.

Blanquer, J. M.; BAtchelli, A.; Schauser, K.; Wolski, R. Qos for internet services: done right. In: EW 11: Proceedings of the 11th workshop on ACM SIGOPS European workshop, New York, NY, USA: ACM, 2004, p. 8.

Bouch, A.; Kuchinsky, A.; Bhatti, N. Quality is in the eye of the beholder: meeting users' requirements for internet quality of service. In: $\mathrm{CHI}$ 'O0: Proceedings of the SIGCHI conference on Human factors in computing systems, New York, NY, USA: ACM, 2000, p. 297304. 
Branco, K.; Santana, M.; Santana, R.; Bruschi, S. Piv and wpiv: Performance index for heterogeneous systems evaluation. In: IEEE International Symposium on Industrial Electronics, 2006, p. 323-328.

Branco, K. R. L. J. C. Avaliação de carga e desempenho em ambientes paralelos/distribuídos, modelagem e métricas. Doutorado em ciências de computação, Instituto de Ciências Matemáticas e de Computação, ICMC - USP - São Carlos, 2004.

Brooks, C. A. An introduction to web services. 2002.

Disponível em: http://www.cs.usask.ca/ cab938/An\%20Introduction\% 20 to 20 Web $\% 20$ Services.pdf (Acessado em 05/04/2010)

Cafaro, M.; Lezzi, D.; Fiore, S.; Aloisio, G.; Engelen, R. The gsi plug-in for gsoap: Building cross-grid interoperable secure grid services. In: WYRZYKOWSKI, R.; DONGARRA, J.; KarcZewski, K.; WASniewski, J., eds. PPAM, Springer, 2007, p. 894-901 (Lecture Notes in Computer Science, v.4967).

Disponível em: http://dblp.uni-trier.de/db/conf/ppam/ppam2007.html\# CafaroLFAE0 7

Chen, H.; Yu, T.; LIN, K.-J. Qcws: an implementation of qos-capable multimedia web services. In: Proceedings of the Fifth International Symposium on Multimedia Software Engineering, 2003, p. $38-45$.

CHEn, T.-S.; CHEN, K.-L. Balancing workload based on content types for scalable web server clusters. In: AINA '04: Proceedings of the 18th International Conference on Advanced Information Networking and Applications, Washington, DC, USA: IEEE Computer Society, 2004, p. 321.

Chen, X.; Mohapatra, P. Providing differentiated service from an internet server. In: Proceedings of the Eight International Conference on Computer Communications and Networks, 1999, p. $214-217$.

Cherkasova, L.; Phate, P. Session-based admission control: A mechanism for peak load management of commercial web sites. IEEE Trans. Comput., v. 51, n. 6, p. 669-685, 2002.

COMuzzI, M.; Pernici, B. An architecture for flexible web service qos negotiation. In: EDOC '05: Proceedings of the Ninth IEEE International EDOC Enterprise Computing Conference, Washington, DC, USA: IEEE Computer Society, 2005, p. 70-82.

Crovella, M. E.; Frangioso, R.; Harchol-Balter, M. Connection scheduling in web servers. In: USITS'99: Proceedings of the 2nd conference on USENIX Symposium on Internet Technologies and Systems, Berkeley, CA, USA: USENIX Association, 1999, p. 22-22. 
Decker, G.; Kopp, O.; Leymann, F.; Weske, M. Bpel4chor: Extending bpel for modeling choreographies. IEEE International Conference on Web Services, v. 0, p. 296-303, 2007.

DiERKS, T.; RESCORLA, E. The transport layer security (tls) protocol version. 2008. Disponível em: http: //tools.ietf.org/html/rfc5246 (Acessado em 05/04/2010)

D’Mello, D. A.; Ananthanarayana, V. S.; Thilagam, S. A qos broker based architecture for dynamic web service selection. In: AMS '08: Proceedings of the 2008 Second Asia International Conference on Modelling \& Simulation (AMS), Washington, DC, USA: IEEE Computer Society, 2008, p. 101-106.

Dong, W.; JiAO, L. Qos-aware web service composition based on sla. In: ICNC '08: Proceedings of the 2008 Fourth International Conference on Natural Computation, Washington, DC, USA: IEEE Computer Society, 2008, p. 247-251.

Dorn, C.; Schall, D.; Dustdar, S. A model and algorithm for self-adaptation in serviceoriented systems. European Conference on Web Services, v. 0, p. 161-170, 2009.

DUSTDAR, S.; SCHREINER, W. A survey on web services composition. International Journal Web Grid Services, v. 1, n. 1, p. 1-30, 2005.

EAger, D. L.; Lazowska, E. D.; Zahorjan, J. Adaptive load sharing in homogeneous distributed systems. IEEE Trans. Softw. Eng., v. 12, n. 5, p. 662-675, 1986.

EgGert, L.; Heidemann, J. Application-level differentiated services for web servers. World Wide Web, v. 2, n. 3, p. 133-142, 1999.

Ehnebuske, D.; Rogers, D.; Riegen, C. V. Uddi version 2.0 data structure reference. 2001. Disponível em: http: / /uddi.xml .org (Acessado em 05/04/2010)

Engelen, R. A. V.; Gallivan, K. A. The gsoap toolkit for web services and peer-to-peer computing networks. In: Proceedings of the 2nd IEEE International Symposium on Cluster Computing and the Grid (CCGrid2002), 2002, p. 128-135.

ERRADI, A.; MAHESHWARI, O. A broker-based approach for improving web services reliability. In: IEEE International Conference on Web Services (ICWS'05), 2005.

Estrella, J. C.; Endo, A. T.; Toyohara, R. K. T.; Santana, R. H.; Santana, M. J.; BRUSCHI, S. M. A performance evaluation study for web services attachments. IEEE International Conference on Web Services, v. 0, p. 799-806, 2009.

Estrella, J. C.; Santana, M. J.; Santana, R. H. C.; Monaco, F. J. In: SiGDoC '08: Proceedings of the 26th annual ACM international conference on Design of communication, New York, NY, USA: ACM, 2008a, p. 163-168. 
Estrella, J. C.; Santana, R. H. C.; Santana, M. J.; Tavares, T. C.; Kuehne, B. T.; Silva, J. C. F.; PacCanaro, L. C. Diretrizes para avaliação de desempenho de web services. In: Wperformance (Workshop em Desempenho de Sistemas Computacionais e de Comunicação), 2008b.

Disponível em: www.prodepa.gov.br/sbc2008/anais/pdf /arq0142.pdf

FARKAS, P.; ChARAF, H. Web services planning concepts. Journal of WSCG, v. 11, n. 1, p. 3-7, 2003.

Disponível em: http://dotnet.zcu.cz/NET_2003/Papers/Farkas.pdf

Ferguson, P.; Huston, G. Quality of service: delivering qos on the internet and in corporate networks. New York, NY, USA: John Wiley \& Sons, Inc., 1998.

FERRARI, D.; ZHOU, S. An empirical investigation of load indices for load balancing applications. In: Performance '87: Proceedings of the 12th IFIP WG 7.3 International Symposium on Computer Performance Modelling, Measurement and Evaluation, Amsterdam, The Netherlands, The Netherlands: North-Holland Publishing Co., 1988, p. 515-528.

Ferris, C.; FArrell, J. What are web services? Communication of ACM, v. 46, n. 6, p. 31, 2003.

FIELDING, R. Hypertext tranfer protocol - http/1.1. 1999.

Disponível em: http://www.ietf.org/rfc/rfc2616.txt (Acessado em 05/04/2010)

Foster, I.; Kesselman, C.; Nick, J. M.; Tuecke, S. The physiology of the grid: An open grid services architecture for distributed systems integration. 2002.

Disponível em: http://www.globus.org/research/papers/ogsa.pdf (Acessado em 05/04/2010)

Freier, A. O.; Karlton, P.; Kocher, P. C. The ssl protocol â version 3.0, internet draft, transport layer security working group. 1996.

Disponível em: http://tools.ietf.org/html/rfc3546

Gardasevic, G.; BojKOVIC, Z. Architectural framework for application level qos adaptation in next generation networks. In: ICNS '09: Proceedings of the 2009 Fifth International Conference on Networking and Services, Washington, DC, USA: IEEE Computer Society, 2009, p. 409-414.

Gudgin, M.; Hadley, M.; Moreau, J.; Nielsen, H. Soap version 1.2 part 1: Adjuncts. 2001a.

Disponível em: http://www.w3.org/TR/2001/WD-soap12-part2-20011217 (Acessado em 05/04/2010) 
Gudgin, M.; Hadley, M.; Moreau, J.; Nielsen, H. Soap version 1.2 part 1: Messaging framework. 2001b.

Disponível em: http://www.w3.org/TR/2001/WD-soap12-part1-20011217 (Acessado em 05/04/2010)

HA, L. Open source high-availability software for linux. 2010.

Disponível em: http: / / www. linux-ha.org/HomePage (Acessado em 05/04/2010)

Heinzl, S.; Mathes, M.; Friese, T.; Smith, M.; Freisleben, B. Flex-swa: Flexible exchange of binary data based on soap messages with attachments. In: ICWS '06: Proceedings of the IEEE International Conference on Web Services, Washington, DC, USA: IEEE Computer Society, 2006, p. 3-10.

Hicks, J.; Govindaraju, M.; Meng, W. Search algorithms for discovery of web services. IEEE International Conference on Web Services, v. 0, p. 1172-1173, 2007.

Ho, L. K.; SiT, H. Y.; Ho, K. S.; LeONG, H. V.; LUK, R. W. P. Improving web server performance by a clustering-based dynamic load balancing algorithm. In: AINA '04: Proceedings of the 18th International Conference on Advanced Information Networking and Applications, Washington, DC, USA: IEEE Computer Society, 2004, p. 232.

HortSmann, M.; KiRTland, M. Dcom architecture. 1997.

Disponível em: http://msdn.microsoft.com/library/en-us/dndcom/html/ msdn_dcomarch.asp (Acessado em 05/04/2010)

HUANG, L.; NIE, J. Using pareto principle to improve efficiency for selection of qos web services. In: 7th IEEE Consumer Communications and Networking Conference (CCNC), 2010, p. $1-2$.

HuANG, P. Capacity allocation for business processes with qos requirements: A heavy traffic approach. In: ICEBE '05: Proceedings of the IEEE International Conference on e-Business Engineering, Washington, DC, USA: IEEE Computer Society, 2005, p. 488-496.

Iввотson, J. Xml protocol usage scenarios. 2001.

Disponível em: http://www.w3.org/TR/2001/WD-xmlpscenarios-20011217 (Acessado em 05/04/2010)

JAeger, M. C.; Muhl, G.; Golze, S. Qos-aware composition of web services: A look at selection algorithms. In: ICWS '05: Proceedings of the IEEE International Conference on Web Services, Washington, DC, USA: IEEE Computer Society, 2005, p. 807-808.

JAIN, R. K. The art of computer systems performance analysis: Techniques for experimental design, measurement, simulation, and modeling. Wiley, 1991. 
Jensen, M.; Gruschka, N.; Herkenh?oner, R.; Luttenberger, N. Soa and web services: New technologies, new standards - new attacks. European Conference on Web Services, v. 0, p. 35-44, 2007.

K., P. C.; FUnG, C. K. Web services security and privacy. In: IEEE International Conference on Services Computing, 2007. SCC 2007, 2007, p. xxxii -xxxii.

KAlEPU, S.; KRishnaswamy, S.; LOKE, S. W. Verity: A qos metric for selecting web services and providers. International Conference on Web Information Systems Engineering Workshops, v. 0, p. 131-139, 2003.

KALEPU, S.; KRIShNASWAMY, S.; LoKe, S. W. Reputation = f(user ranking, compliance, verity). In: ICWS '04: Proceedings of the IEEE International Conference on Web Services, Washington, DC, USA: IEEE Computer Society, 2004, p. 200.

Kawamura, T.; Hasegawa, T.; Ohsuga, A.; Paolucci, M.; Sycara, K. Web services lookup: A matchmaker experiment. IT Professional, v. 7, n. 2, p. 36-41, 2005.

KeIDL, M.; KeMPER, A. Towards context-aware adaptable web services. In: WWW Alt. '04: Proceedings of the 13th international World Wide Web conference on Alternate track papers \& posters, New York, NY, USA: ACM, 2004, p. 55-65.

Keller, A.; Ludwig, H. The wsla framework: Specifying and monitoring service level agreements for web services. J. Netw. Syst. Manage., v. 11, n. 1, p. 57-81, 2003.

Kohlhoff, C.; RD, B. B.; BAY, N.; STEELE, R. Evaluating soap for high performance applications in capital markets. Journal of Computer Systems, Science, and Engineering, v. 19, p. 241-251, 2004.

Kreger, H. Fulfilling the web services promise. Commun. ACM, v. 46, n. 6, p. 29-ff, 2003.

Kuehne, B. T. Modelos e algoritmos para composição de web services com qualidade de serviços. Mestrado em ciências de computação, Instituto de Ciências Matemáticas e de Computação, ICMC - USP - São Carlos, 2009.

Kumar, A.; El-Geniedy, A.; Agarwal, S. A generalized framework for providing qos based registry in service oriented architecture. In: SCC '05: Proceedings of the 2005 IEEE International Conference on Services Computing, Washington, DC, USA: IEEE Computer Society, 2005, p. 295-306.

KUnZ, T. The influence of different workload descriptions on a heuristic load balancing scheme. IEEE Transaction on Software Engineering., v. 17, n. 7, p. 725-730, 1991. 
LASSILA, O. Resource description framework (rdf) model and syntax specification. 1999.

Disponível em: http://www.w3.org/TR/1999/REC-rdf-syntax-19990222 (Acessado em 05/04/2010)

LeAvitt, N. Are web services finally ready to deliver? Computer, v. 37, n. 11, p. 14-18, 2004.

LEYMANN, F. Web services flow language (wsfl 1.0). 2001.

Disponível em: http://www.itee.uq.edu.au/ infs7201/Assessments/ Assignment $\div 201 \div 20$ Material/WSFL.pdf (Acessado em 05/04/2010)

LIANG, Q.; LAU, H. C.; WU, X. Robust application-level qos management in service-oriented systems. In: ICEBE '08: Proceedings of the 2008 IEEE International Conference on e-Business Engineering, Washington, DC, USA: IEEE Computer Society, 2008, p. 239-246.

LiAnG, Q.; WU, X.; LAU, H. C. Optimizing service systems based on application-level qos. IEEE Trans. Serv. Comput., v. 2, n. 2, p. 108-121, 2009.

LiU, C.; LI, Z.; Chen, J.; Lin, X.; MA, D. A service level agreement-based web services performance. In: ICCCN '07: Proceedings of the 16th International Conference on Computer Communications and Networks, 2007a, p. 1279-1284.

LiU, J.; Gu, N.; Zong, Y.; Ding, Z.; Zhang, Q. Service registration and discovery in a domain-oriented uddi registry. In: CIT '05: Proceedings of the The Fifth International Conference on Computer and Information Technology, Washington, DC, USA: IEEE Computer Society, 2005a, p. 276-283.

LiU, J.; Gu, N.; Zong, Y.; Ding, Z.; Zhang, S.; ZHANG, Q. Web services automatic composition based on qos. In: ICEBE '05: Proceedings of the IEEE International Conference on e-Business Engineering, Washington, DC, USA: IEEE Computer Society, 2005b, p. 607610.

LiU, J.; LIU, J.; ChaO, L. Design and implementation of an extended uddi registration center for web service graph. IEEE International Conference on Web Services, v. 0, p. 1174-1175, $2007 b$.

LiVNY, M.; MELmAn, M. Load balancing in homogeneous broadcast distributed systems. SIGMETRICS Perform. Eval. Rev., v. 11, n. 1, p. 47-55, 1981.

LO, N.; WANG, C.-H. Web services qos evaluation and service selection framework - a proxyoriented approach. In: TENCON '07 IEEE Region 10 Conference, 2007, p. 1 -5.

LUDWIG, H. Web services qos: external slas and internal policies or: how do we deliver what we promise? In: Proceedings of the Fourth International Conference on Web Information Systems Engineering Workshops, 2003, 2003, p. 115 - 120. 
MAHEShWARI, P.; TANG, H.; LiAnG, R. Enhancing web services with message-oriented middleware. In: ICWS '04: Proceedings of the IEEE International Conference on Web Services, Washington, DC, USA: IEEE Computer Society, 2004, p. 524.

Mahlo, C.; Hoene, C.; Rostami, A.; Wolisz, A. Adaptive coding and packet rates for tcp-friendly voip flows. In: IST2005: Proceedings of the 3rd International Symposium on Telecommunications, 2005.

Mani, A.; NAgarajan, A. Understanding quality of service for web services. 2002.

Disponível em: http: //www.ibm.com/developerworks/library/ ws-quality.html

Marquezan, C. C.; Santos, C. R.; Salvador, E. M.; Almeida, M. J. B.; Cechin, S. L.; GRAnville, L. Z. Performance evaluation of notifications in a web services and p2p-based network management overlay. In: COMPSAC '07: Proceedings of the 31st Annual International Computer Software and Applications Conference, Washington, DC, USA: IEEE Computer Society, 2007, p. 241-250.

Massie, M. L.; Chun, B. N.; Culler, D. E. The Ganglia Distributed Monitoring System: Design, Implementation, and Experience. Parallel Computing, v. 30, n. 7, 2004.

Matos, J. Distribuição de carga flexível e dinâmica para provedores de web services. Mestrado em ciências de computação, Instituto de Ciências Matemáticas e de Computação, ICMC - USP - São Carlos, 2009.

MEHRA, P. Automated learning of load-balancing strategies for a distributed computer system. Tese de Doutoramento, Champaign, IL, USA, 1993.

Menasce, D. A. Composing web services: A qos view. IEEE Internet Computing, v. 8, n. 6, p. 88-90, 2004.

Miller, J.; NAIR, R.; ZhANG, Z.; ZHAO, H. Jsim: A java-based simulation and animation environment. In: Proceedings. 30th Annual Simulation Symposium, 1997, p. 31 -42.

Nemati, A. G.; TAKizawa, M. Application level qos in multimedia peer-to-peer (p2p) networks. In: AINAW '08: Proceedings of the 22nd International Conference on Advanced Information Networking and Applications - Workshops, Washington, DC, USA: IEEE Computer Society, 2008, p. 319-324.

NETWORKS, N. Introduction to quality of service (qos). 2003.

Disponível em: http://www.nortel.com/products/02/bstk/switches/bps/ collateral/56058.25_022403.pdf (Acessado em 05/04/2010) 
NiCKULL, D. Service oriented architecture - whitepaper. 2005.

Disponível em: http://www.adobe.com/enterprise/pdfs/Services_ Oriented_Architecture_from_Adobe.pdf (Acessado em 05/04/2010)

Nordbotten, N. Xml and web services security standards. IEEE Communications Surveys Tutorials, v. 11, n. 3, p. 4-21, 2009.

Nottingham, M. Xop and mtom. 2004.

Disponível em: http: / / www . mnot . net/blog/2004/02/14/xop

OMG Corba/iiop specification version 2.6. 2001.

Disponível em: http://www.omg.org/technology/documents/formal/ corba_iiop.htm (Acessado em 05/04/2010)

Orta, E.; Ruiz, M.; Toro, M. A system dynamics approach to web service capacity management. European Conference on Web Services, v. 0, p. 109-117, 2009.

PAi, V. S.; Druschel, P.; ZWAenepoel, W. Flash: an efficient and portable web server. In: ATEC '99: Proceedings of the annual conference on USENIX Annual Technical Conference, Berkeley, CA, USA: USENIX Association, 1999, p. 15-15.

PAPAZOGlou, M. P. Service -oriented computing: Concepts, characteristics and directions. In: WISE '03: Proceedings of the Fourth International Conference on Web Information Systems Engineering, Washington, DC, USA: IEEE Computer Society, 2003, p. 3.

Papazoglou, M. P. The challenges of service evolution. In: CAiSE '08: Proceedings of the 20th international conference on Advanced Information Systems Engineering, Berlin, Heidelberg: Springer-Verlag, 2008, p. 1-15.

Papazoglou, M. P.; Heuvel, W.-J. Web services management: A survey. IEEE Internet Computing, v. 9, p. 58-64, 2005.

Papazoglou, M. P.; Traverso, P.; Dustdar, S.; Leymann, F. Service-oriented computing: State of the art and research challenges. Computer, v. 40, p. 38-45, 2007.

Papazoglou, M. P.; Traverso, P.; Dustdar, S.; Leymann, F.; Krämer, B. J. 05462 service-oriented computing: A research roadmap. In: CUBERA, F.; KRÄMER, B. J.; PAPaZOGlou, M. P., eds. Service Oriented Computing (SOC), n. 05462 in Dagstuhl Seminar Proceedings, Dagstuhl, Germany: Internationales Begegnungs- und Forschungszentrum für Informatik (IBFI), Schloss Dagstuhl, Germany, 2006 (Dagstuhl Seminar Proceedings, ).

Disponível em: http://drops.dagstuhl. de/opus/volltexte/2006/524

Pegoraro, R.; Filho, H. F.; Sacoman, M. A. R.; Rosário, Jo A. M. A self-healing architecture for web service-based applications. In: CSEWORKSHOPS '08: Proceedings of 
the 2008 11th IEEE International Conference on Computational Science and Engineering Workshops, Washington, DC, USA: IEEE Computer Society, 2008, p. 221-226.

Peterkin, R.; Solomon, J.; IOnesCU, D. Role based access control for uddi inquiries. In: COMSWARE '07: 2nd International Conference on Communication Systems Software and Middleware, 2007, p. $1-6$.

PHAN, K. A.; TARI, Z.; BERTOK, P. A benchmark on soap's transport protocols performance for mobile applications. In: SAC '06: Proceedings of the 2006 ACM symposium on Applied computing, New York, NY, USA: ACM, 2006, p. 1139-1144.

Pilioura, T.; Kapos, G.-D.; Tsalgatidou, A. Pyramid-s: a scalable infrastructure for semantic web service publication and discovery. In: Proceedings. 14th International Workshop on Research Issues on Data Engineering: Web Services for e-Commerce and e-Government Applications, 2004, p. 15 - 22.

QIQInG, F.; XIAOMInG, P.; QInghuA, L.; Yahui, H. A global qos optimizing web services selection algorithm based on moaco for dynamic web service composition. In: IFITA '09: International Forum on Information Technology and Applications, 2009, 2009, p. 37 -42.

SaEz, G.; Sliva, A. L.; Blake, M. B. Web services-based data management: Evaluating the performance of uddi registries. In: ICWS '04: Proceedings of the IEEE International Conference on Web Services, Washington, DC, USA: IEEE Computer Society, 2004, p. 830.

SAPhiR, W.; TANnER, L. A.; TraVERsat, B. Job management requirements for nas parallel systems and clusters. In: IPPS '95: Proceedings of the Workshop on Job Scheduling Strategies for Parallel Processing, London, UK: Springer-Verlag, 1995, p. 319-336.

SARGEnT, R. G. Validation and verification of simulation models. In: WSC '99: Proceedings of the 31st conference on Winter simulation, New York, NY, USA: ACM, 1999, p. 39-48.

Schmietendorf, A.; Dumke, R.; Reitz, D. Sla management - challenges in the context of web-service-based infrastructures. In: Proceedings of the IEEE International Conference on Web Services (ICWS'04), 2004.

Serhani, M.; Badidi, E.; Benharref, A.; Salem, M. A cooperative approach for qosaware web services'selection. In: ICCCE '08 - International Conference on Computer and Communication Engineering, 2008, p. $1084-1088$.

Sha, L.; Shaozhong, G.; Xin, C.; Minguing, L. A qos based web service selection model. In: IFITA '09 - International Forum on Information Technology and Applications, 2009, p. 353 -356 . 
ShaikhAli, A.; Rana, O. F.; Al-Ali, R.; Walker, D. W. Uddie: An extended registry for web services. In: SAINT-W'03: Proceedings of the 2003 Symposium on Applications and the Internet Workshops, Washington, DC, USA: IEEE Computer Society, 2003, p. 85.

Sheth, A.; Cardoso, J.; Miller, J.; Kochut, K.; KAng, M. QoS for service-oriented middleware. 2002.

Disponível em: http: / / Isdis.cs.uga .edu (Acessado em 05/04/2010)

Siblini, R.; Mansour, N. Testing web services. In: The 3rd ACS/IEEE International Conference on Computer Systems and Applications, 2005, p. 135.

Silva, F. O.; Pacheco, J. A. A.; Rosa, P. F. A srp based handler for web service access control. In: SCC '04: Proceedings of the 2004 IEEE International Conference on Services Computing, Washington, DC, USA: IEEE Computer Society, 2004, p. 57-62.

Skorin-Kapov, L.; Mosmondor, M.; Dobrijevic, O.; Matijasevic, M. Applicationlevel qos negotiation and signaling for advanced multimedia services in the ims. Communications Magazine, IEEE, v. 45, n. 7, p. 108 -116, 2007.

SRinivas, P. B.; RAmanathan, S.; Singhal, S. Web2k: Bringing qos to web servers. 2000. Disponível em: www.hpl.hp.com/techreports/2000/HPL-2000-61.pdf (Acessado em 05/04/2010)

Sun, C.; LIN, Y.; Kemme, B. Comparison of uddi registry replication strategies. In: ICWS '04: Proceedings of the IEEE International Conference on Web Services, Washington, DC, USA: IEEE Computer Society, 2004, p. 218.

SUN, M. Java remote method invocation - distributed computing for java. 2010.

Disponível em: http://java.sun.com/javase/technologies/core/basic/ rmi/index.jsp (Acessado em 05/04/2010)

Suzumura, T.; TAKase, T.; TATsubori, M. Optimizing web services performance by differential deserialization. In: ICWS '05: Proceedings of the IEEE International Conference on Web Services, Washington, DC, USA: IEEE Computer Society, 2005, p. 185-192.

TAbein, R.; Moghadasi, M.; KhoshkbarforoushHa, A. Broker-based web service selection using learning automata. 2008, p. $1-6$.

TABein, R.; Nourollah, A. Dynamic broker-based service selection with qos-driven recurrent counter classes. In: International Conference on Service Systems and Service Management, 2008, p. $1-6$.

TAHER, L.; BASHA, R.; EL KHATIB, H. Establishing association between qos properties in service oriented architecture. In: NWESP '05: Proceedings of the International Conference 
on Next Generation Web Services Practices, Washington, DC, USA: IEEE Computer Society, 2005, p. 163.

Tanenbaum, A. S. Computer networks. N. 3. 982 p. p., 2002.

TAVARES, R.; WestPhall, C. An architecture to provide qos in web services. In: ICC '06 IEEE International Conference on Communications, 2006, p. 921 -925.

Team, W. A.; Dix, C.; Chawla, R.; Chopra, V.; Hong, T.; Norton, F.; Ogbuji Professional xml web services. Birmingham, UK, UK: Wrox Press Ltd., 2001.

Thio, N.; Karunasekera, S. Automatic measurement of a qos metric for web service recommendation. In: ASWEC '05: Proceedings of the 2005 Australian conference on Software Engineering, Washington, DC, USA: IEEE Computer Society, 2005, p. 202-211.

Thomas, J. P.; Thomas, M.; Ghinea, G. Modeling of web services flow. IEEE International Conference on E-Commerce Technology, v. 0, p. 391, 2003.

Tian, M.; Gramm, A.; Naumowicz, T.; Ritter, H.; Schiller, J. A concept for qos integration in web services. International Conference on Web Information Systems Engineering Workshops, v. 0, p. 149-155, 2003.

Tian, M.; Voigt, T.; Naumowicz, T.; Ritter, H.; Schiller, J. Performance considerations for mobile web services. Elsevier Computer Communications Journal, v. 27, n. 1, p. 1097-1105, 2004.

TOYOHARA, K. T. Construindo web services para avaliação de desempenho de uma arquitetura orientada a serviços com qos. Mestrado em ciências de computação (defesa prevista para agosto de 2010), Instituto de Ciências Matemáticas e de Computação, ICMC - USP - São Carlos, 2010.

Tsai, W. T.; LeE, Y.-H.; CaO, Z.; Chen, Y.; XiaO, B. Rtsoa: Real-time service-oriented architecture. In: SOSE '06: Proceedings of the Second IEEE International Symposium on Service-Oriented System Engineering, Washington, DC, USA: IEEE Computer Society, 2006, p. $49-56$.

Vesegna, S. Ip quality of service. Cisco Press, 2001.

VoORsluys, W. Avaliação de índices de carga de memória em sistemas computacionais distribuídos. Mestrado em ciências de computação, Instituto de Ciências Matemáticas e de Computação, ICMC - USP - São Carlos, 2006.

WAng, X.; Yue, K.; HuAng, J. Z.; Zhou, A. Service selection in dynamic demand-driven web services. In: Proceedings of the IEEE International Conference on Web Services, 2004, p. 376-383. 
Weerawarana, S.; Curbera, F.; Leymann, F.; Storey, T.; Ferguson, D. F. Web services platform architecture: Soap, wsdl, ws-policy, ws-addressing, ws-bpel, ws-reliable messaging and more. Upper Saddle River, NJ, USA: Prentice Hall PTR, 2005.

Woodside, M.; Menasce, D. A. Guest editors' introduction: Application-level qos. IEEE Internet Computing, v. 10, n. 3, p. 13-15, 2006.

Wu, C.-H.; Su, D.-C.; Chang, J.; WeI, C.-C.; Lin, K.-J.; Ho, J.-M. The design and implementation of intelligent transportation web services. 2003, p. $49-52$.

XıA, J. Qos-based service composition. COMPSAC '06: Proceedings of the 30th Annual International Computer Software and Applications Conference, p. 359-361, 2006.

YAN, K.; HU, Y.; LU, G. A model of web services with qos based on mas. In: GSIS '09 - IEEE International Conference on Grey Systems and Intelligent Services, 2009, p. 1439 -1443.

YANG, L.; DAI, Y.; ZhANG, B.; GAO, Y. Dynamic selection of composite web services based on a new structured tcnn. In: SOSE '05: Proceedings of the IEEE International Workshop, Washington, DC, USA: IEEE Computer Society, 2005, p. 149-158.

YeOM, G.; TsAI, W.-T.; BAI, X.; MIN, D. Design of a contract-based web services qos management system. In: ICDCSW '09: Proceedings of the 2009 29th IEEE International Conference on Distributed Computing Systems Workshops, Washington, DC, USA: IEEE Computer Society, 2009, p. 306-311.

Yin, K.; ZHOU, B.; ZHANG, S.; XU, B.; CHEN, Y. Qos-aware services replacement of web service composition. In: ITCS '09: Proceedings of the 2009 International Conference on Information Technology and Computer Science, Washington, DC, USA: IEEE Computer Society, 2009, p. 271-274.

YING, Y.; HUANG, Y.; WALKER, D. W. A performance evaluation of using soap with attachments for e-science. 2005.

Disponível em: http://www.allhands.org.uk/2005/proceedings/papers/ 422. pdf (Acessado em 05/04/2010)

YounG, Y. Y. Faster data transport means faster web services with mtom/xop. 2007.

Disponível em: http://www.devx.com/xml/Article/34797

YU, T.; LIN, K.-J. Service selection algorithms for web services with end-to-end qos constraints. In: CEC '04: Proceedings of the IEEE International Conference on E-Commerce Technology, Washington, DC, USA: IEEE Computer Society, 2004, p. 129-136.

Zhang, D.; Coddington, P.; Wendelborn, A. Binary data transfer performance over high-latency networks using web service attachments. In: E-SCIENCE '07: Proceedings of 
the Third IEEE International Conference on e-Science and Grid Computing, Washington, DC, USA: IEEE Computer Society, 2007, p. 261-269.

ZHAO, Q.; TAN, Y. A load balancing based model for dynamic web service selection. International Symposium on Computational Intelligence and Design, v. 1, p. 501-505, 2009.

Zhou, S.; FERRARI, D. An experimental study of load balancing performance. Relatório Técnico, Berkeley, CA, USA, 1987.

Zhou, S.; Zheng, X.; Jingwen, Z.; Delisle, P. Utopia: A load sharing facility for large heterogeneous distributed computer systems. Relatório Técnico, 1992.

Zhou, S.; Zheng, X.; Wang, J.; Delisle, P. Utopia: a load sharing facility for large, heterogeneous distributed computer systems. Softw. Pract. Exper., v. 23, n. 12, p. 1305-1336, 1993.

Zilora, S.; Ketha, S. Think inside the box! optimizing web services performance today [web services in telecommunications, part ii]. IEEE Communications Magazine, v. 46, n. 3, p. 112 $-117,2008$. 